\title{
Liber I
}

I.1

Utrum possibile sit de impressionibus metheorologicis habere simul scientiam et opinionem

Circa librum Metheororum, qui est quartum naturalium, queritur primo utrum possibile sit de impressionibus metheorologicis habere simul scientiam et opinionem.

$\langle 1\rangle$ Et arguitur primo quod non: de impressionibus metheorologicis non contingit habere scientiam nec etiam opinionem; igitur questio est falsa. Consequentia nota est de se. Antecedens probatur, quia nichil potest sciri nec opinari nisi propositio; impressiones autem metheorologice non sunt propositiones, sicut patet de se; igitur etc.

$\langle 2\rangle$ Secundo: idem non est scibile et opinabile; igitur de impressionibus metheorologice non potest simul haberi scientia et opinio. Consequentia tenet de se. Antecedens patet per Aristotelem in primo Posteriorum circa finem ${ }^{1}$. Et probatur ratione, nam scientia est de illo quod impossibile est aliter se habere, opinio autem de eo quod possibile est aliter se habere; sed non est idem quod impossibile est aliter se habere et quod possibile est aliter se habere; et per consequens non est idem scibile et opinabile.

$\langle 3\rangle$ Tertio: de impressionibus metheorologicis non potest esse scientia, et ergo non est possibile de eis simul esse scientiam et opinionem. Consequentia nota est de se. Antecedens probatur, quia quod non est verum non potest sciri, | ex primo Posteriorum ${ }^{2}$; sed impressiones metheorologice non sunt vere, cum non sint complexa que, qualitercumque sit, sic significant.

〈4〉 Quarto: de impressionibus metheorologicis non possunt formari propositiones necessarie; igitur etc. Consequentia tenet, quia de illo de quo debet esse scientia, debent posse formari propositiones necessarie. Et ante-

18-19 quod non est verum non potest sciri] nichil contingit sciri nisi verum $B a K l L U \quad 19$ sed] om. $P \quad 20$ sint complexa que qualitercumque sit sic significant] sint complexa nec qualitercumque est fuit vel erit significant $K l$ sunt propositiones nec sunt complexa nec qualitercumque est fuit vel erit significant $B a$ sunt complexa que qualitercumque stant sic significent $L$ sunt complexa que qualitercumque se habent sic significent $U$

1 Aristoteles, Analytica Posteriora I, 33, 89 a 7-10.

2 Ibid., I, 33, 88 b 34-37; Auct. Arist., 319, n. 95. 
$L 181^{\mathrm{rb}}$ cedens patet, quia | impressiones metheorologice sunt corruptibiles; de corruptibili autem, ut videtur, non possunt formari propositiones necessarie.

$\langle 5\rangle$ Quinto: que fiunt inordinate, de illis non videtur posse haberi scien-

$U 2^{\text {rb }} \quad$ tiam; sed impressiones metheorologice sunt huiusmodi; | igitur etc. Maior est nota, quia de quibus debet esse scientia, non debent fieri inordinate extra semper et frequenter. Minor patet per Aristotelem in littera; dicit enim: hec autem sunt que accidunt secundum naturam quidem inordinatiorem'3 ${ }^{3}$.

<6) In oppositum est Aristoteles et Albertus et alii qui tradiderunt nobis scientiam de impressionibus metheorologicis. Et sic patet auctoritatibus quod de impressionibus metheorologicis potest esse scientia. Quod autem de ipsis potest esse opinio patet, quia de eis possunt formari propositiones quibus aliquis assentit cum formidine; assensus autem cum formidine est opinio. Et confirmatur quod possibile sit de eis simul esse scientiam et opinionem, quia si non, hoc maxime esset ex eo quod non est idem scibile et opinabile, sicut allegabatur per Aristotelem circa finem primi Posteriorum ${ }^{4}$. Sed hoc non, quia de eadem re possibile est simul esse scientiam et opinionem. Posito enim quod pater tuus esset indutus pelle asinina et iret super manus et pedes, ista conclusio esset a te opinata: 'iste est asinus' demonstrando patrem tuum. Et opinando istam conclusionem, haberes opinionem $B a 4^{\text {rb }}$ de patre tuo, nam ipse est res significata $\mid$ per subiectum propositionis a te opinate; tamen hoc non obstante haberes scientiam de eodem in sciendo istam propositionem: 'omnis homo est risibilis'; ipse enim est res significata per subiectum istius propositionis a te scite. Similiter de eodem, puta de eadem conclusione, potest simul esse syllogismus dyalecticus et demonstra-

2 ut videtur non possunt formari] non videntur posse formari $B a K l L$ non est scientia nec possunt formari $U \quad 6$ in littera] in primo huius $B a K l$ in primo illius libri $L$ in primo huius libri $U \|$ dicit enim] ubi dicit $B a K l L U \quad 7$ accidunt] contingunt $B a K l L U \|$ quidem inordinatiorem] inordinatam $K l \quad 8-10$ qui tradiderunt nobis scientiam de impressionibus metheorologicis et sic patet auctoritatibus quod de impressionibus metheorologicis potest esse scientia] om. Ba Kl $U$ scilicet quod de impressionibus metheorologicis posset esse opinio et scientia $L \quad 12$ formidine] ad oppositum $a d d$. Ba Kl LU $\quad 17$ et iret] ambulans $B a$ $K l$ et ambularet $L$ et ambulet $U \quad 18-19$ demonstrando patrem tuum] om. Ba Kl LU $\quad 22$ propositionem] conclusionem $B a U$ om. $P$ \| ipse enim est] quia pater tuus est $B a K l L U \quad 23$ propositionis] conclusionis $\mathrm{Ba} K \mathrm{Kl}$

3 Aristoteles, Meteorologica, I, 1, 338 b 20-22, translatio Guillelmi de Morbeka (translatio noua), $A L \times 2.2,9^{8-10}$ : "Hec autem sunt quecumque accidunt secundum naturam quidem, inordinatiorem tamen ea que primi elementi corporum"; cf. II, 3, 358 a 26.

4 Ibid., I, 33, 89 a 23-39. 
tivus - dyalecticus quidem, qui | generat opinionem; demonstrativus vero, $K l 1^{\mathrm{va}}$ qui generat scientiam. Similiter eandem conclusionem quam Sortes opinatur, Plato potest scire, | quod non esset nisi idem potest esse scibile et opina$P 226^{\mathrm{v}}$ bile.

$5\langle 7\rangle$ In ista questione primo videndum est quid sit scientia et quid opinio; secundo, quot modis aliquid dicitur 'scibile' et 'opinabile'; tertio, an idem sit scibile et opinabile; quarto respondendum est ad quesitum.

$\langle 8\rangle$ Quantum ad primum, sciendum est quod scientia est habitus adhesivus firmus quo aliquis alicui | complexo firmiter vero seu necessario assen-

10 tit sine formidine ad oppositum propter aliquam evidentiam sumptam per principia vel per aliqua ex principiis deducta. Per istam descriptionem scientia distinguitur ab errore quorundam hereticorum, qui quidem error, quamvis sit assensus firmus - immo aliquando ita firmus quod tales heretici mallent mori quam assentire opposito-, tamen non est scientia, quia non est

15 habitus adhesivus complexo vero. Similiter per istam descriptionem scientia distinguitur a fide, quia, quamvis fides sit assensus firmus alicui complexo firmiter, tamen non est scientia, quia non est firmus | propter aliquam evidentiam sumptam per principia vel per ex principiis deducta. Similiter per istam descriptionem scientia distinguitur ab opinione, quia opinio est assensus infirmus seu cum formidine ad oppositum; scientia autem sine formidine. Per istam etiam descriptionem scientia distinguitur ab intellectu seu ab habitu principiorum quia, quamvis habitus primi principii sit habitus adhesivus quo aliquis assentit alicui complexo firmiter vero sine formidine ad oppositum, et quamvis hoc sit propter aliquam evidentiam, tamen non est propter evidentiam sumptam per principia vel per ex principiis deducta. Sic igitur patet descriptio scientie.

〈9〉 Opinio autem est habitus quo aliquis assentit alicui complexo cum formidine ad oppositum. Circa quod est sciendum quod | talis formido vel potest esse ex parte opinantis | seu opinionem habentis de aliquo, vel potest esse ex parte ipsius medii, vel potest esse ex parte ipsiusmet complexi. Verbi gratia, de primo, si esset aliqua conclusio necessaria et scibilis, et Sortes pro

11 ex principiis deducta] experientiis inducta $L U \quad 13$ heretici] om. Ba Kl L $U \quad$ 13-14 mallent mori] prius vellent mori $B a K l$ potius vellent mori $L U \quad$ 16-17 alicui complexo firmiter] om. $B a K l L U \quad$ 17-18 propter aliquam evidentiam sumptam per principia vel per ex principiis deducta] per evidentiam deductam $B a K l L$ ex experientia adducta $U \quad 20$ infirmus seu ] om. Ba KlLU 23 adhesivus] firmus add. Ba KlLU 24 hoc sit] assentit BaLU 25 sumptam per principia vel per] om. $B a K l L U \|$ deducta] deductam $B a K l L U \quad 26$ sic igitur patet descriptio scientie] ideo scientia differt ab eis Ba KlU om. $L \quad 27$ habitus] assensus $P L$ om. $U \quad 29$ esse] vel add. $P$ 
ista conclusione haberet premissas necessarias, et tunc Sortes cum formidine assentiret et conclusioni et premissis, ista formido diceretur attendi ex parte ipsius opinantis. Exemplum secundi sic: si esset aliqua conclusio necessaria et Sortes pro ista conclusione haberet premissas non necessarias, sed contingentes, tunc Sortes illi conclusioni assentiret cum formidine, que quidem formido esset ex parte medii. Exemplum tertii sic: si esset aliqua conclusio que non esset necessaria, sed contingens, et Sortes assentiret illi cum formidine, illa formido diceretur attendi | ex parte ipsiusmet complexi.

$\langle 10\rangle$ Quantum ad secundum, sciendum est quod quoddam dicitur 'scibile propinquum', quoddam vero dicitur 'scibile remotum'. 'Scibile propinquum' dicitur illud complexum firmiter verum cui intellectus assentit sine formidine ad oppositum, propter aliquam evidentiam sumptam ex principiis, et similiter significatum illius complexi quod solet vocari 'significabile complexe' et antiquitus vocabatur 'modus rei'. 'Scibile' vero 'remotum' dicitur subiectum scibilis propinqui, accipiendo 'scibile propinquum' pro ipsomet complexo firmiter vero, et non pro significato illius complexi, seu significabili complexe, seu modo rei. Et similiter 'scibile remotum' dicitur res significata per subiectum talis scibili propinqui. Et sicut est distinctum de scibili, ita proportionaliter potest distingui de opinabili.

$\langle 11\rangle$ Quantum ad tertium, sit prima conclusio quod omnis res mundi est scibilis, accipiendo 'scibile' pro re significata per subiectum propositionis scibilis. Probatur, quia omnis res mundi est significabilis per istum termi-

$U 2^{\mathrm{vb}}$

$\mathrm{Kl} 2^{\text {ra }}$

$P 227^{\mathrm{r}}$ num 'ens', | qui quidem | terminus est subiectum alicuius complexi sciti, sicut istius: 'omne ens est substantia vel accidens'.

$\langle 12\rangle$ Secunda conclusio: omnis res mundi est opinabilis, accipiendo 'opinabile' pro re significata per subiectum conclusionis opinate. Patet, quia omnis res mundi est significabilis per istum terminum 'ens', qui quidem terminus potest esse subiectum alicuius propositionis opinate.

$\langle 13\rangle$ Tertia conclusio: accipiendo 'scibile' et 'opinabile' pro complexo scito vel opinato, adhuc idem est scibile et opinabile, prout opinio est habitus infirmus ex parte habentis eam vel ex parte medii. Patet, quia idem complexum potest sciri a Sorte et opinari a Platone. Similiter Sortes potest primo

1 haberet] habeat $P \quad 2$ attendi] accidere $B a K l \quad 7$ sed contingens $]$ om. $B a K l \quad 11$ firmiter] om. $B a K l \|$ verum] et necessarium $a d d$. $B a K l \|$ intellectus] firmiter $a d d . B a K l \quad 12$ sumptam ex principiis] etc. $P \quad 13^{-14}$ complexe] complexum $B a K l L \quad 16$ vero] etc. $a d d . P$ et necessarium $a d d . B a K l \quad 20$ sit prima conclusio quod] om. $P \quad 23$ est] potest esse $B a K l L U$ 26 conclusionis] propositionis $K l \quad 27$ res mundi] res $B a L U$ terminus $K l \quad 3^{1}$ infirmus] om. Ba KlLU \| eam] om. $P$ 
opinari aliquod complexum et postea scire illud idem; potest enim primo habere pro aliquo complexo syllogismum dyalecticum et postea demonstrativum.

$\langle 14\rangle$ Quarta conclusio: impossibile est ab aliquo idem complexum simul 5 sciri et opinari. Patet, quia impossibile est quod aliquis assentiat alicui sine formidine et cum formidine. | Hoc enim implicat contradictionem.

$\langle 15\rangle$ Quinta conclusio: accipiendo 'scibile' et 'opinabile' pro complexo scito vel opinato et prout infirmitas assensus est ex parte ipsiusmet complexi, non idem est scibile et opinabile. Patet, quia non idem est contingens et necessarium. Et ita intellexit Aristoteles in primo Posteriorum ${ }^{5}$. Ex hiis patet qualiter idem est scibile et opinabile et qualiter non.

$\langle 16\rangle$ Quantum ad quartum sit prima conclusio: de impressionibus metheorologicis potest esse scientia. Probatur, nam, per primam conclusionem tertii articuli, omnis res mundi est scibilis; sed impressiones metheorologicis sunt 15 aliqua res mundi; igitur etc.

$\langle 17\rangle$ Secunda conclusio: de impressionibus metheorologicis potest esse opinio. Patet per secundam conclusionem tertii articuli, quia omnis res mundi est $\mid$ opinabilis.

$\langle 18\rangle$ Tertia conclusio, que est responsalis | ad quesitum: possibile est $B a 4^{\mathrm{vb}}$ $K l 2^{\mathrm{rb}}$ de impressionibus metheorologicis simul habere scientiam et opinionem. Patet, quia impressiones simul possunt significari per subiectum conclusionis scite et per subiectum conclusionis opinate. Similiter de impressionibus metheorologicis Sortes potest habere scientiam quando Plato habet de eis opinionem.

$\langle 19\rangle$ Quarta conclusio: possibile est quod aliquis de impressionibus metheorologicis habeat scientiam et opinionem. Patet, quia aliquis potest formare in mente sua duas propositiones, unam scibilem et unam opinabilem, que sic se habent quod per utriusque propositionis subiectum impressiones metheorologice significentur. Sed diceres: iam dixisti in una conclu-

\footnotetext{
1 opinari] ymaginari $L \quad 4$ ab aliquo idem complexum] de aliquo idem $B a$ de aliquo $K l$ $L$ idem $U \quad 6$ et] pro eodem tempore assentiat eidem $a d d$. $B a$ pro eodem tempore assentiat add. $L U \|$ formidine] ad oppositum $a d d$. $K l \|$ contradictionem] om. $P \quad 10$ in primo posteriorum] cum dixit quod impossibile esset pro eodem et in eodem tempore simul habere scientiam et opinionem Ba Kl Ulect. dub.L 13-14 tertii articuli] om. BaLU 17 secundam] primam $P \|$ tertii articuli] om. Ba KlLU 25 possibile] om. $P \quad 26$ aliquis] idem $B a K l L U$ 27-28 unam scibilem et unam opinabilem] unam scitam et unam opinatam $B a K l L U$
}

5 Ibid., I, 33, 89 a $23-39$. 
sione tertii articuli quod impossibile est idem ab eodem scire et opinari. Concedo capiendo 'scibile' et 'opinabile' pro complexo noto, scito vel opi$U_{3}{ }^{\text {ra }}$ nato; nichilominus possibile est ab eodem sciri et opinari | accipiendo 'scibile' vel 'opinabile' pro 'scibili' vel 'opinabili remoto', videlicet pro re significata per subiectum conclusionis scibilis vel opinabilis, sicut arguebatur in ratione de patre tuo pelle asinina induto.

$L 182^{\mathrm{rb}}\langle 20\rangle$ Ad rationes. Ad primam dico quod ista bene probat quod de impressionibus metheorologicis nec est scientia nec opinio, prout 'scibile' et 'opinabile' accipiuntur pro 'scibili' et 'opinabili propinquo'; nichilominus de eis potest esse scientia et opinio prout 'scibile' et 'opinabile' accipiuntur pro 'scibili' et 'opinabili remoto'.

$\langle 21\rangle$ Ad secundam dico quod ista bene probat quod non est idem scibile et opinabile accipiendo 'scibile' et 'opinabile' pro 'scibili' et 'opinabili propinquo', prout infirmitas assensus attenditur ex parte ipsiusmet complexi.

$\langle 22\rangle$ Ad tertiam: 'quod non est verum non contingit scire'; verum est pro scibili propinquo; nichilominus potest sciri tamquam scibile remotum.

$\langle 23\rangle$ Ad quartam solet dici quod, quamvis de impressionibus metheorologicis, sicut de aliis rebus corruptibilibus, non possunt formari propositiones necessarie categorice, tamen de eis possunt formari propositiones ypotetice necessarie, | sicut sunt propositiones conditionales: | 'si tonitruum est, tonitruum est sonus factus in nubibus'. Aliter potest dici quod immo de impressionibus metheorologicis possunt formari propositiones necessarie, saltem ex terminis sicut isti: 'ens', 'aliquid', etc. Verum est tamen quod hoc non intentum est ad propositum.

24 Ad quintam bene conceditur, sicut et Aristoteles dicit in littera, quod impressiones metheorologice secundum naturam inordinatiorem fiunt et minus regularem quam sit naturam corporum celestium ${ }^{6}$. Hoc tamen non

\footnotetext{
1 tertii articuli] prius posita $a d d$. Ba Kl om. $L \|$ ab eodem] de eodem $B a K l U \quad 2$ noto] om. Ba Kl L U $\quad 3^{-4}$ scibile] om. $P \quad 4-5$ videlicet pro re significata per subiectum conclusionis scibilis vel opinabilis] om. $\mathrm{Ba} \mathrm{Kl} L U \quad 6$ induto] scilicet possibile est idem scire et opinare capiendo scire vel opinare pro scito remoto vel opinato remoto $a d d . K l \quad 7-8$ impressionibus] om. $P \quad 9$ et opinabili] om. $L P \quad 14$ attenditur] est $B a K l L U \|$ complexi] opinati $a d d$.

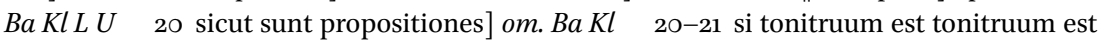
sonus factus in nubibus] om. $B a K l L U \quad 23$ etc] unum de terminis communibus $K l$ verum $B a L U \quad 25$ in littera] om. Ba KlLU 26 naturam] et add. $P$

6 Aristoteles, Meteorologica, I, 1, 338 b 20-22, translatio Guillelmi de Morbeka (translatio noua), $A L \times 2.2,9^{8-10}$ : "Hec autem sunt quecumque accidunt secundum naturam quidem, inordinatiorem tamen ea que primi elementi corporum".
} 
obstante, bene fiunt ita ordinate quod sufficit ad hoc quod de eis habeatur scientiam, et de hoc diffusius in alia questione dicetur?

\section{I.2 Utrum impressiones metheorologice fiant secundum naturam inordinatiorem quam sit natura celi}

Queritur consequenter utrum impressiones metheorologice fiant secundum $B a 5^{\mathrm{ra}}$ naturam inordinatiorem quam sit natura celi.

$5\langle 1\rangle$ Et arguitur primo quod non: impressiones metheorologice non fiunt secundum naturam; igitur non fiunt secundum naturam inordinatiorem. Consequentia tenet. Antecedens probatur, quia impressiones metheorologice fiunt supernaturaliter, nam communiter dicitur quod Deus tonat et quod deus pluit. Sed Aristoteles dicit in De somno et vigilia: 'quod omnes vel

10 plures existimant, prestat fidem tamquam ab experientia dictum'; et Commentator ibidem dicit: 'impossibile est ut famosum sit falsum secundum totum'8.

$\langle 2\rangle$ Secundo ad idem: que fiunt secundum naturam, fiunt ab agente pro$U 3^{\mathrm{rb}}$ prio et sibi simili preter agens commune, ut homo ab homine, equus ab

15 equo. Sic autem non | est de impressionibus metheorologicis: nix non generat nivem, nec grando grandinem.

〈3〉 Tertio ad idem, nam impressiones fiunt per motum violentum; non igitur naturaliter. Consequentia tenet. Antecedens probatur, nam alique impressiones fiunt per ascensum vaporis, qui est de natura aque; ascensus autem vaporis est motus violentus.| Similiter fulmen fit per descensum ignis; descensus autem ignis est motus violentus.

2 et de hoc in alia questione dicetur] om. Ba KlLU\| diffusius] confusius $P \quad 4$ celi] supercelestium $B a$ corporum supercelestium $K l \quad 6$ inordinatiorem $]$ quam sit naturam corporum supercelestium $a d d$. Kl L U om. Ba $\quad 8-9$ deus tonat et quod deus pluit] deus pluit fulminat et tonat et sic de aliis $B a K l U$ deus pluit tonat et sic de aliis $L$ deus pluit fulminat tonitruat $U$ 9 omnes vel] om. $\mathrm{Ba} \mathrm{Kl} 14$ preter agens commune] quod non agit ut agens commune $\mathrm{Ba}$ $K l$ et non ut agens commune $L U$

7 I.2.

8 Aristoteles, De insomniis et de divinatione per somnum, 3, 1462 b 14-16, ed. H.J. Drossaart Lulofs in De insomniis et de divinatione per somnum. A New Edition of the Greek Text with the Latin Translation, Leiden 1947 (Aristoteles Latinus, XV 1-2), 33-7: "nam quod omnes quidam vel plures existimant habere aliquam significationem sompnia prestat fidem tamquam ab experientia dictum"; Averroes, In De somno et vigilia, ed. Shields, 95 ${ }^{32-33}$ : “impossibile enim est ut famosum sit falsum secundum totum"; cf. Auct. Arist., 204, nr. 101. 
〈4〉 Quarto, nam, dato quod impressiones metheorologice fiunt secundum naturam, probatur quod non secundum naturam inordinatiorem; nam sequitur: fiunt secundum naturam inordinatiorem, igitur fiunt secundum naturam inordinatam. Consequens est falsum. Consequentia tenet ex eo quod omnis comparativus presupponit positivum. Falsitas consequentis patet, nam natura non est inordinata. Tertio enim Celi et octavo Physicorum dicitur: 'nichil est inordinatum eorum que secundum naturam fiunt'?

$\langle 5\rangle$ Quinto ad idem: fluxus et refluxus maris est quedam impressio metheorologica et fit ita ordinate sicut motus celi; igitur non omnes impressiones fiunt secundum naturam inordinatiorem quam sit natura celi.

<6) Sexto ad idem: in universo nichil est inordinatum, ex eo quod universum est pulcherrimum; unde Tullius: 'nichil universo pulchrius vel amabilius', etc. ${ }^{10}$.

〈7〉 In oppositum est Aristoteles primo huius, ubi dicit quod impressiones fiunt secundum naturam inordinatiorem ea que est primi elementi corporum ${ }^{11}$, et per 'primum elementum corporum' intendit celum; unde Commentator tertio Celi: 'elementum primum naturaliter dicitur de materia et de forma, sed ex consequenti dicitur de quolibet corpore simplici'12.

4 falsum] ergo et antecedens $a d d$. $K l U \quad 6-7$ tertio enim celi et octavo physicorum dicitur] ut dicitur in tertio huius $B a K l L U \quad 7$ nichil est inordinatum eorum que secundum naturam fiunt] nichil eorum est inordinatum $B a K l \quad 16$ per] ly add. $B a \|$ corporum] corpora $L U \|$ celum] corpus $B a$ corpus celeste $K l U$ ea scilicet corpus celeste celum et alia $L \quad 17$ primum] proprie $B a K l L U \|$ naturaliter] solummodo $B a L$ om. $K l U$

9 Aristoteles, De celo, III, 2, 300 b 5-6; Physica, VIII, 1, 252 a 12-13, translatio Iacobi Veneti (translatio vetus), $A L$ VII 1, eds. Bossier and Brams, 1: 282 ${ }^{11}$ : "At vero nichil inordinatum est eorum que natura et secundum naturam sunt"; translatio Guillelmi de Morbeka (translatio nova), AL VII 3, 373 ${ }^{10}$ : "At vero nihil inordinatum eorum quae natura et secundum naturam sunt".

10 Marcus Tullius Cicero, De natura deorum, II, 40, ed. M. van den Bruwaene, Brussels 1978 (Collectio Latomus, 154), 127 $7^{30-31: ~ " q u o ~ s p e c t a c u l o ~ n i h i l ~ p o t e s t ~ a d m i r a b i l i u s ~ e s s e, ~}$ nihil pulchrius".

11 Aristoteles, Meteorologica, I, 1, 338 b 20-22, translatio Guillelmi de Morbeka (translatio noua), $A L \times 2.2,9^{8-10}$ : "Hec autem sunt quecumque accidunt secundum naturam quidem, inordinatiorem tamen ea que primi elementi corporum".

12 Averroes, Commentarium magnum in De celo, IV, comm. 37, ed. J.F. Carmody and R. Arnzen, Leuven 2003 (Recherches de Théologie et Philosophie médiévales, Bibliotheca 4) (2 vols.), 2: 735 19-21: "Non dico primum elementum-quoniam hoc nomen elementum aliquando dicitur de hiis corporibus quatuor, aliquando de prima materia". 
Modo celum est primum corpus simplex, sicut patet per Aristotelem in primo Celi ${ }^{13}$.

$\langle 8\rangle$ In ista questione primo videndum est quid sit intelligendum per 'impressiones metheorologicas'; secundo videndum est qualiter fiant secundum 5 naturam; tertio videndum est quali ordine fiant.

$\langle 9\rangle$ Quantum ad primum, sciendum quod 'impressio' accipitur uno modo communiter pro quacumque alteratione per quam imprimitur vel inducitur aliqua qualitas, sive sit albedo, sive caliditas, sive sit figura, etc. Et ita communiter non accipitur hic. | Secundo modo accipitur magis stricte pro alteratione $\mid$ ad illas qualitates que immediate consequuntur qualitates primas vel actionem earum aut elementorum, sicut sunt inflammatio, | congelatio, condensatio, digestio et coagulatio, et sic de similibus. Tertio modo accipitur pro mixto immediate consequente | talem alterationem, sicut | est nubes, grando, fulmen, etc., et etiam accidentia eorum, sicut est color nubis $U 3^{\text {va }}$ $K l 43^{\mathrm{vb}}$ $P 228^{\mathrm{r}}$

$L 182^{\mathrm{vb}}$ $\mathrm{Ba} 5^{\mathrm{rb}}$

15 aut motus exalationis, sicut sunt venti aut soni, sicut est tonitruum. Et istis duobus ultimis modis sumitur in proposito.

$\langle 10\rangle$ Secundo sciendum est quod huiusmodi impressiones fiunt sub orbe Lune in regione elementari, et ut in pluribus super nos in aere, sicut est generatio ventorum, nubium et huiusmodi; et etiam aliqua earum fiunt sub terra, sicut fontium generationes.

$\langle 11\rangle$ Tertio sciendum est quod alique earum sunt maioris durationis, alique vero minoris, de quo diffusius apparebit in processu.

$\langle 12\rangle$ Quantum ad secundum, sciendum est primo quod hoc nomen 'natura' non solum dicitur de principio activo motus, verum etiam de passivo, et non solum de principio activo motus particulari, verum etiam de principio activo motus universali, sicut est celum et intelligentia. Nec etiam solum dicitur de principio activo motus principali, verum etiam de principio activo motus instrumentali, sicut est gravitas vel levitas. Similiter non solum dicitur de principio passivo motus remoto, sicut est materia prima, verum etiam de 30 principio passivo motus propinquo, sicut est ipsum mobile quod movetur, sicut ignis vel aqua, et hoc large accipiendo hoc nomen 'natura'.

1 primum corpus simplex] primum corporum simplicium $B a$ corporum simplicium primum $K l$ primum corpus et simplicissimum $L \|$ per aristotelem in] om. BaKlLU 9 magis stricte] om. Ba KlLU 10 alteratione] prima add. BaKlLU 13 immediate] om. BaKlLU 14 color] calor $L \quad 18-19$ est generatio] grandines $K l$ tumores $L \quad 24$ de] om. $P$

13 Aristoteles, De celo, I, 2, 269 a $18-269$ b 17. 
$\langle 13\rangle$ Tunc sit prima conclusio quod impressiones metheorologice fiunt secundum naturam quantum est ex parte agentis. Patet, quia fiunt a celo et elementis, sicut dicit in littera; vult enim quod celum est causa activa impressionum ${ }^{14}$.

$\langle 14\rangle$ Secunda conclusio: alique impressiones non solum fiunt secundum naturam quantum est ex parte agentis, verum etiam quantum est ex parte passi, sicut est descensus pluvie; iste enim est cum inclinatione naturali ipsius passi.

$\langle 15\rangle$ Tertia conclusio: alique impressiones fiunt violente quantum est ex $U 3^{\mathrm{vb}}$ parte $\mid$ passi. Patet, nam descensus fulminis et elevatio vaporis, quamvis quantum est ex parte agentis fiant naturaliter, tamen fiunt violente quantum est ex parte passi. Patet ergo qualiter impressiones metheorologice fiunt secundum naturam et qualiter non.

$\langle 16\rangle$ Quantum ad tertium, sit prima conclusio: universum et omnia que

$L 183^{\text {ra }}$ sunt in ipso sunt bene ordinata loco, tempore et proportione, comparando | quodlibet eorum ad omnia alia. Probatur, quia omnia sunt bene disposita que sunt in universo; igitur omnia que sunt in universo sunt bene ordinata. Consequentia clara est de se. Antecedens patet, quia duodecimo Metaphysice dicitur quod entia nolunt male disponi ${ }^{15}$.

$\langle 17\rangle$ Secundo: omnia que sunt in universo sunt disposita secundum quandam consonantiam et armonicam proportionem; igitur omnia que sunt in universo sunt bene ordinata. Consequentia tenet; antecedens patet per Boe$B a 5^{\text {va }}$ thium in sua Musica, qui dispositionem et ordinem universi vocat | 'musicam mundanam', que non est auribus sensibilis, sed bene intelligibilis, et est debita ordinatio et proportio numero, pondere et mensura ${ }^{16}$.

$\langle 18\rangle$ Sed diceret aliquis contra: multa sunt in universo que non sunt bene ordinata, sicut sunt monstrua et peccata et alia mala. Respondetur quod $\mathrm{Kl}_{3}{ }^{\mathrm{va}}$ quamvis ista secundum se videntur esse inordinata, tamen in ordine ad |

\footnotetext{
3 in littera] om. $\mathrm{Ba} \mathrm{Kl} \mathrm{LU} \quad 4$ impressionum] et qualitates elementorum active concurrunt ad productionem impressionum $a d d . B a K l$ et similiter qualitates elementorum active concurrunt ad productionem impressionum add. $L U \quad 21$ et armonicam proportionem] et armoniam et proportionem $L \quad 24$ sensibilis] perceptibilis $L U \quad 25$ proportio] dispositio $\mathrm{Ba} \mathrm{KlU} \|$ mensura] et figura $a d d . \mathrm{Kl} \quad 27$ et peccata] om. Ba Kl U 28 ordine] comparatione $U$

14 Aristoteles, Meteorologica, I, 2, 339 a 22-32.

15 Aristoteles, Metaphysica, XII, 10, 1076 a 3-5, translatio Guillelmi de Morbeka (translatio noua), $A L \operatorname{XXV}$ 3.2, 269 535-536: "entia uero non uolunt disponi male"; cf. Auct. Arist., 138, n. 279 .

16 Boethius, De institutione musica, I, 2.
} 
totum sunt ita bene ordinata quod non possent melius ordinari. Et sciendum est quod ex hoc universum est pulchrius quam si talia non essent; unde, si omnia equaliter essent bona, universum non esset ita pulchrum sicut modo. Bene hoc potest patere exemplo: | si aliquis paries esset totaliter albus, non tamen ex hoc delitiaretur visus sicut si in una parte esset albus et in alia niger et in alia rubeus, et sic diversis coloribus coloratus. Ita consimili modo ymaginandum est universum. Similiter si essent aliqui qui eque alte sonarent, auditus in audiendo illum sonum non tantum delectaretur sicut delectaretur quando unus cantat alte et alius basse, dummodo tamen hoc fit cum ordine; consimili modo de universo.

$\langle 19\rangle$ Secunda conclusio: | impressiones metheorologice fiunt secundum naturam ordinatam. Patet, nam per precedentem conclusionem omnia entia mundi sunt bene ordinata. Secundo ad idem: motus celi, qui sunt causa istarum impressionum, fiunt ordinate; igitur et huiusmodi impressio15 nes fiunt ordinate. Consequentia tenet, quia ordinatio in causa arguit ordinem in effectu. Tertio: quod huiusmodi impressiones fiant | ordinate patet; quedam enim impressiones presciuntur ex aliis et consequuntur alias, sicut patebit in processu ${ }^{17}$. Istud autem videtur arguere ordinem debitum huiusmodi impressionum.

$\langle 20\rangle$ Tertia conclusio: in isto ordine huiusmodi impressionum est maior difformitas quam sit in motibus celi. Patet per experientiam, quia non ita faciliter nec ad tantum tempus potest presciri pluvia sicut potest | presciri coniunctio aliquarum planetarum.

$\langle 21\rangle$ Quarta conclusio: huiusmodi impressiones non fiunt ita ordinate 25 sicut motus celi. Istam conclusionem intendebat Aristoteles cum dixit: hec autem fiunt secundum naturam inordinatiorem'18, ita quod li 'in' non debet

1 totum] universum $a d d$. $B a K l \quad 2$ essent] in isto mundo $a d d$. $K l \quad 4$ albus] depictus sicut dealbatus totaliter $B a$ dealbatus vel totaliter denigratus $K l$ dealbatus $L U$ 4-5 non tamen ex hoc delitiaretur visus] non esset ita pulcher $B a K l L U \quad 5$ albus $]$ dealbatus $L \quad 6$ et sic diversis coloribus coloratus] et sic de aliis mediis coloribus $B a U$ et sic de aliis $L$ similiter si hic esset depictus passer hic aquila et hic mustela et hic milnus add. $K l \quad 7$ universum] in proposito $B a K l L U \|$ sonarent] cantarent $B a K l L U \quad 8$ auditus] intellectus $B a K l U$ intelligentes $L \|$ delectaretur] delectarentur $L \quad 8-9$ delectaretur] delectarentur $L \quad 13$ mundi] om. $B a K l L U \|$ ordinata] disposita $B a$ et bene disposita $a d d . K l \quad 15$ tenet] et antecedens patet add. Kl LU 22 faciliter] finaliter $B a \|$ nec] ita cito nec add. $K l \quad 23$ coniunctio] motus seu $a d d$. $K l$ effectus $L$

17 II.6.

18 Aristoteles, Meteorologica, I, 1, 338 b 20-22, translatio Guillelmi de Morbeka (translatio noua), $A L \times 2.2,9^{8-10}$ : "Hec autem sunt quecumque accidunt secundum naturam quidem, inordinatiorem tamen ea que primi elementi corporum". 
exponi pro 'non' in proposito, sed ad istum intellectum quod impressiones metheorologice fiunt secundum naturam inordinatiorem, id est minus ordinate quam motus celi, modo quo dicimus unum equum esse peiorem alio, $B a 5^{\mathrm{vb}}$ hoc est minus bonum, | quia ubi est maior difformitas et minus uniformiter fiunt, dicuntur minus ordinate fieri. Sed ita est de impressionibus metheorologicis in respectu ad motum celi; igitur etc.

$\langle 22\rangle$ Ad rationes. Ad primam negatur quod huiusmodi impressiones fiant supernaturaliter. Et cum dicebatur: 'tamen communiter dicitur', etc., hoc verum est, sed non a sapientibus. Et igitur ad auctoritatem Aristotelis et Commentatoris est dicendum quod illud quod plures—supple: sapientesdicunt, prestat fidem; si tamen hoc plures ignorantes dicerent, non propter hoc fidem prestaret.

$\langle 23\rangle$ Ad secundam: 'que fiunt secundum naturam fiunt a sibi simili', breviter: hoc non est universaliter verum, immo hoc oportet intelligi de generatione et factione substantiarum perfectarum.

224 Ad tertiam dico quod ista bene probat quod alique impressiones non fiunt naturaliter, sed violente, quantum est ex parte passi; nichilominus bene fiunt naturaliter quantum est ex parte agentis, sicut dicebatur in secundo articulo questionis ${ }^{19}$.

$\langle 25\rangle$ Ad quartam dico quod predicta auctoritas debet exponi: 'secundum

$\mathrm{Kl}_{4}^{\text {ra }}$ naturam inordinatiorem', id est: 'minus ordinate', et hoc in | comparatione ad motus celi; nec tunc sequitur: 'igitur fiunt secundum naturam inordinatam'. $\langle 26\rangle$ Ad quintam respondetur quod non omnis fluxus et refluxus maris fit $L 183^{\text {va }}$ ita ordinate sicut motus celi; immo aliquando | fit maior, aliquando minor.

$\langle 27\rangle$ Ad sextam: illa probat quod impressiones metheorologice non fiunt 25 inordinate; tamen, hoc non obstante, fiunt minus ordinate quam motus celi.

Hoc de questione.

1-2 ad istum intellectum quod impressiones meteorologice] om. $P \quad 2$ secundum naturam inordinatiorem] inordinate $P \quad 4$ maior difformitas] minor uniformitas $B a K l L U \|$ minus uniformiter] magis difformiter $B a \mathrm{Kl}$ maior difformitas $L U \quad 5$ fiunt] difformiter se habent $L U \quad 20$ predicta auctoritas] om. $P \quad 22$ sequitur] ista fiunt secundum naturam inordinatiorem add. $K l$

19 I.2, 14. 


\section{I.3 Utrum iste mundus inferior sit continuus lationibus superioribus ut virtus eius inde gubernetur}

Queritur consequenter utrum mundus iste inferior sit continuus lationibus $U 4^{\mathrm{rb}}$ superioribus ut virtus eius inde gubernetur.

$\langle 1\rangle$ Ista questio querit primo utrum iste mundus inferior sit continuus lationibus superioribus; secundo querit utrum virtus istius mundi inferioris 5 gubernetur a lationibus superioribus.

$\langle 2\rangle$ De primo probatur primo quod iste mundus non est continuus lationibus superioribus; nam continua sunt quorum motus est unus secundum se; sed sic non est de isto mundo inferiori et celo, seu lationibus superioribus; igitur etc. Maior | patet per diffinitionem continuorum ${ }^{20}$. Minor declaratur, quia celum movetur circulariter; ista autem inferiora, que sunt gravia vel levia, moventur motu recto.

$\langle 3\rangle$ Secundo, continuorum extrema debent esse unum ${ }^{21}$; sed sic non est de isto mundo inferiori et ipso celo; nam extremum istius mundi inferioris et extremum celi sunt diversarum specierum, et per consequens non potest ex eis fieri per se unum, quia non se habent ad invicem sicut actus et | potentia.

$\langle 4\rangle$ Tertio probatur quod nec iste mundus celo est contiguus; nam contiguorum extrema debent esse simul ${ }^{22}$. Sed extrema istius mundi inferioris et ipsius celi non sunt simul. Probatur, quia non sunt in eodem | loco, quia tunc requireretur ad hoc quod essent simul simultate locali. Quod non sunt in eodem loco patet, quia extremum istius mundi inferioris est in loco ignis; extremum autem ipsius celi est super locum ignis.

$\langle 5\rangle$ Deinde probatur quod non totus iste mundus inferior gubernatur a lationibus superioribus seu a motibus celi, quia voluntas humana est pars istius mundi inferioris et tamen non gubernatur a motibus celi, quia si sic, sequeretur quod non esset virtus libera potens libere in opposita ${ }^{23}$. Etiam sapiens vir dominabitur astris, quod non esset si totus iste mundus inferior gubernaretur et regeretur $\mid$ a motibus celi.

7 secundum se] in se $L$ om. $B a K l U \quad 18$ sunt] possunt esse $B a K l L U \quad 19$ sunt] possunt esse $B a K l L U \quad 25$ opposita] quod est contra aristotelem secundo libro ethicorum $a d d . K l^{p c}$ quod est contra aristotelem tertio ethicorum $a d d$. $B a$ quod est contra aristotelem in libro ethicorum add. $K l^{a c} L U \quad 26$ dominabitur] predominabitur $L U$

$\begin{array}{ll}20 & \text { Cf. Aristotelem, Physica, v, 4, 228 a 2O-22. } \\ 21 & \text { Cf. Ibid., v, 4, 228 a 22-24. } \\ 22 & \text { Cf. Ibid., IV, 3, 227 a 6-7. } \\ 23 & \text { Cf. Aristotelem, Ethica, III, 1-3. }\end{array}$


〈6〉 Secundo ad idem, nam, si totus iste mundus inferior gubernaretur a motibus celi, sequeretur quod ista inferiora fierent ita ordinate sicut sunt lationes superiores; sed hoc est falsum et contra illa que dicebantur in ques$U_{4}{ }^{\mathrm{va}}$ tione precedenti ${ }^{24}$. Consequentia declaratur a simili, nam, si sunt duo $\mid$ horologia et motus unius regit motum alterius, tunc tanta esset ordinatio motus unius sicut motus alterius.

$\langle 7\rangle$ Tertio ad idem: gubernare et regere denotat cognitionem, ut patet primo Politice ${ }^{25}$. Motus autem celestes, cum sint accidentia, non cognoscunt, et per consequens non regunt nec gubernant ista inferiora; et similiter celum est unum corpus simplex non cognoscens.

$\langle 8\rangle$ Quarto ad idem: gubernare ista inferiora est agere in ea; sed modo celum non agit in ista inferiora, quia que sic se habent quod unum agit in aliud, debent communicare in materia. Celum autem et ista inferiora non $\mathrm{Kl}_{4}{ }^{\mathrm{va}}$ communicant in materia, ex eo quod materia celi non est $\mid$ subiectum generationis et corruptionis; materia autem istorum inferiorum est subiectum talium; quare una earum est alterius rationis ab alia.

〈9) Quinto ad idem: aliqua fiunt infra terram ad quorum factionem non concurrit ipsum celum; igitur non omnia que fiunt in isto mundo inferiori fiunt virtute celi. Antecedens patet, nam multa fiunt infra terram ad que non potest attingere lumen celi; sed celum illa que agit in istis inferioribus, producit mediante suo lumine; si ergo ad aliqua lumen celi non attingit, videtur quod ad productionem talium non concurrat.

$\langle 10\rangle$ Sexto:posito quod celum non moveretur, adhuc lapis molaris existens in concavo orbis Lune, remoto prohibente, descenderet. Similiter, si celum non moveretur, non est verisimile quin, si ignis approximaretur stuppe, eam $B a 6^{\text {rb }}$ accenderet et combureret ${ }^{26}$. Igitur | videtur quod non ad cuiuslibet effectus productionem in isto mundo inferiori concurrat motus celi, et per consequens non quelibet actio in isto mundo inferiori gubernatur et regitur a motibus celi.

5 regit] tangeret $L U \quad 10$ celum] corpus celeste $B a K l L U \quad 11$ gubernare] regere $B a K l L$ $U \quad 12$ inferiora] ergo nec gubernat seu regit ista inferiora minor patet add. Ba Kl ergo nec gubernat inferiora probatur $a d d$. $L$ ergo nec gubernat inferiora $a d d . U \quad 16$ una earum est alterius rationis ab alia] ista est alterius rationis a materia celesti $B a K l$ ipsa est alterius rationis quam materia celestium $L U \quad 21$ attingit $]$ potest pertingere $B a$ potest attingere $K l U \quad 23$ lapis molaris] homo $K l$ lapis $B a L U \quad 24-25$ si celum non moveretur] om. Ba Kl 25 si ignis approximaretur stuppe] ignis applicatus stuppe $B a K l L U$

24 I.2, 21-22.

25 Aristoteles, Politica, I, 19, 1254 b 5-9; cf. Auct. Arist., 253, n. 28.

26 Cf. Condamnationem parisiensem (anno 1277), art. 156, ed. D. Piché, Paris 1999, 127: "Quod si celum staret, ignis in stupam non ageret, quia natura deesset". 
$\langle 11\rangle$ In oppositum est Aristoteles in primo huius, tractatu primo, capitulo secundo, ubi dicit ista verba: 'est autem ex necessitate continuus iste mundus lationi|bus superioribus, ut omnis ipsius virtus gubernetur inde'27.

$\langle 12\rangle$ In ista questione primo videndum est utrum iste mundus inferior sit 5 continuus vel contiguus ipsi celo; secundo videndum est utrum omnis virtus istius mundi inferioris gubernetur a celo.

$\langle 13\rangle$ Quantum ad primum, sciendum est primo quod per 'mundum inferiorem' intenditur ista tota massa que est infra | orbem Lune, seu in concavitate celi, que quidem massa aggregata est ex mixtis et quatuor elementis.

$\langle 14\rangle$ Secundo sciendum est quod potest ymaginari primo de isto mundo inferiori quod tota materia istorum inferiorum esset una massa continua, extensa circumquaque usque ad orbem Lune, ita quod materia aeris circumstantis Sortem esset continua materie ipsius Sortis; nam, si Sortes corrumpitur et ad ymaginationem maneat materia eius, sic tamen quod de eius 15 potentia non educeretur alia forma, et similiter si forma aeris circumstantis Sortem corrumperetur absque hoc quod alia forma de potentia materie ipsius aeris educeretur, ille due materie essent ad invicem continue et non essent propinquiores tunc quam prius erant; ergo videtur quod etiam prius erant continue, et ita argueretur de aliis. Et secundum istam ymaginationem potest teneri quod iste mundus inferior esset una massa continua recte, sicut unus paries est continuus, quamvis eius una pars sit informata albedine, alia modo nigredine et alia rubedine, etc. Et ita proportionaliter de tota massa materie istius mundi inferioris et formis substantialibus potest dici. Et ulterius secundum istam ymaginationem potest dici quod materia 25 totius mundi-accipiendo 'mundum' pro aggregato ex celo et isto mundo inferiori-esset una massa continua, quamvis una pars materie, puta celum, esset satiata forma quam habet et materia istorum inferiorum non, et quod propter hoc materia celi non est subiectum generationis et corruptionis, qualiter tamen est materia istorum inferiorum. Et secundum istam ymagina-

2 ubi] unde $P$ || ex necessitate] om. BaKlLU 13 sortes] forma sortis $B a K l L U \quad 14$ maneat materia eius sic tamen quod] $\mathrm{om}$. $B a K l L U$ 14-15 de eius potentia] de potentia materie eius Ba Kl L $U \quad 18$ ergo] etiam add. $P \quad 20$ quod] totus $a d d$. Ba Kl L $U \|$ una massa continua recte] continuus ipsi celo recte $B a K l L U \quad 26$ pars materie puta celum] eius pars puta materia celi $B a K l L U$

27 Aristoteles, Meteorologica, I, 2, 339 a 22-23, translatio Guillelmi de Morbeka (translatio noua), $A L \times 2.2,10^{34-35: ~ " E s t ~ a u t e m ~ e x ~ n e c e s s i t a t e ~ c o n t i n u u s ~ i s t e ~ s u p e r i o r i b u s ~ l a t i o n i-~}$ bus, ut omnis ipsius virtus gubernetur inde"; cf. Auct. Arist., 171, n. 2. 
tionem ulterius potest dici quod iste mundus inferior continuus est ipsi celo, nec oportet quod omnes partes eiusdem continui moveantur uno motu con$L 184^{\text {rb }}$ simili; | nam Secana est una massa continua, et tamen una eius pars potest moveri versus unam partem et alia versus aliam.

$\mathrm{Kl}_{5}{ }^{\text {ra }} \quad\left\langle{ }_{15}\right\rangle$ Oportet veruntamen istud esse $\mid$ contra communiter loquentes; communiter enim dicitur quod ad hoc quod aliqua sint continua, requiritur quod ultima eorum sint unum per se; sed modo, quia ultimum istius mundi inferioris et ultimum ipsius celi non sunt unum per se nec constituunt unum $B a 6^{\text {va }}$ per se, cum sint diversarum specierum et unum non est in potentia $\mid$ ad reliquum, sequitur istum mundum inferiorem non esse continuum ipsi celo, et consimili ratione nec aer circumstans Sortem est continuus Sorti. Et cum arguebatur: 'materia Sortis et materia aeris circumstantis Sortem sunt continue; ergo Sortes et aer sunt continui', negetur antecedens. Et cum argueba$U 5^{\text {ra }}$ tur: 'si starent sine formis, | essent continue', admittatur. Et cum dicebatur: 'nunc sunt ita propinque sicut tunc', admittatur. Et cum ulterius dicebatur: 'igitur nunc sunt continue', negatur consequentia, quia continuitas non attenditur solum penes propinquitatem partium, sed etiam penes hoc quod ultima eorum sint unum illorum (supple: que sunt continua). Sed modo, cum partes materie sunt informate formis distinctis specie, non constituunt unum per se, cum ex distinctis specie quorum unum non est in potentia ad aliud non potest fieri unum per se. Finaliter igitur dicendum est secundum communiter loquentes quod iste mundus inferior non est continuus ipsi celo, sed contiguus. Patet, nam ultima eorum non sunt unum sed simul, ex eo quod inter ea nullum est medium.

$\langle 16\rangle$ Quantum ad secundum, sciendum est primo quod per 'virtutem istius mundi inferioris' debemus intelligere non solum virtutem activam, verum etiam passivam, et per 'gubernare' debemus intelligere idem quod agere, sicut principale agens intelligendo bonum finem. Secundo sciendum est quod illud dicitur fieri a motibus supercelestibus quod fit ab intelligentiis et corpore celesti totaliter moto.

$\langle 17\rangle$ Tunc | sit prima conclusio: celum | per suum motum agit in ista inferiora. Patet per experientiam, nam videmus quod Sol per accessum ad nos

2 omnes] om. Ba Kl LU\| continui] simul add. Ba KlLU 3 secana] lancea mota ad latus $B a K l$ lapis $L$ lacus $U \quad 3^{-4}$ potest moveri] movetur $B a K l L U \quad 8-9$ per se nec constituunt unum per se] om. $B a K l L U \quad 13$ antecedens] consequentia $B a K l L U \quad 14$ starent sine formis] materie essent separate a formis $B a K l$ si essent separate a formis $L U$ 20 per se] continuum $\mathrm{BaKl}$ compositum seu continuum $L U \quad 27$ agere] regere $B a K l L U \quad 28$ sicut principale agens intelligendo] om. $B a \|$ bonum finem] finem intentum $K l L U \quad 29$ supercelestibus] celi $B a K l L U$ зо totaliter] taliter $B a K l L U$ 
et recessum in obliquo circulo est causa generationis et corruptionis multorum in hoc mundo. Cum enim Sol accedit ad nos, sicut in vere, incipiunt | florere arbores et generantur de novo multe albe; et iterum per recessum a nobis, sicut in autumno, huiusmodi e contrario tendunt ad corruptionem; unde Aristoteles, in secundo De generatione: 'motus Solis in obliquo circulo est causa generationis et corruptionis in istis inferioribus' 28 . Similiter in secundo Physicorum: 'homo generat hominem et Sol'29. Item experimur quod mare fluit et refluit secundum motum Lune, quod non esset nisi ageret in ista inferiora. Item aliqui planete per eorum accessum causant frigiditatem in istis inferioribus, aliqui vero caliditatem. Item in certis temporibus est generatio aliquorum animalium et similiter aliquarum plantarum, | sic quod non in aliis temporibus, sicut experimur. Ex omnibus istis sequitur quod celum agit in ista inferiora, immo adhuc astrologi dicunt quod celum $\mid$ agit in ista inferiora fortunia et infortunia, propter quod ipsi sciunt, scita nativitate alicuius hominis, an talis in futuro prosperabitur vel non.

$\langle 18\rangle$ Secunda conclusio: celum agit in ista inferiora triplici instrumento, videlicet motu, lumine et influentia. Motu quidem, quia motu celo movetur spera ignis et superior pars aeris una cum ipso, sicut postea videbitur ${ }^{30}$. Ex quo apparet quod celum motu suo agit in ista inferiora. Similiter celum agit in ista inferiora suo | lumine. Patet, quia celum per lumen causat calorem in istis inferioribus, de quo etiam postea dicetur ${ }^{31}$. Similiter celum agit in ista inferiora influentia. Patet, nam aliqua fiunt in terra, sicut metalla et consimilia, ad que non attingit lumen celi; igitur oportet dicere quod celum sua influentia concurrat ad talium productionem. Similiter etiam mare fluit et refluit quando Luna est in puncto medie noctis, nec tunc eius lumen attingit mare; ideo oportet dicere quod Luna sua influentia sit causa talis fluxus maris.

\footnotetext{
1 in obliquo circulo] a nobis $B a K l L U \quad 3$ multe albe] multi fructus $B a K l L U \quad 8$ secundum motum lune] om. Ba Kl LU\| ageret] propter influentiam lune $B a K l L U$ 14-15 propter quod ipsi sciunt scita nativitate alicuius hominis] om. $P \quad$ 20 celum per lumen] lumen $\mathrm{Kl}$ lumen suum $B a L U \quad 20-21$ in istis inferioribus] in mundo isto inferiori $B a K l L U \quad 22$ aliqua] multa $B a K l L U \|$ metalla] gemme $a d d$. Ba KlLU $24-25$ et refluit] scrips. et del. $P \quad 25$ quando] quia $P \|$ medie] medio $P \quad 26$ luna sua influentia] influentia lune $B a$ lune influentia $K l \|$ sua influentia] om. $P$

28 Aristoteles, De generatione et corruptione, II, 10, 336 a 15-b 15; cf. Auct. Arist., 170, n. 41: "motus solis et aliorum planetarum in obliquo circulo est causa generationis et corruptionis rerum inferiorum".

29 Aristoteles, Physica, II, 2, 194 b 13, Translatio Iacobi Veneti (translatio vetus), $A L$ VII 1 , $55^{8}$.

$30 \quad$ I.8, 23 .

$31 \quad$ I.9, 18.
} 
$\langle 19\rangle$ Est sciendum quod talis influentia est una qualitas distincta a lumine et est qualitas insensibilis, diffusa per totum medium, recte sicut est species coloris. Differt a lumine, quia lumen est qualitas sensibilis; huiusmodi autem influentia est qualitas insensibilis. Similiter influentia non impeditur per aliquid opacum; lumen autem impeditur per aliquid opacum, sicut per $L 184^{\mathrm{vb}}$ murum vel per aliquid | huiusmodi. Similiter lumen causatur solum ab astro; influentia autem causatur a qualibet parte celi.

$\langle 20\rangle$ Tertia conclusio: omnis virtus naturalis huius mundi inferioris gubernatur a celo. Patet, quia aliqua virtus naturalis huius mundi inferioris gubernatur a celo, sicut patet ex dictis, et non plus una quam alia; igitur etc. Secundo, quia motus celi est primus motuum; igitur omnes alii motus ab ipso dependent, et celum mediante suo motu est causa cuiuslibet motus in istis inferioribus; ergo etc ${ }^{32}$. Tertio, quia solus motus celi est eternus; igitur videtur quod sit regula istorum motuum inferiorum, et per consequens motus istorum inferiorum et actiones gubernantur et reguntur a motu celi ${ }^{33}$. Ex ista conclusione sequitur quod oportet istum mundum inferiorem esse $B a 7^{\text {ra }}$ contiguum ipsi $\mid$ celo. Patet; aliter enim celum non posset agere in ipsum mundum inferiorem. Si enim inter istum mundum inferiorem et ipsum $\mathrm{Kl} 5^{\mathrm{vb}}$ celum / esset spatium vacuum, celum non posset agere in ista inferiora, ex eo $U 5^{\text {va }}$ quod in vacuo $\mid$ non esset aliquod subiectum receptivum luminis et influen$P_{230^{v}}$ tie celi quod $\mid$ esset delativum istorum in mundum inferiorem. Nichil enim agit in distans nisi per medium: si igitur deficeret medium receptivum actionis, non posset fieri actio in distans.

$\langle 21\rangle$ Quarta conclusio: celum non agit in voluntatem cogendo ipsam, sed bene inclinando ipsam. Patet, aliter enim actus voluntatis non essent liberi, quod est falsum, quia experimur quod libere fiunt in nobis actus voluntatis.

$\langle 22\rangle$ Ad rationes. Ad primam concedo quod mundus iste inferior non est continuus lationibus superioribus, sicut due prime rationes probant. Et cum Aristoteles dicit quod iste mundus inferior est continuus celo, etc., oportet exponi pro li 'continuus' idem quod 'contiguus', et ideo utitur isto nomine

$5^{-6}$ per murum] puta a muro vel ferro $L U \quad 11$ motus] istorum inferiorum add. Kl $L U \quad 13$ eternus] necessarius $B a K l L U \quad 15$ et actiones] om. Ba KlLU 21 delativum] et portativum add. $U \|$ mundum inferiorem] ista inferiora $B a K l L U \quad 22-23$ deficeret medium receptivum actionis] illud medium non esset receptivum actionis $B a K l L U \quad 24$ voluntatem] humanam $a d d$. $B a K l L U \quad 25$ liberi] actus puri liberi arbitrii $B a$ actus liberi arbitrii $K l$ actus pure liberi $L$ pure liberi $U \quad 28$ lationibus superioribus] celo $B a K l L U \|$ rationes] ante oppositum add. BaKlLU $\quad$ o li] ly $B a K l L U$

32 Cf. Aristotelem, Metaphysica, II, 2, 994 a 18-20.

33 Cf. Aristotelem, Meteorologica, I, 2, 339 a 24-27. 
'continuus' improprie. Vel forte littera habet 'contiguus', et potest esse ex vitio translatoris vel scriptoris, unde communiter expositores pro 'continuus' exponunt 'contiguus' 34 .

$\langle 23\rangle$ Ad tertiam: 'quecumque sunt contigua, eorum ultima debent esse 5 simul', concedo. Et quando dicitur quod sic non est de ultimo celi et istius mundi, negatur: bene sunt simul propter hoc quod inter ea nullum est medium.

$\langle 24\rangle$ Ad alias rationes quibus probatur quod iste mundus non gubernatur a celo-nam voluntas, etc.- , de hoc dictum est in ultima conclusione ${ }^{35}$.

$\langle 25\rangle$ Ad secundam: 'sequitur quod ista inferiora fierent ita ordinate sicut motus celi', negatur, quia non omnia reguntur a lationibus superioribus, puta voluntas humana et actus eius. Etiam posito quod omnia indifferenter et equaliter $\mid$ gubernarentur a celo, tamen, quia est maior difformitas in istis inferioribus, non apparet ibi tanta ordinatio sicut in motibus celi.

$\langle 26\rangle$ Ad tertiam conceditur quod nec motus celi nec celum, circumscripto motore, cognoscit. Nichilominus intelligentia movens celum et producens motum cognoscit, et hoc sufficit ad hoc quod large loquendo dicamus celum regere et gu|bernare ista inferiora.

$\langle 27\rangle$ Ad quartam: 'celum non agit', etc., negatur. Et cum dicebatur: 'quia 20 celum et ista inferiora non communicant in materia', admittatur. Et propter hoc bene conceditur quod celum non agit in ista inferiora sic quod ista inferiora reagant in ipsum celum, seu non agit in ista inferiora mediante qualitate habente contrarium in materia. Et propter hoc non oportet quod celum et ista inferiora communicent in materia. Unde, si aliqua agerent et 25 paterentur ad invicem, tunc bene oporteret quod | communicarent in mate$U 5^{\mathrm{vb}}$ ria; sed sic non est de celo et de istis inferioribus: ista enim inferiora non agunt in celum, quamvis tamen bene e contrario.

$\langle 28\rangle$ Ad quintam respondetur quod quamvis celum non concurrat ad productionem eorum que fiunt in terra suo lumine, tamen concurrit ad productionem eorum sua influentia.

6 mundi] inferioris $a d d$. $B a K l U \quad 8$ gubernatur] regularetur $B a K l$ regeretur $L U$ 9 voluntas] humana $a d d$. $B a K l L U \quad 10-11$ ita ordinate sicut motus celi] inordinate $P \quad 11$ non] om. $P$ \| omnia] ista inferiora $a d d$. BaKlLU 13 gubernarentur] regerentur $B a K l U \quad 27 \mathrm{e}$ contrario] celum agat in ipsa $a d d . B a K l L U$

34 Cf. Thomam de Aquino, Super Meteora, lib. 1, cap. 2, lect. 3, in Opera omnia iussu impensaque Leonis XIII P. M. edita, Rome 1886, 3: 329: "continuum autem hic accipit pro contiguo". 
$\langle 29\rangle$ Ad ultimam respondetur quod si celum quiesceret, forte, naturaliter loquendo, lapis in concavo orbis Lune non descenderet, nec ignis applicatus stuppe in eam ageret. Sed finaliter, secundum veritatem loquendo, quamvis Commentator non dixisset, sic dicendum est: quod quamvis celum quiesce-

$K l 6^{\text {rb }}$ ret, et tamen prima causa influentiam suam non retraheret, adhuc lapis | descenderet et ignis combureret stuppam. Sed si prima causa omnem suam influentiam retraheret, omnia subito adnichilarentur. Unde ymaginandum est quod omnia bene et semper ab ipso primo dependent in esse et in con-

$L 185^{\mathrm{rb}}$ servari sicut lumen dependet a corpore luminoso; | unde quam cito corpus luminosum retraheretur, tam cito lumen in medio desinit esse. Ita, tam cito omnia entia a primo in nichil caderent, quam cito prima causa omnem suam influentiam retraheret.

\section{I.4 Utrum, cessante motu celi, cessarent motus in isto mundo inferiori}

Queritur consequenter utrum, cessante motu celi, cessarent motus in isto inferiori.

$\langle 1\rangle$ Et arguitur primo quod non, nam, si sic, sequeretur quod si cessaret motus celi, ista inferiora essent magis perfecta quam sunt modo et melius ordinata;

$P 23^{r} \quad$ sed hoc est falsum et contra prius $\mid \operatorname{dicta}^{36}$. Et consequentia probatur, nam, si cessante motu celi cessarent motus istorum inferiorum, sequeretur quod $B a 7^{\text {va }}$ cessante motu celi ista inferiora manerent perpetua et si sic, essent $\mid$ perfectiora quam modo et melius ordinata, ut videtur. Cum enim non essent

1-2 naturaliter loquendo] om. $\mathrm{Ba} \mathrm{Kl} \quad 2$ lapis] molaris existens add. $B a K l L$ existens add. $U \quad 3$ ageret] ut dicunt philosophi $a d d . B a K l L \quad 4$ commentator non dixisset] aristoteles et commentator sic non dixissent $B a K l L U \quad 5$ influentiam suam non retraheret] influeret istis inferioribus $B a K l L$ influeret in ista inferiora $U \|$ lapis] molaris de concavo orbis lune $a d d$. $K l$ molaris existens in concavo orbis lune $a d d$. $B a L$ de concavo orbis lune $a d d$. $U$ 6 combureret] applicatus stuppe in eam ageret $K l U$ applicatus stuppe eam combureret $B a$ appositus stuppe in eam ageret $L \|$ stuppam] quia omnia dependent ab ipso primo in esse et conservari $a d d$. $B a K l U$ quia omnia dependent ab ipso primo in esse et consiliari et conservari $a d d$. $L \quad 7$ subito] penitus $B a K l L U \quad 8-9$ quod omnia bene ... a corpore luminoso] de prima causa et sua influentia sicut de corpore luminoso et lumine $B a K l L U \quad 10$ in medio desinit esse] deficeret $B a K l L U \quad$ 10-12 ita tam cito omnia entia a primo in nichil caderent quam cito prima causa omnem suam influentiam retraheret] et sic est de prima causa $K l U$ om. Ba etiam de prima causa $L \quad 16$ et melius ordinata $]$ om. Ba Kl $L U$

$36 \quad$ I.2, 21-22. 
aliqui motus in istis inferioribus, non esset alteratio, et per consequens nec generatio nec corruptio.

$\langle 2\rangle$ Secundo, nam, cessante motu celi, non ex hoc cessaret illuminatio et influentia celestis; sed illuminatione et influentia celesti manente, adhuc possunt fieri motus in istis inferioribus, sicut alie alterationes et huiusmodi.

〈3〉 Tertio sic: cessante motu celi, non est verisimile quin, si adhuc ignis approximaretur stuppe, ageret in ipsam et unum contrarium applicatum alteri | ageret in ipsum ${ }^{37}$.

$\langle 4\rangle$ Quarto ad idem: intelligentie et celum mediante solo motu regunt ista inferiora et motus et actiones istorum. Igitur, quamvis | cessante motu celi $U 6^{\mathrm{ra}}$ non ita ordinate fierent motus et actiones istorum inferiorum, non tamen propter hoc desinerent esse totaliter, scilicet si celum non moveretur. Et potest exemplificari de hoc, nam in absentia rectoris alicuius politie non totaliter desinit regimen illius politie, quamvis illa politia non ita bene regatur in absentia illius rectoris politie sicut in presentia.

$\langle 5\rangle$ Oppositum videntur dicere dicta posita in precedenti questione: dicebatur enim quod celum per suum motum regit et gubernat ista inferiora, et similiter motus et actiones ipsorum ${ }^{38}$.

(6) Secundo ad idem: cessante causa, cessat effectus; sed motus celi est causa istorum motuum inferiorum; igitur etc. Et precipue in essentialiter ordinatis, cessante primo, cessant postrema ${ }^{39}$. Modo, quia cause effective secundarie, sicut sunt ista agentia | inferiora, sunt subordinate causis universalibus, sicut intelligentiis, igitur, cessante actione intelligentiarum qua movent suos orbes, videntur etiam cessare actiones istorum agentium inferiorum.

$\langle 7\rangle$ Breviter, ista propositio: 'cessante motu celi, cessarent motus istorum inferiorum', secundum quod habemus ex logica, equivalet uni conditionali, vel causali vel temporali; et ergo intellectus questionis est: utrum, si cessarent motus celi, etiam cessarent motus istorum inferiorum, vel quia cessarent, vel dum cessarent motus celi, cessarent motus istorum inferiorum.

1 alteratio et per consequens nec $]$ om. $B a K l L U \quad 6$ sic $]$ sicut tangebatur in precedenti questione $a d d$. $B a K l L U \quad 6-7$ si adhuc ignis approximaretur stuppe] ignis applicatus stuppe $B a$ $K l L U \quad 9$ et celum] universaliter $B a K l$ et celum ultimum $U \|$ mediante solo motu] per suum motum $B a K l L U \quad 21$ ordinatis] subordinatis $K l L$

$37 \quad$ I.3, 28.

38 I.3, 16-17.

39 Cf. Aristotelem, Metaphysica, II, 2, 994 b 19-2o. 
$B a 7^{\mathrm{vb}} \quad$ Modo aliqua conditionalis potest esse vera cuius tamen antecedens $\mid$ est impossibile, ut ista: 'si asinus volat, asinus habet pennas' ${ }^{40}$; et ergo, stante quod impossibile est naturaliter cessare motum celi, tamen potest queri, si cessaret, quid fieret de motu istorum inferiorum.

$K l 6^{\mathrm{vb}} \quad\langle 8\rangle$ Et ad videndum hoc suppono primo | quod celum agit in ista inferiora triplici instrumento, scilicet motu, lumine et influentia—hoc prius declaratum est ${ }^{41}$.

$\langle 9\rangle$ Et ulterius sciendum est quod celum per motum agit in ista inferiora dupliciter. Uno modo immediate, scilicet movendo ignem secum sibi propinquum. Alio modo celum agit in ista inferiora per suum motum mediate, isto modo quod quia celum movetur localiter, aliquando una pars celi est presens alicui parti quiescenti in isto mundo, et deinde alia, et sic aliter et aliter influit illi parti secundum quod est alia et alia influentia et aliud et aliud lumen secundum alterius et alterius partis celi presentiam.

$U 6^{\text {rb }} \quad\langle 10\rangle$ Tunc sit prima conclusio: | si celum cessaret a quolibet istorum trium, videlicet tam a motu quam a lumine quam ab influentia, sic quod non moveretur nec ageret aliquod lumen in ista inferiora nec aliquam influen$P_{231^{v}}$ tiam, nulla fieret actio neque motus $\mid$ in istis inferioribus. Patet, nam in essentialiter ordinatis, cessante primo, cessant postrema. Similiter, si essent decem rote et prima moveret secundam, nec secunda moveretur aliunde, et secunda tertiam, etc., stante prima, starent alie. Sic in proposito ymaginandum est de celo et isto mundo inferiori.

$\langle 11\rangle$ Secunda conclusio: si celum cessaret a motu solum, et non a lumine $L 185^{\mathrm{vb}}$ nec ab influentia, non propter hoc cessarent $\mid$ motus et actiones istorum inferiorum. Patet, quia adhuc Sol suo lumine calefaceret ista inferiora et similiter sua influentia alteraret ea, quibus alteratis, alterarent alia. Verum est tamen quod, si celum cessaret a motu solum, aliter fierent actiones in istis inferioribus quam modo fiant. Patet, quia Sol non sic diversimode applicaretur istis inferioribus sicut si celum moveretur.

$\langle 12\rangle$ Sed contra conclusionem diceret aliquis: motus celi localis est primus $\mathrm{Kl} 7^{\text {ra }}$ omnium motuum | istorum inferiorum ${ }^{42}$; igitur videtur quod ipso cessante,

5 primo] istud quod dictum est in precedenti questione add. Ba Kl L 9-10 propinquum] illud enim quod movetur localiter movet corpus sibi propinquum add. $B a K l L U \quad 25$ suo lumine $]$ om. Ba Kl L $U \quad 25^{-26}$ similiter sua influentia] om. Ba Kl LU 28 applicaretur] applicatur $P \quad 31$ istorum inferiorum] aliorum $B a K l L U$

40 Cf. Averroem, In Physicam, vi , comm. 2, ed. apud Iunctas, 4: f. 308 вC; Auct. Arist., 156, n. 195 .

41 I.3, 17.

42 Cf. Aristotelem, Meteorologica, I, 2, 339 a 23-24; Auct. Arist., 171, n. 4.; Physica, viII, 9, 265 b 8-12; Auct. Arist., 158, n. 224. 
omnes alii motus | inferiores cessent. Respondetur quod bene verum est $B a 8^{\mathrm{ra}}$ quod motus celi est causa et primus omnium motuum aliorum qui fiunt isto modo qualiter iam fiunt; tamen, hoc non obstante, si ipse cessaret, adhuc fierent motus et actiones istorum inferiorum, sed aliter tunc quam modo. Et igitur, si celum quiesceret, stante lumine et influentia, nullum mixtum perfectum generaretur, cum ad generationem mixti perfecti requiritur quod Sol et planete aliter et aliter se habeant secundum accessum et recessum ad ista inferiora. Et ergo fetus stat in ventre tempore determinato per motum Solis; et etiam, sicut videmus, arbores per accessum Solis pullulant, per recessum vero Solis arescunt. Similiter, stante celo in quiete, mixta perfecta bene durarent per aliquod tempus, deinde corrumperentur in alia mixta imperfecta, deinde tandem resolverentur in elementa; et tunc fieret continua generatio et corruptio elementorum, ita quod tandem elementa calida essent sub Sole et elementa frigida fluerent ad alia loca ad oppositum.

$\langle 13\rangle$ Tertia conclusio: si celum moveretur unico motu, scilicet motu diurno, adhuc fierent actiones et motus, generationes et corruptiones in istis inferioribus, licet tunc aliter quam modo. Patet, quia Sol aliquando accederet et aliquando recederet. Verum est tamen | quod tunc non esset hiems nec estas, nec esset distinctio temporum nisi per diem et noctem.

$\langle 14\rangle$ Et ergo sequitur quarta conclusio, quod ad hoc quod fiant actiones et motus, generationes et corruptiones in istis inferioribus, sicut modo fiunt requiruntur duo motus, scilicet motus diur|nus et obliquus—scilicet planetarum. Et secundum hoc Sol accedit et recedit ad nos vel a nobis.

$\langle 15\rangle$ Quinta conclusio: si celum esset uniforme in suis partibus ita quod Sol esset consimilis influentie sicut pars orbis sibi propinqua, et celum moveretur, nihil de novo generaretur. Patet, quia a voluntate antiqua non provenit actio nova, secundum naturaliter loquentes, nisi mediante $\mid$ celo aliter et aliter se habente ${ }^{43}$. Sed modo, si celum esset uniforme in suis partibus, non se haberet aliter nec in toto nec in parte quoad lumen et influentiam, sed semper consimili modo; et igitur bene factum est $\mid$ quod celum est dissimile in

$5^{-6}$ nullum mixtum perfectum generaretur] nichil generaretur saltem in mixtis perfectis $B a$ nichil generaretur saltem in mixtis $K l L U \quad 8$ fetus] animalis add. $B a K l L U \quad 9$ sicut] ut sicut $P \quad 10$ in quiete] om. Ba KlLU 12 elementa] alia $P \quad 17-18$ patet quia sol ... et aliquando recederet] om. $B a \mathrm{Kl} L U \quad 21$ sicut modo fiunt] om. Ba Kl LU $\quad 22-23$ scilicet planetarum] om. $B a K l L U \quad 23$ sol accedit et recedit] sol et planete accedunt et recedunt $B a$ $K l L U \|$ vel a nobis] om. Ba KlLU $\quad 25^{-26}$ moveretur] localiter adhuc add. Ba KlLU 28 se habente] influente $B a K l L$

43 Cf. Averroem, In Physicam, viII, comm, 4, 341 I; comm. 8, f. 344 I-K; comm. 15, f. 349 L-35o M; comm. 43, f. 383 G; cf. Auct. Arist., 159, n. 237. 
suis partibus, sic scilicet quod Sol habeat aliam influentiam quam alia pars orbis et unus planeta aliam quam alius.

$\langle 16\rangle$ Sexta conclusio: si celum cessaret a lumine et influentia, non tamen a motu locali, nihil ageret in ista inferiora nisi forte quod moveret ignem secum. Patet: quod agit in ista inferiora, hoc est mediante lumine et influentia, et movetur localiter ut aliter et aliter secundum alias et alias partes pos$P 22^{r} \quad$ sit | influere.

$\langle 17\rangle$ Ad rationes. Ad primam dico quod si omnia ista inferiora essent perpetua, non essent ita bene ordinata sicut modo, nec universum esset ita pulchrum sicut modo. Decor enim universi est quod modo generentur aliqua et postea corrumpuntur et postea generantur altera.

$\langle 18\rangle$ Ad secundam bene concedo quod si celum cessaret a motu, non tamen a lumine et influentia, adhuc fierent actiones et motus in istis inferioribus, quamvis non eodem modo sicut nunc, sicut dictum est in questione.

$\langle 19\rangle$ Ad tertiam ex eadem radice.

$\langle 20\rangle$ Ad quartam consimili modo.

Et sic patet ad questionem.

\section{I.5 Utrum eedem opiniones infinities reiterentur}

Queritur consequenter utrum eedem opiniones infinities reiterentur.

$\langle 1\rangle$ Et arguitur primo quod non, nam, si sic, sequeretur quod mundus esset

$\mathrm{Kl} 7^{\text {va }}$ eternus. Consequens est falsum: est enim contra veritatem; veritas $\mid$ enim

$L 186^{\mathrm{rb}}$ est quod mundus | incepit per creationem. Consequentia tenet, nam impossibile esset opiniones easdem infinities reiterari in hominibus nisi mundus esset eternus.

$U 6^{\mathrm{vb}} \quad\langle 2\rangle$ Secundo: intellectus non variat suum iudicium de eodem; ergo opiniones non variantur nec reiterantur. Consequentia tenet, nam ad hoc quod 25 intellectus varietur in opinione de eadem re, oportet eum variare suum iudicium. Sed antecedens patet ex eo quod sic videtur esse de intellectu sicut de sensu; sed sensus non variat iudicium suum de suo sensibili: non enim quod modo iudicat albedinem, postea iudicat nigredinem.

2 orbis] sibi propinqui $a d d$. Ba KlLU 4 locali] om. BaKlLU $\quad 4-5$ nisi forte quod moveret ignem secum] om. Ba KlLU 12 motu] solum add. Ba KlLU 13 motus] passiones $B a K l L$ $U \quad 22$ in hominibus] om. Ba KlLU 25 nec reiterantur] om. Ba KlLU 
$\langle 3\rangle$ Tertio sic: nulle opiniones reiterantur; ergo falsum est quod eedem opiniones infinities reiterentur in hominibus. Consequentia tenet. Antecedens probatur, nam, si aliqua opinio reiteraretur, sequeretur quod idem numero post eius corruptionem posset redire, quod est contra philosophice loquentes.

〈4〉 Quarto ad idem: scientie sunt eterne; ergo, postquam habita est scientiam de uno, numquam corrumperetur; et per consequens non amplius de illo erit opinio, sed semper scientia.

$\langle 5\rangle$ Quinto: alique veritates sunt ita evidentes quod intellectus non potest $\mid$ $B a 8^{\text {va }}$ eis assentire cum formidine; ergo circa illas non contingit esse opinio; ergo non circa quamcumque veritatem contingit infinities opiniones reiterari; primum enim principium est ita evidens quod intellectus non potest ei dissentire nec assentire cum formidine.

<6) Sexto ad idem: si questio esset vera, sequeretur quod aliquando esset 15 vel fuisset vel foret aliquod tempus in quo quasi omnes homines errarent. Hoc falsum est. Falsitas patet per Aristotelem in primo Rhetorice, ubi dicit sic: 'autem homines, ut plurimum, attingunt ad veritatem'44. Consequentia tenet, quia illo tempore quo ista opinio communiter variaretur quod mundus esset eternus, communiter homines errarent.

$20\langle 7\rangle$ In oppositum est Aristoteles in littera, dicens quod contingit easdem opiniones infinities reiterari ${ }^{45}$.

$\langle 8\rangle$ In ista questione videndum est circa quas materias contingit fieri variationem opinionum et circa quas non; secundo videbitur quomodo contingit fieri variationem huiusmodi opinionum; tertio videndum est de causa efficiente universali huiusmodi variationis; quarto videndum est de causa $\mid$ efficiente particulari huiusmodi variationis; quinto, de causa finali huiusmodi variationis.

10 eis] dissentire nec add. $L U \|$ esse] om. $P \quad 12$ principium] in aliqua scientia $a d d$. $B a \|$ evidens] in sua veritate $a d d$. $B a K l L U \quad 15$ quasi omnes homines] homines communiter $B a K l L U \quad 16$ dicit] om. $P \quad 18$ variaretur] om. $P \quad 20$ aristoteles] volens reddere causam cuiusdam dicti $a d d$. $B a K l L U \quad 21$ infinities] bis vel ter ymmo infinities reverti $B a \|$ reiterari] in hominibus add. $K l L U$

44 Aristoteles, Rhetorica, I, 1, 1355 b 14-16, translatio Guillelmi de Morbeka, $A L$ Xxxi 2, $161^{26}$ : "autem et homines ad veritatem apti nati sunt sufficienter et in pluribus adipiscuntur veritatem".

45 Aristoteles, Meteorologica, I, 3, 339 b 27-30. 
$\langle 9\rangle$ Quantum ad primum, sciendum est primo quod quedam sunt veritates $L 186^{\text {va }}$ ita evidentes quod circa eas non contingit esse | opiniones, sed scientiam vel intellectum, sicut est veritas primi principii. Ipsum enim est ita evidens in sua veritate quod quam cito intellectus circa ipsum considerat, ei assen$U 7^{\text {ra }}$ tit nec potest ei dissentire, | cum intellectus naturaliter inclinatus sit ad $P 22^{\mathrm{v}}$ assentiendum vero sibi evidenti, | sicut lapis naturaliter inclinatus est ad descendendum. Et quia circa huiusmodi veritates non contingit esse opiniones, etiam circa huiusmodi veritates non contingit opiniones reiterari.

$\langle 10\rangle$ Secundo est sciendum quod alique partes alicuius contradictionis sic se habent quod non est maior ratio pro una parte quam pro alia, quamvis in veritate una earum sit vera; que tamen sit illa, latet homines. Et circa tales partes etiam non contingit esse opiniones, nec circa tales contingit opiniones reiterari. Verbi gratia, nam sic se habent partes istius contradictionis, 'omnes stelle sunt pares; non omnes stelle sunt pares' sic intelligendo: 'tota multitudo stellarum est numerus par; non tota multitudo stellarum est numerus par'; quelibet enim istarum est equaliter dubia.

$\langle 11\rangle$ Tertio est sciendum quod alique partes eiusdem contradictionis sic se habent quod una pars est magis probabilis quam alia; immo aliquando falsa est magis probabilis quam vera, cum nihil prohibeat quedam falsa esse probabiliora quibusdam veris ${ }^{46}$. Et circa tales partes contradictionis contingit esse opiniones, et circa eas contingit opiniones reiterari. | Et alique | de illis sic se habent quod circa unam istarum solum contingit esse duas opiniones, et sic se habet ista: 'anima intellectiva est indivisibilis'. Aliqua autem sic se habet quod circa eam contingit esse plures opiniones duabus, et sic se habet ista: 'mundus est perpetuus'. Unde aliqui opinabantur quod mundus esset perpetuus et a parte ante et a parte post ${ }^{47}$; aliqui quod esset perpetuus a parte post et non a parte ante; aliqui autem quod nec esset perpetuus a parte ante nec a parte post ${ }^{48}$.

$\langle 12\rangle$ Quarto est sciendum quod aliqua sunt circa que reiterantur opiniones diversimode absque mutatione illarum rerum circa quas variantur huius-

3 principii] et sicut patet de isto primo omne totum sua parte est maius add. Ba Kl L $U \quad 4$ in sua veritate] om. $B a K l L U \quad 7$ descendendum] existens extra suum locum add. $B a K l L$ $U \quad 8$ opiniones] infinities $a d d$. $B a K l L U \quad 13$ opiniones] infinities add. $B a K l L U \quad 19$ est] om. $P \|$ nihil] non codd. $\quad 21$ reiterari] et sic se habet ista mundus est eternus similiter sic se habet ista anima intellectiva est indivisibilis $a d d$. $B a K l L U \quad 22-23$ opiniones] partes opinionis $K l \quad 25$ perpetuus] eternus $B a K l L U$ 30 diversimode] om. $B a K l \|$ mutatione] variatione $B a K l L U$

46 Cf. Aristotelem, Topica, viI, 11, 161 a 30-31; Auct. Arist., 331. n. 121.

47 Cf. Aristotelem, De celo, I, 12.

48 Cf. Ibid., I, 10, 279 b 12-17. 
modi opiniones et reiterantur, sicut est de eternitate mundi; similiter de indivisibilitate anime intellective: absque enim mutatione veritatum circa ista, reiterantur et variantur | opiniones circa ea. Alia autem sunt ex quorum mutatione variantur opiniones et assensus circa ea; unde ex variatione rei aliquando opinamur quod talis cibus sit sanus in tali tempore et insanus in alio. Similiter quod in tali loco expedit esse talia edificia et in tali talia, et sic de consimilibus.

$\langle 13\rangle$ Quinto est sciendum quod non solum fit opinionum variatio in speculativis, verum etiam in practicis, ut in legibus, in artibus mecanicis, in 10 ydeomatibus, in modo tradendi scientias | et in consimilibus; unde nos videmus quod in artibus mecanicis magis fit variatio: tunice enim que sic forte aliquando placebant, nunc displacent, et e converso. Similiter ydeomata in regionibus per processum temporis valde variantur. Similiter sepe fit variatio in modo tradendi scientiam; hoc videmus, nam Antiqui alio modo tradide-

15 runt scientias et in alio modo loquendi quam Moderni, sicut patet in libris Antiquorum. Sic ergo patet circa quam materiam contingit huiusmodi variatio et opinionum reiteratio.

$\langle 14\rangle$ Quantum ad secundum, sciendum est quod opinio aliquando mutatur in opinionem contrariam, aliquando autem simpliciter in ignorantiam. Hoc

20 patet, nam quandoque in aliquo studio magistri habent aliquam opinionem et postea per processum temporis opinionem contrariam; et aliquando simpliciter illam opinionem dimittunt, non habentes de ea opinionem, nec circa eam amplius considerant. Et sic patet qualiter diversimode contingit opinionem mutari. Etiam aliquando aliqua opinio mutatur in una regione et non

$\langle 15\rangle$ Quantum ad tertium, sit ista conclusio: huiusmodi variatio fit effective a $K l 8^{\mathrm{rb}}$ corpore celesti tamquam ab agente universali et generali. Patet ex precedentibus duabus questionibus, nam ista inferiora reguntur ab illis superioribus, sicut prius dicebatur ${ }^{49}$; ergo causa variationis in istis inferioribus est influentia $\mid$ celestis. Istud etiam patet per astrologos, ponentes quod aliquando fiunt

6 loco] tempore $L \quad 10$ scientias] in mutatione vestium add. Ba Kl L $U$ 10-11 unde nos videmus quod in artibus mecanicis magis fit variatio] om. $K l$ videmus enim quod multiplex fit variatio vestium $B a L U \quad 11$ tunice] vestes $B a K l L U \quad 15$ et in alio modo loquendi] om. $B a K l L U \quad 1^{-17}$ sicut patet in ... et opinionum reiteratio] om. Ba Kl L U 24 mutatur] servatur $B a K l L U \quad 27$ ab agente universali generali] a causa efficiente universali et generali $B a K l L U \|$ et] in $P$

49 I.3, 19; I.4, 10. 
alique magne coniunctiones que sunt cause inceptionis quarundam sectarum et opinionum que diu durant, si non sint mediocres; si autem sint parve, tunc sunt cause inceptionis sectarum et opinionum que per modicum tempus durant.

$L 187^{\text {ra }}\langle 16\rangle$ Quantum ad quartum, dico quod causa agens | particularis variationis opinionum potest esse depopulatio que potest fieri per diluvium vel per mortalitatem, ita quod postquam homines perierunt per diluvium vel per mortalitatem, postea novi novas inveniunt opiniones. Similiter variatio opinionum in aliquo regno potest fieri per guerras in illo regno; unde, cum sunt guerre in aliquo regno, homines non possunt insistere studio, sed oportet eos insistere aliis, et sic potest accidere variatio opinionum in regno. Etiam potest fieri propter sterilitatem; unde, acquisitis necessariis, Antiqui inceperunt philosophari ${ }^{50}$. Similiter potest accidere variatio opinionum propter variationem complexionum et inclinationum hominum; unde

$K l 8^{\text {va }}$ aliquando homines magis inclinantur ad praxim | quam ad speculandum, et hoc aliquando accidit propter malitiam hominum. Cum enim speculativi $U 7^{\text {va }}$ non honorentur, | qui bene insisterent speculationibus ponunt se ad practicam, sicut tempore hodierno experimur. Plures enim se dant legibus quam artibus, et isto modo opiniones variantur in ignorantiam et non in opinionem contrariam.

$\langle 17\rangle$ Quantum ad quintum, potest dici quod causa finalis huiusmodi variationis et reiterationis opinionum est decor universi, unde propter talem variationem universum est pulchrius. Unde propter aliquam rem in se turpem

6 depopulatio] destructio seu mortalitas hominum $\mathrm{Ba}$ depopulatio hominum $\mathrm{Kl}$ destructio hominum $U$ 7-8 postquam homines perierunt per diluvium vel per mortalitatem] post talem mortalitatem $B a$ post mortem hominum per diluvium vel per mortalitatem $K l$ post obitum hominum per diluvium vel per mortalitatem $L$ lect. dub. $U \quad 9$ in aliquo regno] in aliqua regione $B a K l L U \|$ per guerras] propter errores $L \|$ in illo regno] om. $B a K l L U$ 9-10 unde cum sunt guerre in aliquo regno] nam in regionibus hominum propter errores $L U$ 11-12 sed oportet eos insistere aliis et sic potest accidere variatio opinionum in regno] om. Ba Kl L $U \quad 13$ philosophari] sicut recitat aristoteles in prohemio metaphysice ubi dicit quod antiqui sacerdotes in egypto iam habentes omnia vite necessaria invenierunt scientias speculativas add. BaKlLU 14 variationem complexionum et inclinationum hominum] naturalem inclinationem hominum ad alias opiniones $B a$ naturalem inclinationem hominum ad opiniones $K l$ naturalem inclinationem hominum ad opiniones aliquas $L U \quad 15$ praxim] scientias practicas $B a$ id est ad scientias practicas $a d d . K l L U$ 17-19 qui bene insisterent ... legibus quam artibus] ponunt se ad leges $K l L U$ om. $B a \quad$ 19-20 opinionem contrariam] scientiam ut si artiste student leges $\mathrm{Ba} K l \mathrm{~L} U$

$5^{\circ}$ Aristoteles, Metaphysica, I, 1, 918 b 20-25; cf. Auct. Arist., 116, n. 20. 
una tota multitudo potest fieri pulchrior, sicut potest apparere picturis. Alia causa similiter huiusmodi variationis potest esse exercitium et intellectus hominum delectatio, quia delectatur in novitatibus et variationibus.

$\langle 18\rangle$ Ad rationes. Ad primam dico quod secundum Philosophum concedi5 tur quod mundus est eternus ${ }^{51}$, et isto sumpto infinities eedem opiniones reiterantur; cuius causa dicta est in questione, quia infinities consimiles fiunt coniunctiones planetarum que aliquando erant, que sunt causa huiusmodi variationis et reiterationis opinionum ${ }^{52}$.

$\langle 19\rangle$ Ad secundam dico quod non est simile de sensu et in|tellectu; nam bene contingit intellectum errare circa intelligibile, non autem contingit | sensum errare circa suum proprium sensibile, ut dicit Aristoteles secundo De anima, appositis tribus condicionibus quas Temixtius ibi apponit ${ }^{53}$.

$\langle 20\rangle$ Ad tertiam dicendum est quod dictum Aristotelis debet intelligi quod 'eedem' opiniones, hoc est 'consimiles', ita quod dictum Aristotelis debet intelligi de eisdem opinionibus in specie, non autem in numero.

〈21 $\rangle$ Ad quartam concedo quod | scientie sunt eterne secundum speciem, $K l 8^{\mathrm{vb}}$ non autem secundum numerum, immo non adhuc simpliciter et continue scientie eterne sunt secundum speciem, licet intercise, ita quod ante quodlibet tempus fuit scientiam et post quodlibet tempus erit scientiam.

$\langle 22\rangle$ Ad quintam patet ex dictis in questione.

$\langle 23\rangle$ Ad sextam respondetur quod dictum Aristotelis, cum dicit 'homines ut plurimum attingunt ad veritatem', hoc debet intelligi quod hoc est verum

1 picturis] ut si aliquis paries est depictus colore albo viridi et nigro cum hoc uno alio colore hoc est in se turpis $a d d$. $B a$ ut si aliquis paries est depictus albo colore et viridi et nigro qui color tamen in se turpis est et sic de aliis coloribus tamen ex hoc ille color redderetur pulchrior $a d d$. $K l$ ut si aliquis paries est depictus albo colore et viridi et nigro qui color tamen in se turpis est et sic de aliis coloribus tamen ex hoc ille color redderetur pulchrior $a d d . L$ ut si aliquis paries est depictus colore albo et viridi et nigro qui color in se turpis est et sic de aliis coloribus tamen ex hoc ille paries redderetur pulchrior $a d d$. $U \quad 6-8$ quia infinities consimiles ... et reiterationis opinionum] om. Ba Kl L U $\quad 1^{-15}$ dictum aristotelis debet ... autem in numero] eedem opiniones infinities reiterentur sed non eedem in numero sed eedem in specie $B a K l L U \quad 18$ intercise] discontinue $B a K l L U$

\footnotetext{
51 Cf. Aristotelem, De celo, I, 12, 281 a 28-283 b 22; II, 1, 283 b 26-284 b 5 .

$5^{2}$ I. 5,15 .

53 Aristoteles, De anima, II, 2, 418 a 14-15; Themistius, In De anima, ed. G. Verbeke, Commentaire sur le traité de l'âme d'Aristote. Traduction de Guillaume de Moerbeke. Édition critique et étude sur l'utilisation du Commentaire dans l'œuvre de saint Thomas, Louvain-la-Neuve/Paris 1957 (Corpus Latinum Commentariorum in Aristotelem Graecorum, 1), 132-133; cf. Auct. Arist., 179, n. 66; Nicolaum Oresme, Questiones in De anima, II.1O, ed. B. Patar, Louvain-la-Neuve 1995, 194 $4^{15-17}$.
} 
in agibilibus et in factis particularibus, de quorum numero non est eternitas mundi, et ex hoc patet solutio argumenti.

Hoc de questione.

\section{I.6 Utrum elementa sint continue proportionalia ad invicem}

$P 233^{v}$ Queritur consequenter utrum elementa sint continue proportionalia ad invicem.

$\langle 1\rangle$ Et arguitur quod sic. Et primo quod sint continue proportionalia in quantitate; nam elementa sunt equalia in quantitate; ergo sunt continue proportionalia in quantitate. Consequentia tenet, nam, si sint quatuor termini qui sic se habent quod qualis est proportio primi ad secundum, talis etiam est secundi ad tertium et similiter tertii ad quartum, illi sunt continue proportionales ad invicem. Sed si sint equalia in quantitate, tunc qualis est proportio ignis ad aerem, talis est proportio aeris ad aquam, et similiter aque ad terram. Antecedens probatur, nam si elementa essent inequalia in quanti-

$U 7^{\mathrm{vb}}$ tate et magnitudine, tunc etiam essent inequalia | in virtute, cum in maiori magnitudine sit maior virtus. Sed hoc est falsum, nam si essent inequalia in virtute, tunc illud quod esset maioris virtutis cetera corrumperet, cum elementa sint ad invicem contraria.

$\langle 2\rangle$ Secundo videtur quod sint continue proportionalia in raritate, nam, in quanto ignis est rarior aere, in tanto aer est rarior aqua, et aqua est rarior terra; et sic consimiliter in densitate, cum ex uno pugillo terre fiunt decem aque, et ex uno aque decem aeris, et sic ultra. Ex hoc etiam argueretur quod continue essent proportionalia in magnitudine; nam videtur quod taliter se

$K l g^{\text {ra }}$ habeant ad invicem in magnitudine qualiter se habent ad invicem | in raritate et densitate.

$\langle 3\rangle$ Tertio videtur quod sint proportionalia in gravitate et levitate: in quan-

$L 187^{\text {va }}$ tum enim ignis est levior $\mid$ aere, in tantum aer est levior aqua et in tantum

$B a 9^{\text {va }}$ aqua est levior terra; et in quantum terra est gravior aqua, in tantum aqua | est gravior aere, et sic ultra.

$\langle 4\rangle$ In oppositum arguitur probando quod elementa non sint continue proportionalia in quantitate, nam, si sint, sequitur quod in quanto ignis esset maior aere et aer maior aque, quod in tantum aqua esset maior terra; sed

1 in agibilibus et] om. $B a K l L U \quad 14$ et magnitudine] om. Ba KlLU 24 et densitate] om. $B a K l L U \quad 28$ et sic ultra] et aer igne $K l$ 
hoc est falsum. Consequentia tenet ex diffinitione continue proportionalium. Falsitas consequentis patet, nam aqua non est maior terra, et ad minus non in tantum in quantum aer est maior aqua; nam, si sic, sequeretur quod, sicut aer circuit, ambit et cooperit totam aquam, ita etiam aqua ambiret et cooperiret totam terram. Hoc autem est falsum, sicut patet per experientiam.

$\langle 5\rangle$ In ista questione primo videndum est de intellectu quorundam terminorum; secundo videndum est an elementa sint equalia; tertio videndum est de quesito principali, an sint continue proportionalia.

$\langle 6\rangle$ Quantum ad primum, sciendum est quod per 'elementa', prout 'elementum' accipitur in proposito, intelligo elementa pura vel corpora eis similia. Secundo sciendum est quod continua proportionalitas et geometrica, de qua intendimus in proposito, dicitur similitudo proportionum terminorum sic se habentium ad invicem quod qualis est proportio primi ad secundum, talis est secundi ad tertium, et sic deinceps. Verbi gratia: 8, 4, 2, 1. Isti termini dicuntur ad invicem continue proportionales, nam sicut 8 ad 4 est proportio dupla, ita similiter 4 ad 2, et similiter 2 ad 1 . Proportionalitas autem geometrica discontinua est quando non est eadem proportio primi ad secundum | sicut secundi ad tertium, licet bene sit eadem proportio primi ad secundum | sicut tertii ad quartum. Verbi gratia: 6, 3, 2, 1. Isti termini sunt proportionales discontinue: sunt enim proportionales, quia sicut proportio 6 ad 3 est dupla, ita similiter proportio 2 ad 1 est dupla; sed non sunt proportionales continue, quia non se habent 3 ad 2 sicut 6 ad $3: 3$ enim ad 2 est proportio sesquialtera; 6 autem ad 3 est $\mid$ dupla.

$\langle 7\rangle$ Et differt proportionalitas continua a discontinua, quia minimus numerus terminorum in quibus potest reperiri proportionalitas continua est numerus ternarius, sed minimus numerus terminorum in quibus reperiri potest proportionalitas discontinua est numerus quaternarius. Conveniunt autem in hoc quod non est dare maximum numerum terminorum in quibus aliqua earum potest reperiri, sed quocumque dato, dabilis est maior in quo quelibet predictarum proportionum potest inveniri. Disproportionalitas autem | dicitur proportionum dissimilitudo, verbi gratia sicut hic: 4, 3, 2 , 1. Sicut enim se habent 4 ad 3, ita non se habent 2 ad 1. Similiter, sicut se habent 4 ad 3 , ita non se habent 3 ad 2 .

7 intellectu] expositione $K l L U \quad 19$ sicut secundi ad tertium licet bene sit eadem proportio primi ad secundum] om. hom. $P \quad 3{ }^{1-32}$ disproportionalitas] terminorum add. Ba Kl U 
$\langle 8\rangle$ Quantum ad secundum, sciendum est quod elementa possunt ymagi$B a 9^{\mathrm{vb}}$ nari equalia quadrupliciter: primo modo in extensione; | secundo modo in virtute; tertio modo in materia; quarto modo in spissitudine.

$\langle 9\rangle$ De primo ergo sit prima conclusio: elementa non sunt equalia in quantitate seu extensione. Patet, quia ignis est maior aere et aer maior aqua et aqua terra; unde, nisi aer et ignis essent maiores terra et aqua, non sufficerent ad implendum speram inter nos et celum, quod tamen est necessarium ne sit vacuum.

$\langle 10\rangle$ Secunda conclusio: nec sunt equalia in virtute. Patet, nam videmus quod modicus ignis consumit multum aerem; ergo, si modicus ignis est

$K l 9^{\text {va }}$ maioris | virtutis quam sit multus aer, et cum orbis ignis sit maior quam sit orbis aeris, sequitur etiam quod sit maior in virtute. Secundo: si elementa essent equalia in virtute, sequeretur quod terra esset tante virtutis sicut aliquod aliorum elementorum; quod est falsum, quia, accepta aliqua terra equalis quantitatis cum alio elemento, ipsa habet minorem virtutem quam illud elementum, et propter hoc terra in mixtis habundat quantum

$U 8^{\text {rb }}$ ad quantitatem. | Per istam conclusionem excluditur una opinio que dicit omnia elementa esse equalia in virtute, sed non in magnitudine.

$\langle 11\rangle$ Tertia conclusio est quod elementa non sunt equalia secundum materiam, id est non quodlibet elementum habet tantum de materia sicut aliud. Patet, nam si sic, cum aqua sit rarior quam terra, si cum hoc haberet tantum de materia sicut terra, oporteret quod esset multo maior quam sit terra. Modo hoc est falsum, quia tunc terra totaliter esset aquis cooperta.

$\langle 12\rangle$ Sed diceret aliquis: immo aqua est maior terra, sed tamen celum elevat aquam maris plus quam terra sit elevata et preservat terram ex una parte sicca et non aquis cooperta propter generationem et conservationem animalium $^{54}$. Breviter hoc non valet, nam si hoc esset verum, demonstratio Aristotelis in secundo Celi non valeret, qua demonstrat spericitatem aque ${ }^{55}$, $L 188^{\text {ra }}$ nam in ista demonstratione presupponitur quod aqua | semper tendit ad locum decliviorem et bassiorem; modo hoc esset falsum si aqua maris sic per celum esset elevata.

$\langle 13\rangle$ Per istam conclusionem excluditur una opinio que ymaginatur elementa esse equalia secundum materiam. Ymaginatur quod terra tantum

6 aqua] om. $P \quad 26$ conservationem] salvationem $B a K l L U \quad$ 30 et bassiorem] om. Ba KlL $U \|$ esset] om. $P$

54 Cf. Iohannem Buridanum, Questiones in Meteorologica, I.3, ed. S. Bages, Les Questiones super tres libros Metheororum Aristotelis de Jean Buridan: étude suivie de l'édition du livre I, Thèse de doctorat de l'École des Chartes, 1986 (2 vols.), 2: 34-35. 
habeat de materia sicut aqua, et aqua tantum sicut aer et sic ultra. Sed quia terra est magis densa quam sit aer, | ipsa est minus extensa quam sit aer, non obstante quod tantum habeat de materia sicut aer. Unde ista opinio ymaginatur quod tota materia prima equaliter sit divisa in materias elementorum, excepta illa parte materie que est materia mixtorum ${ }^{56}$.

〈14〉 Quarta conclusio: nec spissitudines | orbium elementorum sunt equales; nam, si sic, tunc tantum esset de concavo aeris usque ad concavum ignis quantum est de concavo ignis usque ad concavum orbis Lune; et similiter tantum esset de centro Terre usque ad concavum aeris, quantum esset a concavo aeris usque ad concavum orbis Lune. Sed hoc est falsum. Consequentia primi patet ex eo quod spissitudo orbis aeris est spatium inter concavum aeris et concavum ignis, et similiter spissitudo orbis ignis est spatium inter concavum orbis ignis et concavum | orbis Lune. Consequentia autem secundi patet eo quod distantia a centro Terre usque ad concavum aeris est spissitudo duorum elementorum, scilicet terre et aque, sicut distantia a concavo aeris usque ad concavum orbis Lune, scilicet aeris et ignis.

$\langle 15\rangle$ Per istam conclusionem | excluditur opinio illorum qui ymaginabantur quod tota semidyameter istius mundi inferioris esset divisa in quatuor partes equales quarum una esset distantia a centro Terre usque ad convexum Terre, secunda autem esset distantia a concavo aque usque ad eius convexum, tertia vero esset distantia a concavo aeris usque ad eius convexum, quarta vero esset distantia a concavo ignis usque ad eius convexum. Ista opinio exclusa est per predictam conclusionem.

$\langle 16\rangle$ Et est sciendum quod si ista opinio esset vera, possent alique conclusiones curiales deduci ex principiis et conclusionibus geometrie.| Unde, sumpta veritate opinionis, posset inveniri et geometrice demonstrari in qua proportione se habeat aggregatum ex terra et aqua ad terram solum; similiter, in qua proportione se habeat aggregatum ex terra, aqua et aere ad terram 30 solum; similiter, in qua proportione se habeat aggregatum ex terra, aqua, aere et igne ad terram solum. Et ad hoc demonstrandum oportet supponere penultimam | duodecim Elementorum Euclidis, videlicet quod propor$K l 10^{r a}$ tio sperarum est tripla ad proportionem dyametrorum istarum sperarum

\footnotetext{
1 et sic ultra] et aer sicut ignis $B a \quad 2$ aer] aliquod aliorum elementorum $B a$ aqua $L$ vel aliquod aliorum elementorum $a d d . K l \|$ aer] vel aliquod aliorum elementorum $a d d . B a K l \quad 3$ aer] aqua $L$ aliquod ipsorum $B a$ vel aliquod aliorum elementorum $a d d . K l \quad 22$ a concavo] om. $P \quad 26$ curiales] om. $\mathrm{Ba} \mathrm{KlLU}$
}

56 Cf. Iohannem Buridanum, Questiones in Meteorologica, I.3, ed. Bages, 2: 20. 
$B a 1^{\mathrm{rb}}$ vel semidyametrorum ${ }^{57}$, quia qualis est proportio dyame|trorum ad invicem, talis est proportio semidyametrorum ad invicem, cum qualis est proportio totorum ad invicem, talis etiam est proportio medietatum istorum totorum. Sicut igitur proportio dyametri ad dyametrum est proportio spere ad speram proportio triplicata, ita etiam proportio semidyametri ad semidyametrum est proportio sperarum illarum semidyametrorum proportio triplicata. Ista ergo proportione presupposita, statim, supposita dicta opinione, inveniretur proportio aggregati ex terra et aqua ad terram. Nam, cum semidyameter terre esset equalis distantie a concavo aque usque ad eius convexum, sequitur statim quod proportio semidyametri aggregati ex terra et aqua est dupla ad semidyametrum terre; et si sic, sequitur per propositionem allegatam quod proportio aggregati ex terra et aqua — puta illius spere aggregate — ad speram terre est proportio que est tripla duple; et cum proportio octupla sit tripla duple, sequitur proportionem spere aggregate ex terra et aqua ad speram terre esse octupla, qualis est proportio 8 ad 1. Quod autem proportio 8 $U 8^{\mathrm{vb}}$ ad 1 sit tripla duple patet faciliter signatis quatuor terminis continue | proportionalibus proportione dupla, scilicet 1, 2, 4, 8. Hic sunt quatuor termini continue proportionales proportione dupla; igitur, per unam propositionem quinti Elementorum Euclidis $^{58}$, proportio primi ad ultimum est tripla ad proportionem primi ad secundum, secundi ad tertium, tertii ad quartum. Et hoc

$K l \mathrm{O}^{\mathrm{rb}}$ etiam | patet ex alio, nam, cum aliquod totum componitur ex tribus partibus equalibus, tunc istud totum est triplum ad quamlibet istarum partium.

$L 188^{\text {va }}$ Cum ergo proportio 8 ad 1 componatur ex tribus duplis, videlicet $\mid$ ex proportione 2 ad 1 et ex proportione 4 ad 2 et ex proportione 8 ad 4, sequitur proportionem 8 ad 1, que est octupla, esse tripla ad quamlibet istarum quarum quelibet est dupla. Sic ergo patet quod octupla est tripla duple et per consequens, si semidyameter aggregati ex terra et aqua est dupla ad semidyametrum terre, sequitur proportionem totius spere aggregate ex terra et aqua ad terram esse proportionem 8 ad 1.

5-6 ita etiam proportio ... semidyametrorum proportio triplicata] om. hom. Ba Kl 7 proportione] suppositione $B a K l L U$ a terre $]$ om. $B a K l L U \|$ convexum] sicut a concavo terre usque ad eius convexum $a d d$. $B a K l L U$ 11 propositionem] euclidis prius add. Ba Kl euclidis add. $L U \quad 16$ faciliter] om. $B a K l L U \quad$ 18-19 propositionem quinti elementorum euclidis] quinti $P$

57 Ibid., $365^{16}-366^{12}$ : "Spere ad se invicem in triplici proportione sunt propriorum diametrorum".

$5^{8}$ Campanus de Novara, Liber Elementorum Euclidis, XII.18, ed. H.L.L. Busard, Wiesbaden $2005,365^{16}-366^{12}$ : "Spere ad se invicem in triplici proportione sunt propriorum dyametrorum". 
$\langle 17\rangle$ Similiter ex eadem radice potest inveniri | in qua proportione se habeat aggregatum ex terra et aqua et aere ad terram solum. Nam ex quo semidyameter totius aggregati ad | semidyametrum terre habet se in proportione tripla, qualis est proportio $3 \mathrm{ad}$ 1, sequitur ex propositione Euclidis allegata quod proportio aggregati ex terra, aqua et aere ad terram solum est tripla triple, qualis est proportio 27 ad 1, quod faciliter potest videri si ponantur quatuor termini continui proportionales proportione tripla, verbi gratia: 1, 3, 9, 27. Hic sunt quatuor termini continue proportionales proportione tripla, ergo proportio primi-hoc est maximi-ad ultimum est tripla ad quamlibet istarum proportionum quarum quelibet est tripla. Ex isto ergo patet quod proportio 27 ad 1 est tripla triple.

$\langle 18\rangle$ Ex eadem radice potest inveniri in qua proportione se habeat aggregatum ex omnibus quatuor elementis ad terram solum. Nam, stante predicta opinione, | proportio semidyametri aggregati ex quatuor elementis est qua$K l 10^{\text {va }}$

15 drupla ad proportionem semidyametri terre, et per consequens proportio totius aggregati ex quatuor elementis ad terram est proportio que est tripla quadruple, qualis est proportio 64 ad 1 . Hoc enim patet quod illa sit tripla quadruple si signentur quatuor termini continue proportionales proportione quadrupla isto modo: $1,6,16,64$. Hic enim sunt quatuor termini continue proportionales; ergo proportio maximi ad minimum est tripla ad proportionem primi ad secundum, secundi ad tertium, tertii ad quartum. Et cum quelibet istarum | proportionum sit quadrupla, sequitur proportionem 64 ad 1 esse tripla quadruple. Ecce ergo primos tres numeros cubitos: 8, 27, 64. Et ita aliqui putabant proportionem elementorum iam dictam se habere, et hoc esset verum supposita veritate illius opinionis.

$\langle 19\rangle$ Ex hoc tunc ulterius potest inveniri quanta esset spera aeris sola et similiter spera ignis sola et similiter spera aque sola. Supposito quod spera terre esset sicut 1 , tunc, secundum dicta, aqua esset sicut $\mid 7$, aer vero sicut $L 188^{\mathrm{vb}}$ 19, ignis vero sicut 37. Et secundum hoc tunc elementa non essent continue 30 proportionalia, sed disproportionalia.

$\langle 20\rangle$ Ulterius, supposita veritate predicte opinionis, posset inveniri in qua proportione se haberet aggregatum ex aere, aqua et terra ad aggregatum ex aqua et terra, | et similiter in qua proportione se haberet aggregatum ex omnibus elementis ad aggregatum ex terra, aqua et aere. Primum patet, nam proportio semidyametri aggregati ex terra, aqua et aere habet se in proportione sesquialtera ad semidyametrum aggregati ex terra et aqua. Ergo

1 ex] iter. $P \quad 3$ habet se $]$ om. $P \quad 6$ faciliter $]$ om. Ba KlLU $\quad 26-27$ et similiter spera ignis sola] om. Ba Kl 2937$] 27$ codd. 
proportio aggregati ex illis tribus ad aggregatum ex illis duobus est tripla$K l 10^{\text {vb }}$ sesquialtere. Et cum proportio semi|dyametri aggregati ex omnibus quatuor elementis habeat se in proportione sesquitertia ad semidyametrum aggregati ex terra, aere et aqua, sequitur proportionem totius aggregati ex omnibus elementis ad aggregatum ex tribus esse proportionem tripla sesquitertie proportionis, cum proportio sperarum sit tripla ad proportionem semidyametrorum.

$\langle 21\rangle$ Quantum ad tertium, sciendum est quod aliqui posuerunt elementa esse continue proportionalia secundum eorum magnitudinem, sic quod sicut se habet ignis ad aerem in extensione, ita aer ad aquam et aqua ad terram; vel sicut ignis se habet ad aggregatum ex tribus aliis elementis, ita aer se habet ad aggregatum ex aliis duobus elementis, et sic se habet aggregatum ex aliis duobus ad terram solum. Et crediderunt hoc esse ideo, quia sicut $P 235^{\mathrm{v}}$ se habent elementa | in eorum transmutatione ad invicem, ita et in eorum quiete. Sed in transmutatione eorum ad invicem sunt continue proportionalia, nam, sicut ex uno pugillo terre fiunt decem pugilla aque, ita ex uno aque pugillo fiunt decem pugilli aeris, et ex uno aeris decem ignis. Et isti ulterius

$U 9^{\text {rb }}$ dix|erunt quod elementa in eorum magnitudine essent continue ad invicem proportionalia proportione decupla, ex quo sic ... in eorum transmutatione.

$\langle 22\rangle$ Alii autem dixerunt quod elementa essent continue proportionalia in proportione qua se habent $33 \mathrm{ad}$ 1, dimissis fractionibus, et hoc quoad eorum dyametros vel semidyametros. Unde ymaginabantur quod, si semidyameter $L 189^{\text {ra }}$ terre esset sicut unum, tunc semidyameter aque esset sicut $\mid 33$, et ulterius semidyameter aeris esset signanda per unum numerum qui haberet se in $B a 11^{\text {ra }}$ $K l{ }_{11} \mathrm{ra}$ eadem proportione ad 33 in qua se habent 33 ad 1 . Et ulterius | semi|dyameter ignis esset signanda per unum numerum qui sic se haberet ad numerum quo signanda est semidyameter aeris sicut 33 ad 1 , ita quod voluerunt quod semidyameter spere ignis esset trigintuplatripla ad semidyametrum spere aeris, et quod semidyameter spere aeris esset trigintuplatripla ad semidyameter aque, et semidyameter aque trigintuplatripla ad semidyametrum terre. Et

10 in extensione] om. Ba Kl L $U \quad 11-12$ ita aer se ... aliis duobus elementis] om. $P \quad 13^{-14}$ sicut se habent elementa] sicut elementa sunt continue proportionalia $B a K l L U \quad 14$ eorum] magnitudine et in $a d d . B a \quad 18$ magnitudine] transmutatione ad invicem $B a K l L U \quad 19$ ita etiam proportio ... semidyametrorum proportio triplicata] quia sicut se habent ad invicem in eorum magnitudine sic etiam se habent ad invicem in eorum transmutatione $\mathrm{Ba} K \mathrm{~K}$ quia sicut se habent ad invicem in eorum magnitudine sic etiam in eorum transmutatione sicut ipsi dixerunt $L U \quad 22$ semidyameter] diameter $P \quad 28-29$ spere aeris et ... trigintuplatripla ad semidyameter] om. hom. $P$ 
ex proportione istarum semidyametrorum ad invicem ulterius inveniebant proportionem sperarum elementorum ad invicem mediante ista propositione: 'proportio sperarum est tripla ad proportionem semidyametrorum'59.

$\langle 23\rangle$ Contra istas duas opiniones pono istam conclusionem quod ele5 menta non sunt continue proportionalia secundum eorum magnitudines. Probatur, nam, si sic, tunc oporteret quod in eadem proportione aqua esset maior terra in qua ignis est maior aere et aer maior aqua. Modo hoc est falsum, nam, si sic, sequeretur quod aqua cooperiret totam terram. Modo hoc est falsum, igitur etc.

$10\langle 24\rangle$ Ad rationes. Ad primam: 'elementa sunt equalia in quantitate', nego. Et quando dicebatur: 'si non, sequeretur quod unum esset maioris virtutis quam reliquum', concedo. Et quando dicebatur: 'qualiter ergo istud quod est maxime virtutis inter alia non corrumpit alia?', dico quod ratio huius est quia quanto aliquod elementorum est maioris activitatis, tanto est minoris

15 resistentie et maioris passivitatis; et quanto aliquod elementum est minoris activitatis, tanto est maioris resistentie et minoris passivitatis; et ergo, quamvis inter elementa unum eorum sit maxime activitatis, non tamen propter hoc corrumpit alia propter magnam resistentiam aliorum.

$\langle 25\rangle$ De secunda autem et tertia, an sint continue proportionalia in rari- $K l_{11^{\mathrm{rb}}}$ tate vel in gravitate vel levitate, videbitur in questione sequenti ${ }^{60}$.

\section{I.7 Utrum quatuor elementa semper et immutabiliter habeant eandem proportionem ad invicem}

Queritur consequenter utrum quatuor elementa semper et immutabiliter habeant eandem proportionem ad invicem, sic quod una vice ignis non sit maior | quam alia, nec similiter aer; etc.

$\langle 1\rangle$ Et arguitur quod sic: | continue tantum est de raritate sicut modo est,

8 terram] sicut aer cooperit totam aquam add. Ba KlLU 9 igitur etc] quod patet ad experientiam $B a K l$ ut patet de se $L U \quad 13$ inter alia] et activitatis $K l U$ om. $B a L \quad 14$ activitatis] virtutis in agendo $B a \quad 23$ maior] scrips. maior corr. sup. lin. rarior $B a$ rarior $L$

59 Campanus de Novara, Libri Elementorum Euclidis, XII.18, ed. Busard, $365^{16}-366^{12}$ : "Spere ad se invicem in triplici proportione sunt propriorum dyametrorum".

$60 \quad$ I.7, 7 . 
densitas habent eandem proportionem ad invicem; igitur continue equaliter est de elementis gravibus et levibus; et per consequens, cum omnia elementa sint gravia vel levia, immutabiliter omnia elementa obtinebunt eandem proportionem ad invicem. Antecedens probatur, nam tota massa $B a 1^{\mathrm{rb}} \quad$ istorum corruptibilium | replet orbem Lune; si igitur aliquando raritas et $P_{23} 6^{r}$ densitas haberent se inequaliter ad invicem quam modo se $\mid$ habent, oporteret vel quod latera celi magis appropinquarentur ad invicem, vel quod fieret vacuum, quorum utrumque est impossibile naturaliter.

$\langle 2\rangle$ Secundo ad idem sic: si aliquid condensatur, necesse est quod aliquid rarefiat; igitur continue equaliter est de raritate et densitate, et per consequens de caliditate et frigiditate, cum huiusmodi qualitates mutuo se consequuntur ad invicem; et sic continue elementa calida et frigida obtinebunt eandem proportionem ad invicem.

〈3〉 Tertio: continue caliditas et frigiditas habent se equaliter; ergo elementa calida et frigida continue habebunt se equaliter, et hoc quoad eorum proportionem. Consequentia tenet; sed antecedens probatur, nam, cum Sol causat calorem super terram, generatur frigiditas infra; et e contrario, cum recedit et est frigiditas super terram, remittitur frigiditas infra terram ${ }^{61}$, quod videtur esse signum quod caliditas et frigiditas equaliter se habent ad invicem quoad earum proportionem.

$K l{ }_{11}$ va $\quad\langle 4\rangle$ Quarto ad idem: Sol per eius accessum $\mid$ ad nos causat caliditatem circa nos et per eius recessum a nobis causatur circa nos frigiditas. Ita etiam videtur consimili modo circa illos qui morantur nobis opposito modo; et si sic, sequeretur quod quando Sol accedit versus nos et habemus circa nos calorem, ipsi habent frigiditatem, et e contrario. Quod videtur esse signum quod continue se habeant equaliter ad invicem caliditas et frigiditas.

$\langle 5\rangle$ In oppositum arguitur, nam aliquis potest multam caliditatem generare et frigiditatem corrumpere per combustionem aliquorum terrestrium et frigidorum; et per consequens non equaliter se habebunt ad invicem caliditas et frigiditas; et per consequens nec elementa calida et frigida; et per consequens non immutabiliter quatuor elementa obtinebunt eandem proportionem ad invicem.

17 generatur] intenditur $\mathrm{Ba} K l L \mathrm{~L} \quad{ }_{17-18}$ cum recedit et est ... frigiditas infra terram ] om. $\mathrm{Ba} \mathrm{Kl}$

61 Cf. I.10. 
$\langle 6\rangle$ In ista | questione, quia visum erat in alia questione de proportione ele$U 9^{\text {vb }}$ mentorum ad invicem quoad magnitudinem ${ }^{62}$, nunc primo videndum est de proportione elementorum ad invicem quoad eorum raritatem et densitatem, | gravitatem et levitatem. Secundo videndum est de quesito principali. Tertio videndum est qualiter elementa possunt ad invicem perpetuari, cum tamen sint ad invicem contraria activa et passiva mutuo se corrumpentia.

$\langle 7\rangle$ Quantum ad primum, sit prima conclusio: non semper elementa habent se in continua proportione ad invicem in raritate et densitate. Patet, nam aliquando nec terra nec aqua condensata vel rarefacta, ignis est densior et aer rarior, vel e contrario, quod non potest esse si semper quatuor elementa | essent ad invicem proportionalia in raritate et densitate.

$\langle 8\rangle$ Secunda conclusio: nec semper | sunt continue proportionalia ad invicem in gravitate et levitate. Patet, nam ignis nullo modo est gravis, vocando 'grave' quod tendit versus medium infra orbem Lune; igitur nulla est propor-

15 tio gravitatis aliorum elementorum ad gravitatem ignis, cum nullam gravitatem habeat.

$\langle 9\rangle$ Quantum ad secundum, sit prima conclusio: quatuor elementa non semper habent se in eadem proportione ad invicem quoad eorum magnitudines. Patet per rationem qua arguebatur ad oppositum: aliquis enim potest comburere multa terrestria et destruere frigiditatem et generare caliditatem, cum non necesse sit quod semper caliditas et frigiditas equaliter habeant se ad invicem; nec est simile de raritate et densitate propter repletionem loci infra orbem Lune. Secundo, nam aliqui planete causant in istis inferioribus caliditatem, aliqui vero frigiditatem; sed aliquando sunt coniuncti plures 25 planete frigidi quam aliquando, et aliquando plures planete calidi; igitur aliquando causatur in istis inferioribus plus de frigiditate et aliquando | minus; et similiter est de caliditate.

$\langle 10\rangle$ Quantum ad tertium, quomodo elementa possunt perpetuari, cum tamen sint contraria et activa et passiva ad invicem, oportet primo supponere 30 quod si verbi gratia ignis rarefiat, quod oportet aerem condensari; aliter enim oporteret quod latera celi ab invicem plus recederent, quod est impossibile.

9 rarefacta] rarificata $P \quad 14$ orbem $]$ speram $K l \quad 22$ repletionem $]$ capacitatem $K l \quad 26$ frigiditate] caliditate $P \quad 29$ contraria] inequalia et contraria $K l$ inequalia contraria $B a U$

$62 \quad$ I.6, 9. 
$\langle 11\rangle$ Oportet secundo supponere quod si ignis augetur, quod oportet ipsum

$U 10^{\mathrm{ra}}$

$K l 12^{\text {ra }}$

$L 189^{\mathrm{vb}}$

$B a 11^{\mathrm{vb}}$ condensari vel aerem sibi propinquum propter eandem rationem.

$\langle 12\rangle$ Oportet tertio supponere quod si ignis diminuatur, | oportet quod ignis rarefiat vel aer sibi contiguus vel aliquid aliorum elementorum, ne fiat vacuum infra orbem Lune vel ne oporteat latera celi plus ad invicem | appropinquari.

$\langle 13\rangle$ Oportet supponere quarto quod quodlibet elementorum determinat sibi certam latitudinem raritatis et densitatis quam non transgreditur nisi violenter ${ }^{63}$.

$\langle 14\rangle$ Oportet supponere quinto quod est dare unam certam latitudinem raritatis et densitatis quam non transgreditur elementum nisi cum eius corruptione: est enim aliqua latitudo raritatis sub qua non potest esse aqua de sua natura, hoc est illam formam aqua non sibi determinat; nichilominus sub illa potest esse aqua per actionem ignis in eam. Similiter est una raritas maior sub qua aqua non potest esse neque naturaliter neque violenter, sic quod quam cito illam attingit, | ipsa corrumpitur.

$\langle 15\rangle$ Tunc sit prima conclusio: impossibile est quod ignis omnia infra concavum orbis Lune corrumperet. Patet, quia cum celum vel latera celi non possunt extendi, oporteret ignem attingere tantam densitatem sub qua esse non potest. Et per consequens, cum ipse ignis continue entia mundi corrumperet alia ab ipso, continue plus et plus condensaretur et magis violentaretur, cum stare sub densitate sit sibi violentum. Et per consequens continue in actione eius debilitaretur et ante combustionem omnium aliorum a se tantum debilitaretur in eius actione quod non posset plus agere et per consequens nec alia corrumpere.

$\langle 16\rangle$ Ex ista conclusione sequitur quod ignis in spera sua tantum posset augeri quod non posset plus agere et quod, si stuppa sibi approximaretur, ipsa se non combureret. Patet, quia tantum posset augeri quod tantum condensaretur quod eius actio totaliter remitteretur; unde ex condensatione ignis, ignis remittitur in agendo, sicut patet cum aliquis ignis quod non

2 propinquum] contiguum $K l \quad 3$ diminuatur] condensetur vel diminuatur $L \quad 11$ elementum] nec naturaliter nec violente $a d d$. Ba Kl L $U \quad 15$ maior] om. Ba Kl L U $\quad$ 17-18 impossibile est quod ... orbis lune corrumperet] quod ignis posset tantum corrumpere quod impossibile esset quod naturaliter plura infra orbem lune corrumpeat $B a$ quod ignis non posset tantum corrumpere quod impossibile esset naturaliter quod plura infra orbem lune corrumperet $\mathrm{Kl} \quad 17$ est] om. $P \quad 18$ celum vel] om. Ba Kl LU

63 Cf. Nicolaum Oresme, Questiones super De generatione et corruptione, I.4, ed. Caroti, $29^{154-157}$. 
potest libere se dilatare non comburit ita intense sicut cum libere se dilatare $\mid K l 12^{\mathrm{rb}}$ potest.

$\langle 17\rangle$ Sed diceret aliquis: hoc videtur esse contra Aristotelem in secundo De anima, ubi dicit quod si infinita combustibilia igni apponerentur, ignis cresceret ad infinitum ${ }^{64}$. | Breviter respondetur quod bene hoc verum est cum esset in loco in quo libere ad quamcumque distantiam posset se dilatare; sed sic non est infra orbem Lune; igitur non quantumcumque infra orbem Lune potest augeri.

$\langle 18\rangle$ Ex isto etiam potest reddi causa quare diluvia non diu durant, nam per talem augmentationem et multiplicationem unius elementi, elementa non sunt sub raritate et densitate sibi naturalibus, sed violentis; et quia violentum non est diu durativum, sequitur huiusmodi diluvia non posse diu permanere.

$\langle 19\rangle$ Ex istis patet ad tertium articulum, nam, quamvis elementa sint con15 traria et activa et passiva ad invicem, tamen quodlibet eorum tantum potest augeri quod eius actio debilitatur et non ulterius agit, sicut dicebatur de augmentatione ignis et remissione sue actionis.

$\langle 20\rangle$ Ad rationes. Ad primam dico quod quamvis equaliter sit continue de raritate et densitate, | tamen ex hoc non oporteret quod continue equaliter $B a 12^{\mathrm{ra}}$ sit de gravitate et levitate. Et quando dicebatur: |'cum mutuo se consequuntur', respondetur quod quamvis ita sit, hoc tamen non est proportionaliter, quia, cum ferrum ignitur, ipsum non tantum acquirit de levitate sicut de caliditate.

$\langle 21\rangle$ Ad secundam patet eodem modo quod quamvis caliditas et frigiditas,

25 raritas et densitas, mutuo se consequantur, tamen hoc non est proportionaliter, sicut patet de ferro ignito.

$\langle 22\rangle$ Ad tertiam respondetur quod non tantum proportionaliter generatur de frigiditate infra terram quantum de caliditatem super terram, nec e contrario. Et ex hoc patet ad articulum.

$\langle 23\rangle$ Ad quartam respondetur quod non semper proportionaliter | tantum generatur circa nos caliditas, quantum frigiditas generatur nobis opposito modo, solum per accessum Solis et recessum. Et ratio est quia non solum Sol productivus est caliditatis in istis inferioribus, verum etiam alii planete; et ideo possibile est quod quando Sol generat circa nos calorem per eius acces-

5 est] quod add. $P \quad 7$ quantumcumque] in infinitum $B a$ qualitercumque $K l U \quad 12$ est $] \mathrm{om}$. $P \quad$ 2o de gravitate et levitate] de caliditate et frigiditate $B a K l L U$

64 Aristoteles, De anima, II, 4, 416 a 15-16. 
sum ad nos, quod alii planete in loco opposito etiam generant calorem; et sic non proportionaliter, quantum est hic calidius, est ibi frigidius.

Hoc de questione.

\section{I.8 Utrum motus celi sit causa calefactionis ignis in sua spera et etiam aeris superioris}

$L 190^{\text {rb }}$ Queritur consequenter utrum motus celi sit causa calefactionis ignis $\mid$ in sua spera et etiam aeris superioris.

$\langle 1\rangle$ Et arguitur primo in generali quod motus localis non est causa caloris sic: id quod est causa frigiditatis non est causa caloris; sed motus localis est huiusmodi; ergo etc. Maior est nota, quia idem non videtur esse oppositorum causa ${ }^{65}$. Minor probatur, quia videmus quod poreta calida, cum move-

$U 10^{\text {va }}$ tur, frigefit; unde videtur quod motus | localis sit causa frigiditatis.

$\langle 2\rangle$ Secundo, nam experimur quod aqua currens frigidior est quam aqua stans, que tamen deberet esse calidior si motus esset causa caloris.

$\langle 3\rangle$ Tertio ad idem: si motus esset causa caloris, sequeretur quod, cum aliquod mobile descenderet_puta aliquod grave, ut lapis-propter eius descensum calefieret; sed hoc non fit, nam, si sic, sequeretur etiam quod grave in descendendo leve fieret, cum levitas consequatur caliditatem; et per consequens grave in fine tardius descenderet quam in principio, quia in fine esset minus grave. Et ex hoc tunc sequeretur quod motus naturalis non esset in fine velocior quam in principio, quod est contra philosophice loquentes ${ }^{66}$.

〈4〉 Quarto ad idem, nam aliqui sunt habentes manus tremulas, quibus

$\mathrm{Ba} 12^{\mathrm{rb}}$ $K l 12^{\mathrm{vb}}$ tamen non propter hoc manus sunt $\mid$ calidi|ores. Similiter aliqui febricitantes tremunt et fortiter per totum eorum corpus moventur; non tamen propter hoc calefiunt.

$\langle 5\rangle$ Quinto ad idem: si motus localis calefaceret, vel hoc esset accipiendo 'motum' pro 'fluxu', vel accipiendo 'motum' pro 'forma fluente', vel acci-

1 in loco opposito] circa nos $B a K l L U \quad 2$ non] semper add. Ba KlLU 9 poreta] boreas add. $B a K l L U \quad 17$ grave] gravius $P \quad 19$ philosophice loquentes] communiter loquentes $B a$ plures $K l L U$

65 Cf. Aristotelem, De generatione et corruptione, II, 10, 336 a 30-31; Auct. Arist., 170, n. 42. 66 Cf. Aristotelem, De celo, II, 6, 288 a 27-33; Averroem, Commentarium magnum in De celo, II, comm. 35, ed. Carmody, Arnzen, 333 88-96: f. 119 C; Nicolaum Oresme, Questiones in De celo, II.7 Utrum motus naturalis sit velocior in fine quam in principio, ed. C. Kren, unpub. Ph.D. Dissertation, University of Wisconsin, 1965, 525. 
piendo 'motum' pro 'mobili': non pro 'fluxu', quia sic esset de genere passionis et non esset agens productivum alicuius. Nec etiam potest dici quod pro 'forma fluente', nam forma fluens in motu est ipsum ubi; illud autem non est causa caloris, quia potest esse frigidum. Similiter nec motus accipiendo 'motum' pro 'mobili', quia potest esse mobile quod nec formaliter nec virtualiter est calidum.

〈6) Deinde specialiter probatur quod motus celi non calefacit speram ignis. Patet, nam hoc esset quia celum movet speram ignis secum; sed hoc non, quia ipsum celum est corpus politissimum, et ergo in nulla sui parte ignis potest sibi adherere ut circumducatur vel rapiatur una cum celo.

〈7〉 Secundo, certum est quod ille motus circularis ignis non esset igni naturalis, cum ex primo Celi uni corpori simplici non insunt plures motus naturales ${ }^{67}$. Sed quia igni naturaliter inest moveri sursum, sequitur quod sibi non inest naturaliter moveri circulariter, et per consequens inest sibi violen-

15 ter; et cum violenta non diu durant, cum nullum violentum | sit perpetuum, $L 190^{\mathrm{va}}$ non est verisimile quod tam diu durasset motus circularis ipsius ignis una cum celo.

$\langle 8\rangle$ Tertio: ignis est calidus in summo; ergo non potest calefieri, et per consequens celum per suum motum non calefacit ignem in spera sua.

$\langle 9\rangle$ Deinde | probatur quarto quod celum per suum motum non ca|lefacit aerem superiorem, quia inter ipsum et celum mediat | spera ignis, igitur ille aer et celum distant; sed quia agens et passum debent esse immediata ${ }^{68}$, videtur quod celum non calefaciat aerem superiorem.

$\langle 10\rangle$ In oppositum est Aristoteles in primo huius, cum dicit: 'lato enim circu25 lariter primo elemento', etc. ${ }^{69}$

\footnotetext{
1 mobili] nullum istorum potest dici ergo etc. maior patet per sufficientem divisionem minor probatur $a d d$. $B a K l U$ nullum istorum potest dici ergo etc. maior patet per sufficientem divisionem minor probatur $a d d$. $L \|$ esset] est $P \quad 2$ esset] est $P \quad 3$ motu] locali $a d d$. $B a K l L$

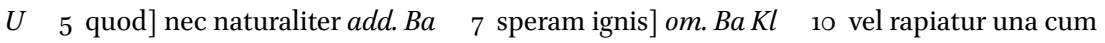
celo] om. BaKl 11 circularis] localis $K l \quad 18$ summo] gradu add. KlLU 20 motum] om. $P \quad 24$ huius] tractatu primo capitulo secundo $a d d$. $K l$ tractatu primo $B a L U$

67 Aristoteles, De celo, I, 268 b 30-269 a 2.

68 Cf. Aristotelem, Physica, III, 2, 202 a 5-8; De celo, II, 7, 289 a 29-30; De generatione et corruptione, I, 6, 322 b 19-25; Auct. Arist., 168, n. 14.

69 Aristoteles, Meteorologica, I, 3, 340 b 11, translatio Guillelmi de Morbeka (translatio noua), $A L \times 2.2,13^{125}$ : "Lato autem primum elementum circulariter".
} 
$B a 12^{\text {va }}\langle 11\rangle$ Breviter in ista questione videndum est qualiter motus localis $\mid$ sit causa caloris; secundo videndum est qualiter celum movet speram ignis et aerisutrum scilicet rapiendo vel alio modo-; tertio videndum est qualiter per hoc ista calefiunt a celo.

$\langle 12\rangle$ Quantum ad primum, sciendum est quod fuit opinio Sancti Thome quod motus localis est causa calefactionis quia in genere motuum, motus localis est primus. Sed in decimo Metaphysice dicitur quod in quolibet genere, primum debet esse causa aliorum in illo genere, et specialiter priorum post ipsum $^{70}$. Cum igitur post motum localem sit calefactio-que ceteris paribus est prior et nobilior, quia est productiva nobilioris qualitatis, ut puta caliditatis-sequitur motum localem esse causam calefactionis.

$\langle 13\rangle$ Alia erat opinio quod motus localis est causa calefactionis quia proprium est calidi moveri et movere, et ergo motus est perfectio ipsius calidi. Cum igitur unam perfectionem consequatur alia, et cum caliditas etiam sit perfectio ipsius calidi, sequitur quod, habito motu locali, consequenter habebitur caliditas; et sic motus dicetur causa caloris quia, ipso habito, habetur caliditas ${ }^{71}$.

$\langle 14\rangle$ Tertia erat opinio quod motus localis, sicut in animali, est causa caloris propter duplicem inclinationem, que quidem inclinationes sunt ad invicem contrarie; et ex tali contrarietate inclinationum causatur calor.

$\langle 15\rangle$ Breviter prima opinio non valet, quia tunc quilibet motus localis deberet calefacere; modo hoc est falsum. Falsitas patet quia, cum aliquid $K l_{13}{ }^{\text {rb }}$ movetur, sicut terebellum, partes | extremales calefiunt citius quam partes centrales, et tamen ita bene partes centrales moventur localiter sicut partes extremales; centrales enim non calefiunt nisi a partibus extremalibus primo

$L 190^{\mathrm{vb}}$ calefactis. Sed consequentia tenet, cum non plus ipse intendat de uno motu | locali quam de alio.

1 est $]$ in generali $a d d . B a K l \quad 3$ utrum scilicet rapiendo vel alio modo] om. $B a K l \quad 5$ quod] fuerunt plures opiniones prima $a d d . B a K l \quad 7$ quod] om. $P \quad 9$ igitur] immediate add. $B a K l$ $L U \quad 20$ calor] in animali $a d d$. Ba KlLU 26 tenet] per opinionem add. Ba Kl

70 Thomas de Aquino, In De celo, lib. 2, tract. 7, lect. 10, in Opera omnia iussu impensaque Leonis XIII P.M. edita, Rome 1886, 3: 158, n. 10. Cf. Aristotelem, Metaphysica, X, 1, 1052 b 18-19; 31-32; Averroem, In Metaph., X, comm. 2, ed. apud Iunctas, 8: f. 251 I; Auct. Arist., 135, n. 239.

71 Cf. Averroem, Commentarium magnum in De celo, II, comm. 42, eds. Carmody, Arnzen, 2: 355 197-205; Thomam de Aquino, In De celo, lib. 2, cap. 7, lect. 10, ed. Leonina, 3: 158, n. 10. 
$\langle 16\rangle$ Nec secunda opinio valet, per eandem rationem. Nec tertia valet, quia grave in descendendo solum habet unam inclinationem, quo tamen non obstante ipsum calefit in descendendo. Secundo patet quod tertia opinio non valet nec sufficit, | quia quod in motu animalis generatur caloris, hoc est propter emissionem spirituum.

$\langle 17\rangle$ Alia est opinio Alberti. Sed premittatur primo una distinctio, quod motus localis | potest fieri dupliciter: uno modo potest fieri per quem fit distractio et confricatio partium ipsius mobilis; alio modo potest fieri per quem non fit aliquid tale, sicut si aliquid movetur in vacuo ${ }^{72}$.

$\langle 18\rangle$ Tunc secundum opinionem Alberti sit prima conclusio: motus localis qui fit primo modo est causa caloris et calefacit, nisi sit aliquid impediens. Patet de ferro in molendino circa | quod volvitur lapis molaris, et cum ibi apponitur aliquid viscosum vel pingue, videtur quod consumitur, quod non videtur nisi per calorem generatum. Similiter videmus quod terebellum cale-

15 fit postquam diu est motum in foramine. Similiter, cum sagitta plumbata movetur, expertum est quod plumbum fuit liquefactum, quod fuit ex calore liquefaciente causato ex motu talis sagitte ${ }^{73}$. Item cum animal movetur localiter, tunc calefit, et hoc quia in motu eius fit confricatio membrorum et musculorum, quamvis etiam alia causa concurrat, videlicet quod cor mit-

20 tit calores et spiritus ad exteriora membra ipsius animalis. Sic ergo motus qui fit cum confricatione est causa caloris. Unde ymaginandum est quod ex tali confricatione fit quedam rarefactio et quedam partium distractio quam consequitur caliditas.

$\langle 19\rangle$ Sed diceret aliquis contra: si hoc esset verum, sequeretur quod cali25 ditas non esset | qualitas prima, propter hoc quod ipsa caliditas causatur ex alia et sequitur alteram, puta raritatem. Respondetur quod caliditas bene dicitur qualitas prima activa; hoc tamen non obstante ipsa potest consequi unam aliam qualitatem, puta raritatem ${ }^{74}$. Vel potest dici quod ut plurium et

\footnotetext{
3-5 secundo patet quod ... propter emissionem spirituum] om. $P \quad 6$ opinio] modernorum et est opinio $a d d . K l \quad 8$ fieri] localis $a d d . P \quad 9$ vacuo] tunc dicit albertus quod ratio est quod ex tali confricatione et collisione fit rarefactio violente et istam rarefactionem violentam consequitur calefactio et hec opinio concordat cum omnibus experientiis unde videmus quod ex tali confricatione et calefactione corrumpuntur quedam partes circa locum confricationis et etiam videmus quod quanto sunt aliqua corpora magis polita tanto est minor confricatio et calefactio add. Ba Kl 13 viscosum vel pingue] unctuosum $B a K l L U \quad 20$ membra] om. $P L \quad 25^{-26}$ causatur ex alia et] om. Ba KlLU
}

72 Albertus Magnus, Meteora, lib. 1, tract. 1, cap. 11, ed. Colon. vi/1, 15 $5^{30-41}$.

73 Cf. Aristotelem, De celo, II, 7, 289 a 25-30.

74 Cf. Nicolaum Oresme, Questiones in Physicam, IV.14, ed. Caroti [et al.], 517 $7^{133-135}$. 
pluries raritas sequitur caliditatem quam e converso; ideo caliditas dicitur qualitas prima, et non raritas.

$\langle 20\rangle$ Secunda conclusio: si aliquis sit motus localis sine confricatione et partium distractione, ille non est causa caloris. Patet, quia partes centrales $L 19 \mathrm{r}^{\mathrm{ra}}$ terebelli circa quas non fit confricatio $\mid$ non calefiunt nisi a partibus extrema$B a 13^{\text {ra }}$ libus | calefactis propter confricationem. Similiter, si illud ferrum in molendino circa quod volvitur lapis molaris moveretur una cum illo lapide versus eandem differentiam positionis sic quod non fieret confricatio, non calefieret.

$K l 13^{\mathrm{vb}} \quad\langle 21\rangle$ Ex isto sequitur quod si aliquod grave quantumcumque | velociter moveretur in vacuo, vel etiam sagitta plumbata, non calefieret, quia ibi non fieret confricatio ipsius ad aerem. Similiter, si esset aliqua sagitta plumbata et plumbum esset involutum in aliquo ligno vel aliquo huiusmodi, et si moveretur in aere, non propter hoc illud plumbum liquefieret, cum tunc non

$U \mathbf{1 1}^{\mathrm{rb}}$ fieret confricatio eius ad aerem. Similiter, | cum aliquis lapis percutitur ferro, non generantur scintille nisi ubi fit talis confricatio. Sic igitur patet qualiter motus localis est causa caloris et qualiter calefacere non inest omni motu locali, sed illi per quem fit confricatio et partium distractio.

$\langle 22\rangle$ Quantum ad secundum, sit ista conclusio quod ignis non ex hoc movetur circulariter cum celo quod celum trahat ignem secum. Patet, quia celum est corpus ita politum quod in nulla parte ignis potest sibi adherere sic quod ignis una cum ipso circumducatur et ab ipso celo rapiatur. Secundo a simili: unus orbis celestis motu suo non vehit secum alium; ergo nec in perpetuo celum rapit et trahit secum ignem. Consequentia tenet de se; sed antecedens patet per Commentatorem in secundo Celi, ubi dicit quod ibi non est raptus nec violentia, nisi fictitie ${ }^{75}$.

$\langle 23\rangle$ Secunda conclusio: ignis sic movetur, videlicet circulariter una cum celo, per virtutem sibi impressam a celo, eo modo quo ferrum movetur insequendo magnetem. Patet, quia ex quo non movetur motu raptus, sicut dicebat prima conclusio, non videtur esse alius modus dicendi nisi dicatur quod

3 secunda] quarta $P \quad 4$ centrales] om. BaKlLU 8 eandem] eam $P \quad 10$ velociter] om. $B a K l L U \quad 11$ plumbata] om. BaKlLU 13 esset involutum] poneretur $B a K l L U \quad 14$ in aere] om. $B a K l L U \|$ plumbum] calefieret vel $a d d$. $B a K l L U \quad 20$ trahat] rapiat $B a K l L U$ 21 corpus] om. $P \quad 23$ vehit] trahit $B a K l L$ rapit vel trahit $U \|$ in perpetuo] om. $B a K l L U$ 3 o modus dicendi] motus $B a K l$ modus $L$

75 Averroes, Commentarium magnum in De celo, II, comm. 3, eds. Carmody, Arnzen, 2: 274-275. 
sic movetur per virtutem sibi impressam a celo. Nec ille motus est igni naturalis, quia non sequitur suam naturam, scilicet formam eius, nec etiam est ei violentus, quia motui circulari nullus motus est contrarius ${ }^{76}$; sed cuilibet motui violento alius motus est contrarius, puta motus naturalis illius | cui talis motus est violentus.

$\langle 24\rangle$ Sed diceres: quomodo ergo ille motus inest igni? Respondetur quod inest sibi preter naturam, sicut etiam dicit Aristoteles in primo Celi ${ }^{77}$. Et potest dici ei impertinens; impertinens enim in arte obligatoria dicitur | quod nec sequitur ad positum nec repugnat posito ${ }^{78}$ : ita motus circularis $L 191^{\mathrm{rb}}$ ignis, quia nec inest ei naturaliter nec inest ei violenter, ergo potest dici impertinens sibi.

$\langle 25\rangle$ Quantum ad tertium, dico quod ignis non calefit a celo per confricationem eius ad celum. Patet, quia ibi nulla | est confricatio, propter hoc quod ipsum celum est corpus politissimum. Sed tamen, quia virtus celi supra est

15 fortior quam infra, partes superiores ipsius ignis moventur velocius quam partes inferiores, et similiter partes superiores aeris moventur velocius quam partes inferiores. Et ergo, quia partes inferiores non ita velociter insequuntur partes superiores, ibi fit quedam distractio partium et rarefactio quam consequitur caliditas, et sic ibi causatur calor.

$\langle 26\rangle$ Ad rationes. Ad primam de motu porete dicitur quod cum poreta movetur, est in alio et alio aere continue recenti et frigido, qui plus infrigidat quam ex tali motu possit calefieri.

$\langle 27\rangle$ Ad secundam respondetur quod aqua stans est calidior quam aqua currens, | non propter hoc quod est stans, sed propter hoc quod radii Solis 25 magis unite reflectuntur super eam quam super aquam currentem. | Et quando dicebatur quod si motus localis est causa caloris, aqua currens deberet calefieri, conceditur quod bene aliqualiter calefieret nisi esset aliquid

2 suam naturam scilicet formam eius] formam ignis $B a K l L U \quad 6$ igni] celo $P \quad 18$ rarefactio] sicut in confricatione $a d d . K l \quad 19$ et sic ibi causatur calor] om. $K l$ consimili modo ymaginandum est de aere $B a \quad 20$ porete] boree $B a K l L U \|$ poreta] boreas $B a K l L U \quad 24$ currens] fluens $B a K l L U \quad 25$ reflectuntur] refranguntur $P \|$ eam] ea $P$

76 Cf. Aristotelem, De celo, I, 3, 270 a 19-20; 4, 270 b 32; Auct. Arist., 16o, n. 8.

77 Aristoteles, De celo, I, 2, 269 a 9-269 b 16.

78 Cf. Martinum Anglicum, De obligationibus-Über die Verpflichtungen, LateinischDeutsch, ed. F. Schupp, Hamburg 2014 (Philosophische Bibliothek, 462) 18; Paulum Venetum, Logica magna, ed. E.J. Ashworth, Oxford 1988 (Classical and Medieval Logic Texts, 8) 180. 
impediens, videlicet quod continue est circa alium et alium aerem recen$K l 14^{\text {rb }} \quad$ tem frigidum qui potest re|conpensari caliditati que posset causari ex tali motu.

$\langle 28\rangle$ Ad tertiam concedo quod lapis in descendendo calefit. Et quando dicebatur: 'igitur leve fieret', concedo-hoc est, fit minus gravis. Et cum dicebatur: 'igitur in fine moveretur tardius quam in principio', concedo nisi aliud obesset; sed modo in eius descensu acquirit quemdam impetum de quo dicebatur super primum $\mathrm{Celi}^{79}$, qui magis permovet ad velocitatem descensus quam sit illa levitas impeditiva que acquiritur ex calefactione illius mobilis in eius descensu.

$\langle 29\rangle$ Ad quartam concedo quod non quilibet motus localis calefacit, nisi qui fit cum confricatione; et aliquando aliqua possunt adesse que tantum vel plus de frigiditate generant quam ille motus possit generare de caliditate. Et ex hoc dicatur ad argumentum.

$L 191^{\text {va }} \quad\langle 30\rangle$ Ad quintam dico quod motus calefacit accipiendo | 'motum' pro 'mobili taliter se habente'; sed utrum mobile sic se habere sit ipsum mobile vel aliud, vel que res sit, dictum est in libro Physicorum ${ }^{80}$.

$\langle 31\rangle$ Ad alias rationes quibus probatur quod ignis non movetur circulariter cum celo, concedo quod non sic quod celum trahat ipsum secum - nec aliud probat articulum-, sed bene sic quod movetur sic per virtutem celi sibi impressam-nec contra hoc fuit articulum.

$\langle 32\rangle$ Ad secundam concedo quod ille motus non inest igni naturaliter, nec etiam violenter, sed inest sibi preter naturam.

6 aliud] aliunde $B a K l L \quad$ 7-8 de quo dicebatur super primum celi] om. $B a$ de quo dicebatur in primo celi $U \quad 8$ permovet] pro motu illius $P \quad 9$ levitas] caliditas $B a K l L U \quad 15$ calefacit] om. $P \quad 16$ mobile sic se habere sit ipsum mobile] motus sit mobile $B a \quad 17$ vel aliud vel que res sit] om. $B a K l L$ motus taliter se habeat sicut in ipso mobili $U \|$ dictum est in libro physicorum] non modo $P \quad 22$ motus] circularis add. Kl LU

79 Nicolaus Oresme, Questiones super De celo, II.7, Utrum motus naturalis sit velocior in fine quam in principio, ed. Kren, 559 343-346: "Quarto modo quod est ad propositum, ex velocitatione motus per quam acquiritur quedam habilitas vel impetus et quedam fortificatio accidentalis ad velocius movendum". Cf. Anonymum (Nicolaum Oresme?), Questiones super De celo, ms. München, Bayerische Staatsbibliothek, Clm 4375, ff. $47^{\text {ra }}$ $7^{6} 6^{\text {ra }}$, I.22, Utrum motus naturalis sit velocior in fine quam in principio, f. 61 $1^{\text {va: }}$ "omne motum naturaliter ab intrinseco in velocitando motum acquirit fortitudinem et habilitatem eo adiuvantem ipsum motum, quod potest dici impetus vel inclinatio accidentalis".

8o Nicole Oresme, Questiones in Physicam, III.2-III.8, ed. Caroti [et al.], 304-348. 
$\langle 33\rangle$ Ad tertiam | concedo quod celum per suum motum non calefacit $B a 13^{\text {va }}$ ignem, cum est calidus in summo; nichilominus, si esset calidus remisse, calefieret ex tali motu.

$\langle 34\rangle$ Ad quartam dico quod non oportet quod quodlibet passum sit imme5 diatum agenti principali, sed bene oportet quod cuilibet agenti aliquid sit immediatum, si debet agere in illud et mediante illo, seu per illud, in aliquod non sibi immediatum potest agere. Et ex hoc potest dici ad formam argumenti.

Hoc de questione.

\section{I.9 Utrum lumen sit productivum caloris}

10 Queritur consequenter utrum lumen sit productivum caloris.

$\langle 1\rangle$ Et arguitur quod non. Omne quod fit et generatur fit a sibi simili in specie; sed calor est alterius speciei a lumine; ergo calor non producitur a lumine, et per consequens conclusio falsa.

$\langle 2\rangle$ Secundo, nam, si sic, sequeretur quod lumen esset qualitas prima, 15 immo prior quam caliditas. Consequentia tenet ex eo quod | lumen esset $U 11^{\mathrm{vb}}$ productivum caloris. Falsitas consequentis patet, quia solum sunt quatuor qualitates prime, videlicet caliditas, frigiditas, etc.

$\langle 3\rangle$ Tertio ad idem: si sic, sequeretur quod, posito lumine, ponetur caliditas; sed hoc est falsum. Consequentia tenet ex eo quod, posita causa, ponitur 20 effectus. Falsitas consequentis patet, quia lumen fit subito ${ }^{81}$, caliditas autem fit successive; ergo non ita cito ponitur caliditas sicut lumen.

$\langle 4\rangle$ Quarto ad idem: probatur quod lumen Solis non calefacit ista inferiora. Nam, cum inter speram Solis et ista inferiora sint aliqui orbes celestes, oporteret quod Sol suo lumine prius calefaceret illos quam ista inferiora.

25 Consequentia tenet ex eo quod agens non agit in remotum nisi prius agat in propinquum. Falsitas consequentis patet, quia orbes celestes non sunt susceptivi caloris.

$\langle 5\rangle$ Quinto: sequeretur etiam quod Sol suo lumine calefaceret mediam regionem aeris; sed hoc non, cum semper media regio aeris sit frigida. Con-

1 celum per suum motum] om. $P \quad 3$ ex tali motu] a celo $B a K l U$ a celo quia propter unumquodque tale etc. $L \quad 6$ agere] et $a d d . P \quad 19$ est $]$ om. $P \quad 23$ aliqui] alique $P$

81 Cf. Aristotelem, De anima, II, 7, 418 b 23-26; Auct. Arist., 180, n. 7o. 
$L 191^{\mathrm{vb}}$ sequentia tenet, quia non potest agere calorem hic inferius iuxta terram nisi | prius ageret calorem in media aeris regione.

$\langle 6\rangle$ Sexto ad idem: si questio esset vera, sequeretur quod ubi esset plus de $K l 14^{\mathrm{vb}}$ lumine, ibi esset plus de caliditate; sed hoc est falsum. | Consequentia tenet ex eo quod lumen esset productivum caloris: ubi autem esset plus de productivo caloris, ibi esset plus de calore. Falsitas consequentis patet, nam tunc in $B a 13^{\mathrm{vb}}$ media aeris regione esset plus de calore | quam sit inferius prope terram; sed hoc est falsum, cum media regio aeris sit semper frigida. Consequentia tenet ex eo quod ibi est plus de lumine.

$\langle 7\rangle$ Septimo ad idem: alique stelle non producunt in istis inferioribus caliditatem, non obstante quod producunt lumen in istis inferioribus; igitur non omne lumen est productivum caloris.

$P 239^{\mathrm{r}} \quad\langle 8\rangle$ Octavo: multa $\mid$ lucent, sicut squame piscium et putredines quercuum, que tamen non sunt productiva caloris ${ }^{82}$.

$\langle 9\rangle$ In oppositum est Aristoteles in primo huius: vult enim quod celum per 15 motum et lumen calefacit ista inferiora et elevat exalationes que sunt materia impressionum 83 .

$\langle 10\rangle$ Breviter in ista questione primo videndum est de generatione luminis; secundo videndum est si omne lumen sit productivum caloris; tertio videndum est de causa et modo quo lumen producit calorem.

$\langle 11\rangle$ Quantum ad primum, potest notari primo differentia inter 'lucem' et 'lumen' et 'splendorem'. Unde 'lux' est qualitas incorporata corpori lucido, $U 12^{\text {ra }}$ et movetur | ad motum corporis lucidi. 'Lumen' autem dicitur species illius qualitatis causata in medio, sicut species coloris. Unde species lucis voca$K l 15^{\text {ra }}$ tur 'lumen' et non movetur ad motum corporis | lucidi; alias enim accidens migraret de subiecto in subiectum, cum ipsum lumen non sit in corpore

\footnotetext{
7 sit inferius prope terram] hic circa nos $B a$ hic prope nos $L \quad 8$ est] om. $P \quad 8-9$ consequentia tenet ex eo quod ibi est plus de lumine] om. Ba Kl L U $10-11$ non producunt in istis inferioribus caliditatem] producunt in istis inferioribus frigiditatem $B a K l L U \quad 13$ quercuum] et aliqui vermiculi $a d d$. $B a$ et oculi catorum et aliqua alia de nocte $a d d$. $K l$ et vermiculi aliqui add. $L U \quad 15$ celum] sol $B a K l L U \quad 23-24$ species illius qualitatis] illa qualitas $B a K l$ 24 medio] perspicuo $a d d$. $B a K l \quad 25$ lucidi] luminosi $B a K l L U \quad 26$ migraret] iret $B a K l U$

82 Cf. Aristotelem, De anima, II, 7, 419 a 1-7; Averroem, Commentarium magnum in Aristotelis De anima libros, II, comm. 72, ed. Crawford, 239-240.

83 Aristoteles, Meteorologica, I, 3, 341 a 13-b 36; I, 9, 346 b 22-25.
} 
lucido, sed in medio. Sed 'splendor' dicitur lumen reflexum supra aliquo corpore terso et polito, sicut supra auro vel speculo. Unde tale dicitur 'splendere'; corpus autem luminosum 'lucere' dicitur; medium autem 'illuminare'. Verum est tamen quod, large utendo istis vocabulis, solemus accipere unum 5 pro alio. Secundo, quia lumen multiplicatur directe, nos dicimus corpus lucidum 'radiare'.

$\langle 12\rangle$ Potest notari quod quidam dicitur 'radius rectus', quidam vero 'reflexus', quidam autem 'refractus'. 'Rectus' dicitur qui transit libere ipsum medium sine fractione et reflexione notabili. Radius autem 'reflexus' dicitur qui non transit per medium sine reflexione, sed reflectitur versus eandem partem unde venit, sicut pila cum proicitur super terram. Et si iste radius | incidens incidit perpendiculariter super ipso reflectente, tunc idem fit radius incidens et reflexus; si autem radius incidens incidit oblique, tunc alius est radius incidens et alius est radius reflexus. Radius autem refractus | dicitur qui non totaliter reflectitur nec etiam totaliter libere transit non fractus per medium, sed aliqualiter frangitur-aliquando a perpendiculari, aliquando ad perpendicularem-, sicut contingit quando aliquis radius incidit supra aliqua superficie media diversarum rationum coniungente, sicut patet cum denarius positus in aqua videtur, oculo existente in aere, maior ${ }^{84}$.

$\langle 13\rangle$ Tunc sit prima conclusio: lumen generatur per reflexionem vel refractionem. Patet, nam omne medium est aliqualiter | densum ${ }^{85}$; ergo omne medium aliqualiter reflectit; ergo ubicumque multiplicatur lumen, ibi reflectitur: nichil enim est aliud multiplicatio luminis nisi illa reflexio continua.

1 lucido] luminoso $B a K l L$ om. $U \quad 3$ corpus autem luminosum] lumen autem $B a K l L U \quad 8$ dicitur] om. $P \quad 10$ sine reflexione] om. $P \quad 11$ super terram] ad parietem $B a L$ in parietem $K l$ in parieta $U \quad 14$ incidens] incidentie $P \quad 16-17$ frangitur aliquando a ... aliquando ad perpendicularem] propinquat ad perpendicularem $B a L$ appropinquat ad perpendicularitatem $\mathrm{Kl}$ appropinquat ad perpendicularem $U$ 18-19 patet cum denarius ... in aere maior] cum res est posita in aqua $B a \mathrm{Kl}$

84 Cf. Alhazen, Perspectiva, lib. 7, cap. 5, prop. 14, ed. P. Pietquin, Le septième livre du traité De aspectibus d'Alhazen, traduction latine médiévale de l'Optique d'Ibn al-Haytham, Brussels 2010 (Mémoires de la Classe des lettres, Collection in-80; зe série, 5), 151-165; Witelonem, Perspectiva, lib. 10, prop. 4, ed. F. Risner, Opticae Thesaurus: Alhazeni arabis libri septem, nunc primum editi. Eiusdem Liber de crepusculis et nubium ascensionibus. Item Vitellonis Thuringopoloni librix, Basel 1572, reprint New York 1972 (The Source of Science, 94), 407-408; Robertum Grossatestam, De lineis, angulis et figuris, ed. L. Baur, Die philosophischen Werke des Robertus Grosseteste, Bischofs von Lincoln, Münster i.W. 1912 (Beiträge zur Geschichte der Philosophie des Mittelalters, 9), 1912, 6311-19; De iride seu de iride et speculo, ed. Baur, $74^{9-10}$; Iohannem Pecham, Perspectiva communis, pars 1, prop. 15-16, ed. D. Lindberg, John Pecham and the Science of Optics, Madison 1970, 89-91, pars 2, prop. 2, ed. Lindberg, 212.

85 Cf. Alhazen, Perspectiva, lib. 7, cap. 2, prop. 8, ed Pietquin, 10111-13. 
$\langle 14\rangle$ Sequitur correlarie quod ceteris paribus, ubi medium est magis rarum, ibi est minus lumen, et ubi est magis densus-non tamen nimis-, ibi est plus de lumine recte, ut de caliditate, que non est ita intensa in raro sicut in denso.

$\langle 15\rangle$ Sed diceres contra, nam videtur quod quanto aer est rarior et serenior, tanto est maius lumen circa terram; sed hoc non esset verum si in medio $U_{12^{\text {rb }}}$ raro esset $\mid$ minus de lumine quam in medio denso. Secundo sequeretur quod prope Solem vel prope celum esset valde modicum de lumine, eo quod medium est ibi valde rarum.

$\langle 16\rangle$ Ad primum respondetur: concedo quod quanto aer est magis rarus, tanto est maius lumen circa terram, sed non maius in aere, propter hoc quod est rarior; sed tunc, quia aer est rarus, omnes radii Solis transeunt sine magna reflexione et tota activitas terminatur ad terram. Ad secundam concedo quod prope celum est modicum lumen in actu, sed tamen prope celum dicitur magnum lumen in potentia, nam, si prope celum esset corpus opacum bene potens reflectere radios solares, maius causaretur ibi lumen quam si idem corpus opacum reflecteret hic inferius radios solares.

$\langle 17\rangle$ Quantum ad secundum, sciendum est quod duo sunt corpora lucida in $P 239^{v}$ mundo, videlicet Sol et ignis. Omnes enim alie stelle et planete alii a | Sole $K l 1^{\text {va }}$ recipiunt lumen | a Sole; unde lumen Lune non est aliud quam lumen Solis 20 $L 192^{\mathrm{rb}} \quad$ reflexum supra $\mid$ corpore lunari; et sic similiter de lumine aliorum planetarum et stellarum.

$\langle 18\rangle$ Et breviter sit ista prima conclusio: lumen Lune et etiam lumen alia$\mathrm{Ba} 14^{\mathrm{rb}} \quad$ rum stellarum calefacit. Patet: lumen | Solis calefacit; ergo et lumen aliarum stellarum. Antecedens patet per experientiam. Notandum est tamen quod quamvis Sol suo lumine calefaciat, non tamen Sol est formaliter calidus. Si quis enim Solem digito tangeret, non sentiret calorem, cum corpora celestia a qualitatibus habentibus contrarium sint exempta, cum sint perpetua, secundum quod probatum est in primo $\mathrm{Celi}^{86}$. Consequentia principalis patet, nam lumen aliarum stellarum non est nisi lumen Solis reflexum; si ergo lumen Solis est calefactivum, et lumen aliarum stellarum erit calefactivum. Et confirmatur, nam calefacere est de ratione ipsius luminis; ergo, si est aliquod lumen quod est calefactivum, sicut lumen Solis, sequitur quod omne

2 et ubi] iter. $P \|$ non tamen nimis] om. Ba Kl L $\quad 3$ ita] om. $P \quad 5$ aer] medium $K l \quad 7-9$ secundo sequeretur quod ... ibi valde rarum] om. $\mathrm{Ba} \mathrm{Kl} \quad 10$ aer est] est aer est $P \quad 14$ celum] solem $L \|$ modicum] modicus $P \|$ celum] solem $L U \quad{ }_{15}$ celum] solem $L U \quad 16$ radios solares] om. $P \quad 17$ inferius] prope terram $a d d$. $B a K l U$ circa terram $a d d . ~ L$ 
lumen erit calefactivum. Item specialiter de Luna patet, quia lumen Lune est calefactivum auctoritate Aristotelis in De animalibus, ubi dicit quod noctes in plenilunio sunt calidiores ${ }^{87}$, quod non videtur esse ex alio nisi quia tunc est maius lumen Lune. Item patet de stellis fixis auctoritate Commentato5 ris secundo Celi, qui dicit quod omnes stelle calefaciunt, | licet secundum magis et minus ${ }^{88}$. Item hoc potest experiri per magna specula comburentia, congregando radios Lune vel radios aliarum stellarum.

$\langle 19\rangle$ Secunda conclusio: ignis, | qui est unum corpus de corporibus lucidis qui sunt in mundo, calefacit et per lumen et per calorem; tamen differenter, quia magis per calorem quam per lumen. Item quia per lumen calefacit ita cito remote sicut propinque; sed per calorem prius calefacit partem sibi propinquam quam partem remotam.

$\langle 20\rangle$ De aliis lucidis, sicut sunt squame piscium, potest dici quod etiam lux ipsarum calefacit, sed hoc est bene remisse; et forte habent quasdam 15 alias virtutes fortiores frigefactivas, quarum actio per huiusmodi lucem vel lumen remittitur; et ergo, quia virtus eius est fortior, aliquando effectus eius apparet et non effectus lucis, quamvis forte intensius appareret si non obstaret lumen.

〈21 $\rangle$ Quantum ad tertium, dico quod lumen est productivum caloris. Patet, | $B a 14^{\text {va }}$ quia lumen est una qualitas valde nobilis; et ergo, cum multiplicatur per medium, de potentia illius medii aptum natum est educere qualitatem nobiliorem de qualitatibus activis et passivis ad invicem; et cum inter istas | caliditas sit nobilissima, sequitur quod lumen, cum multiplicatur per medium, educit de ipso caliditatem. Similiter, cum ipsum lumen sit una qualitas

25 ita nobilis, ipsum aptum natum est disponere ad generationem elementi nobilissimi, quod quidem elementum est ignis. Et cum generando caliditatem disponit ad generationem ignis, sequitur quod lumen producit caliditatem. Quod autem ignis inter cetera elementa sit nobilissimus | patet signo

4 patet de stellis fixis] specialiter de aliis patet $P \quad 6$ comburentia] concava $B a K l L U \quad 7$ lune] vel solis $a d d . K l \quad 8$ unum corpus de corporibus lucidis] minimum corpus de corporis magnis $\mathrm{Ba} \mathrm{Kl}$ minimum corpus de corporibus $L$ unum corpus de corporibus magnis $U \quad 11$ propinque] remoto impedimento $a d d . K l \quad 14$ et] quia $B a K l L U \quad 18$ lumen] lux vel lumen $\mathrm{Ba} \mathrm{Kl} 22$ istas] om. $P \quad 26-27$ generando caliditatem disponit ad generationem ignis] generando caliditatem sequitur formam substantialem ipsius ignis $B a$ generando caliditatem sequatur formam ignis $K l L U$

87 Aristoteles, De partibus animalium, IV, 5, 680 a 34-35.

88 Averroes, Commentarium magnum in De celo, II, comm. 42, eds. Carmody, Arnzen: 2, $35^{0^{61}-35^{16}} ; 35^{2^{102-117}}$. 
et ratione. Signo quidem, quia quidam, sicut Caldei, adoraverunt ignem tamquam Deum propter eius nobilitatem. Patet hoc etiam ratione, quia inter cetera elementa ignis est magis activus. Finaliter igitur concludo quod lumen est productivum caloris, non tamen tamquam agens principale, sed instrumentale. Corpus enim lucidum est productivum principale ipsius caloris; lumen autem est instrumentum mediante quo corpus lucidum huiusmodi calorem producit.

$\langle 22\rangle$ Ad rationes. Ad primam: 'simile', etc., dico quod sufficit similitudo virtualis, ita quod agens sit potens facere quod passum aptum natum est recipere.

$U_{12} 2^{\mathrm{vb}} \quad\langle 23\rangle$ Ad secundam concedo quod lumen est qualitas prima, immo prior qualitatibus activis et passivis ad invicem. Et cum dicitur: 'qualitates prime sunt quatuor qualitates elementorum', concedo, qualitates prime habentes contrarium, sed sic non est de lumine.

$\langle 24\rangle$ Ad tertiam potest negari quod lumen fiat subito. Si tamen concederetur quod fieret subito, non tamen propter hoc oporteret concedere quod caliditas fieret subito; unde non oportet quod quam cito incipit esse causa sufficiens alicuius effectus, quod ita cito incipiat ille effectus, sed sufficit quod ita cito incipiat posse produci; et sic esset in proposito de lumine et calore si lumen produceretur subito.

$\langle 25\rangle$ Ad quartam dico quod lumen Solis bene recipitur in orbibus celesti$P 240^{\mathrm{r}}$ bus, sed tamen, quia orbes celestes non sunt apti nati recipere calorem, | inde $K l 16^{\text {rb }}$ est quod mediante lumine non generatur in eis calor. Cum | tamen ipsum lumen sit multiplicatum per orbes celestes usque ad ista inferiora, et cum ista inferiora sint receptiva caloris, inde est quod mediante lumine causatur in istis inferioribus calor et non in orbibus celestibus. Et ulterius con-

$L 192^{\mathrm{vb}}$ cedo quod Sol non posset agere lumen in ista inferiora | nisi primo ageret in orbes celestes, quia tunc Sol non immediate producit calorem, sed mediante lumine, secundum dispositionem recipientis, lumen potest aliquando agere calorem et aliquando non, et aliquando intensiorem et aliquando remissiorem.

$\langle 26\rangle$ Ad quintam dico ex eadem radice quod potest agere calorem hic inferius et non in media regione aeris, quia, quantum ibi adduceretur de calore,

9-10 recipere] pati $B a K l L U \quad 19$ posse produci] produci $P \quad 29$ agere] producere $K l L U$ $3^{2-33}$ hic inferius] in istis inferioribus prope terram $K l$ hic inferius prope terram $B a L U \quad 33$ adduceretur] educeretur $B a K l L U$ 
plus remitteretur de frigiditate medie regionis; et qua sit causa frigiditatis medie regionis postea videbitur in una questione ${ }^{89}$.

$\langle 27\rangle$ Ad sextam ex eadem radice.

$\langle 28\rangle$ Ad septimam potest dici quod alique stelle habent unam aliam vir-

5 tutem, seu multiplicant de se unam virtutem insensibilem aliam a lumine, que aliquando est productiva frigiditatis et aliquando caliditatis una cum lumine, et aliquando plus frigiditatis quam lumen aliarum stellarum sit productivum caliditatis. Et inde est quod alique stelle dicuntur frigefacere, non tamen per lumen, sed per unam aliam qualitatem que potest vocari 'influen-

10 tia'. Alii dicunt quod omnes | stelle calefaciunt; et cum dicitur eis: 'alique $K l 16^{\mathrm{va}}$ frigefaciunt', exponunt: 'id est minus calefaciunt' ${ }^{\prime 90}$.

$\langle 29\rangle$ Ad octavam de squamis piscium dictum est in corpore questionis ${ }^{91}$. Et sic est finis.

\section{I.1O Utrum contrarium circumstans suum contrarium fortificet ipsum}

Queritur consequenter utrum contrarium circumstans suum contrarium $U_{13^{\text {ra }}}$

15 fortificet ipsum.

$\langle 1\rangle$ Et arguitur primo quod non: contrarium circumstans suum contrarium agit in ipsum destruendo ipsum; ergo non fortificat ipsum. Consequentia tenet; antecedens patet si aqua approximetur igni.

$\langle 2\rangle$ Secundo: si sic, sequeretur quod aqua ex aere posset generare ignem; sed hoc est impossibile. Impossibilitas patet ex eo quod unum contrarium non generat reliquum. Sed consequentia patet, nam, si aqua frigida sit approximata aeri calido, si eius caliditatem intenderet, tamen non posset eam intendere quod ex illo aere fieret ignis.

5 insensibilem] in istis inferioribus $\mathrm{Kl} \mathrm{om.} \mathrm{Ba} \quad 6$ frigiditatis et aliquando] om. $\mathrm{Ba} \mathrm{Kl} U$ 7-8 lumen aliarum stellarum sit productivum caliditatis] caliditatis sit productivum lumen earum $P \quad 9$ qualitatem] insensibilem $a d d . B a L U$ seu virtutem insensibilem add. $K l \quad 12$ dictum est in corpore questionis] patebit in questione sequenti $B a K l L$ patebit quid sit dicendum in una alia questione $U \quad 21$ frigida] frigido $P \quad 22$ non] om. $P B a L U$

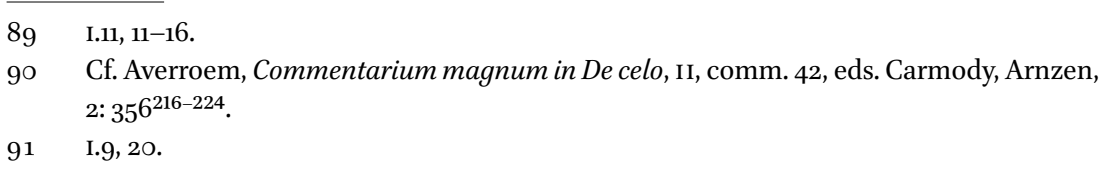


$\langle 3\rangle$ Tertio: si sic, sequeretur quod si una gutta aque poneretur ad medium ignis, quod plus frigefieret; et similiter, si panis poneretur in furno, deberet $B a 15^{\text {ra }}$ plus frigefieri. Ista sunt falsa, | sicut patet per experientiam. Consequentia vel consequentie sunt bone, si questio est vera.

$\langle 4\rangle$ Quarto ad idem: sequitur quod ignis, quia circumdat alia elementa, deberet ipsa in qualitatibus eorum intendere; et sic ignis alia elementa fortificaret, et per consequens non corrumperet. Et sic ex hac augmentatione $L 193^{\text {ra }}$ ipsius ignis in spera sua non posset argui aliorum elementorum corruptio, | sed magis fortificatio, quod est contra Aristotelem in primo huius ${ }^{92}$.

$\langle 5\rangle$ Quinto ad idem: si questio esset vera, hoc esset isto modo quod qua-

$K l 16^{\mathrm{vb}}$ litas | que esset in partibus extremalibus per contrarium circumstans pelleretur versus partes interiores et quod ex tali unione qualitatis in partibus interioribus subiecti illa qualitas intenderetur. Sed probo quod non fiat isto modo, nam, si sic, sequeretur quod accidens migraret de subiecto in subiectum; sed hoc est impossibile. Consequentia videtur tenere ex eo quod ista eadem qualitas que fuit in partibus extremalibus esset pulsa ad partes interiores. Sequeretur etiam secundo quod unum contrarium fugaret alterum et moveret ipsum localiter, quod iterum non videtur verisimile.

$\langle 6\rangle$ In oppositum est Aristoteles, quasi per totum processum istius libri: in reddendo enim multorum effectuum causas presupponit quod subiectum contrarium circumstans aliud fortificat ipsum et intendit eius qualitatem sue qualitati contrariam ${ }^{93}$. Et istud etiam bene patet ad experientiam, nam in estate quidam fontes sunt magis frigidi quam in hieme, cuius ratio non $U 13^{\text {rb }}$ videtur esse alia nisi quod in estate tales fontes circumstat | calor, qui est contrarius frigiditati, ex cuius circumstantia illa frigiditas intenditur. Similiter nam videmus quod si aliqua gutta aque proiciatur super mappam siccam, partes eius tenent se simul et aliqualiter illa gutta rotundatur, ac si humiditas illius gutte timeat et fugiat siccitatem mappe illius. Et ex tali unione partium videtur quod illa humiditas intendatur, cum virtus unita sit fortior se ipsa $P 240^{v} \quad$ dispersa ${ }^{94}$. Cum autem gutta | aque proicitur super mappam humidam vel mensam, fluit et dilatat se, quia simile applaudit suo simili.

2 si panis poneretur] om. $P \|$ in furno] ad furnum calefactum $B a K l L U \quad 11-12$ pelleretur] moveretur $B a K l$ tenderetur $L \quad 19$ quasi] om. $B a K l L U \quad 26$ nam $]$ non $P \quad 28$ timeat et] om. BaKlLU 3 o proicitur] producitur $P \quad 31$ mensam] super aliquid huiusmodi $B a K l L U$

92 Aristoteles, Meteorologica, I, 3, 340 a 1-3.

93 Ibid., I, 4, 342 a 1-16; I, 12.

94 Cf. Anonymum, Liber de causis, prop. XVI, ed. A. Pattin, Le Liber de causis. Édition établie à l'aide de go manuscrits avec introduction et notes, Leuven 1966 (Extrait du Tijdschrift voor filosofie, 28), 138 ${ }^{15-16} ;$ Auct. Arist., 232, n. 13. 
$\langle 7\rangle$ In ista questione primo videndum est an unum contrarium possit movere $K l 7^{\text {ra }}$ aliud localiter; secundo videndum est de modo per quem unum contrarium movet suum contrarium localiter; tertio videndum est an ex condensatione alicuius subiecti caliditas vel frigiditas illius subiecti intendantur.

$5\langle 8\rangle$ Quantum ad primum, primo sciendum est quod questio et illud quod dicetur in ista questione debet intelligi de qualitatibus primis, sicut sunt caliditas, frigiditas, etc., | et non de qualitatibus secundis, sicut sunt albedo, nigredo et consimilia. Unde albedo posita iuxta nigredinem non facit ipsam intensiorem, sed bene facit quod apparet intensior: contraria enim iuxta se 10 posita magis elucescunt ${ }^{95}$.

$\langle 9\rangle$ Et sit breviter una conclusio quod unum contrarium potest movere aliud localiter, verbi gratia ignis potest movere aquam localiter. Patet, nam, si aliquod lignum viride ponatur ad ignem, videmus quod aqua vel humor aqueus qui est in illo ligno pellitur | et fugatur, et movetur usque ad extre-

15 mitatem illius ligni, que quidem extremitas ligni sita est extra ignem; igitur etc.

$\langle 10\rangle$ Secunda conclusio: cum unum contrarium circumdat aliud, puta ignis aquam, condensat ipsum. Patet, nam ex quo unum contrarium movet aliud localiter, per primam conclusionem partes circumferentiales aque, cum circumdantur igne, moventur omnes indifferenter versus partes centrales illius aque, et ex hoc tunc fit condensatio illius aque.

〈11 Tertia conclusio: contrarium circumstans suum contrarium intendit ipsum. Probatur, quia per secundam conclusionem condensat ipsum et facit quod partes eius fiunt propinquiores quam prius erant; sed talem condensationem et approximationem partium sequitur intensio virtutis et qualitatis illius subiecti. Confirmatur | ista conclusio signo, nam propter | frigus circumstans in hieme aliqui fontes sunt minus frigidi quam in estate; et in estate, propter calorem circumstantem sunt magis frigidi. Secundo, nam propter hoc etiam ventres hominum in hieme sunt calidiores quam in estate $^{96}$, et similiter homines et cetera animalia in regionibus frigidis sunt

6 qualitatibus] contrariis $P \quad 7$ qualitatibus] contrariis $P \quad 13$ viride] om. BaKlLU 14 et movetur] om. $B a K l L U \quad 24$ eius] fugiunt intra et $a d d$. $K l \quad 29$ hominum] animalium $B a$ om. $K l L U \quad 3$ o estate] ut dicit ypocras $a d d$. $B a K l L U \|$ in regionibus frigidis] in hieme $K l L$ om. BaU

95 Cf. Aristotelem, De sophisticis elenchis, 15, 174 b 5-6, Auct. Arist., 333, n. 17; Rhetorica, III, 3, 1405 a 12-13, Auct. Arist., 267, n. 57.

96 Cf. Aristotelem, Meteorologica, I, 12, 348 b 2-5; Auct. Arist., 172, n. 9. 
magis condensata et compacta, et in regionibus calidis magis rara; et calor in animalibus habitantibus in regionibus frigidis est magis intensus quam $B a 15^{\text {va }}$ sit in animalibus habitantibus in regionibus calidis, | et propter hoc dicitur quod homines de regionibus frigidis sunt magis audaces quam homines de regionibus calidis.

$\langle 12\rangle$ Quantum ad secundum, videlicet quomodo fit quod unum contrarium movet sic aliud, breviter potest dici uno modo quod hoc fit isto modo, nam cuiuslibet subiecti qualitas apta nata est se diffundere et dilatare; cum ergo sic se dilatando invenit aliquid sibi contrarium resistens, non potens ulterius se dilatari, reflectitur versus partem unde venit, recte sicut lumen inveniens obstaculum reflectitur et similiter pila proiecta ad terram movetur e contrario versus partem unde venit, et ita consimili modo in proposito.

$\langle 13\rangle$ Breviter potest dici aliter, supponendo quod omne ens diligit se permanere: quia ergo unum contrarium est corruptivum et destructivum alte-

$K l 7^{\mathrm{va}}$ rius, quodlibet contrariorum ex naturali in|clinatione fugit suum contrarium et movetur ab eo; unde in tali motu forma illius quod movetur est movens principale, reliquum autem contrarium est movens occasionale. Unde, si aqua circumdaretur igne, partes circumferentiales aque moverentur versus

$L 193^{\text {va }}$ partes centrales et movens principale esset forma ipsius aque; | ignis autem esset movens occasionale. Si enim aqua non circumdaretur igne, forma aque non moveret partes circumferentiales aque versus centrales.

$\langle 14\rangle$ Dubitatur hic utrum talis motus localis quo partes circumferentiales aque moventur versus partes centrales eiusdem propter ignem circumstantem sit aque naturalis vel violentus. Et videtur quod sit aque naturalis, quia

$U_{13}{ }^{\mathrm{vb}}$ principaliter est a principio intrinseco, | scilicet a forma ipsius aque. Probatur autem quod sit aque violentus et non naturalis, quia aliter eiusdem corporis simplicis essent plures motus naturales, quod est contra Aristote-

$P_{241^{\mathrm{r}}} \quad$ lem in primo Celi ${ }^{97}$. Respondetur quod talis motus est naturalis, recte sicut | motus aque sursum ad replendum vacuum est naturalis, quamvis bene pre$B a 15^{\mathrm{vb}} \quad$ supponat violentiam alicuius corporis. | Et quando dicebatur: 'solum unius corporis est unus motus naturalis', conceditur absolute et non facta violen-

1 condensata] dempsata $P \|$ compacta] propter frigiditatem add. Ba Kl $L U \|$ rara] raro $P$ propter calorem $a d d$. Ba KlLU $\quad{ }_{1-3}$ et calor in ... in regionibus calidis] similiter animalia habitantia in regionibus frigidis sunt magis condensata quam animalia habitantia in regionibus calidis $B a K l L U \quad 8$ diffundere] discendere $L \quad 9$ sic se dilatando] om. $B a K l L U \quad 12$ proposito] sed non est verisimile quod ex tali reflexione potest fieri intensio add. Ba Kl LU

97 Aristoteles, De celo, I, 2, 268 b 30-269 a 2. 
tia alicui corpori; nichilominus, ex presuppositione, unius corporis simplicis possunt esse plures motus naturales. Unde, cum aer in fistula posita in aqua secundum unum eius extremum extrahitur et movetur violenter sursum, aqua naturaliter insequitur istum aerem ne fiat vacuum, et ista insecutio et motus aque sursum potest dici naturalis ipsi aque, quia inest sibi a principio intrinseco, puta forma substantiali ipsius aque, quamvis illa forma non sic moveret illam aquam | nisi esset facta violentia alicui corpori, scilicet aeri.

$\langle 15\rangle$ Item dubitatur, posito quod duo contraria, puta ignis et aqua, ad invicem approximentur et ignis sit multo fortior quam aqua, utrum ista aqua

10 fugat ignem sicut ignis fugat aquam. Respondetur quod sic, quia quamvis ignis sit fortior in agendo quam aqua, potest tamen esse debilior in resistendo quam ipsa aqua sit in agendo; et ergo, quia quodlibet eorum est fortius in agendo quam sit reliquum in resistendo, per actionem et reactionem eorum ad invicem quodlibet fugat aliud et movet ipsum localiter. Si tamen

15 ignis et aqua tantum distarent quod ignis bene posset attingere sua actione aquam, aqua autem non posset e contrario attingere ignem, tunc ignis moveret aquam localiter et aqua non moveret ignem localiter.

$\langle 16\rangle$ Item dubitatur, postquam per fugam unius contrarii ab alio contraria ab invicem elongantur ab alio, sic quod non amplius se tangant, utrum 20 unum adhuc fugat aliud. Potest dici quod sic, quia quamvis non se tangant, tamen adhuc quodlibet eorum potest attingere aliud sua virtute, mediante aere intermedio.

$\langle 17\rangle$ Item dubitatur an semper sic fiat, videlicet quod unum contra|rium approximatum alteri fugat ipsum. Respondetur quod non semper sic fit:

25 aliquando enim propter nimiam gravitatem unius contrarii reliquum non potest ipsum fugare, verbi gratia sicut cum ferrum frigidum ponitur ad ignem, non propter hoc, saltem notabiliter, fugantur partes extremales | versus $\mid$ centrales. Notandum est hic quod intensio contrarii que fit ex tali pulsu partium circumferentialium vel lateralium versus partes centrales per contrarium circumstans vocatur 'antiparistasis'.

$\langle 18\rangle$ Secundo est sciendum quod aliquando contrario approximato suo contrario, sicut ignis aque tantum ipsum excedit quod quamvis in principio sic moveat partes circumferentiales versus partes centrales et intendat illud contrarium, tamen postea sua virtute penetrat $\mid$ istud contrarium, puta illam aquam, et e contrario ipsam rarefacit et virtutem eius prius intensam remit-

1 simplicis] om. $P \quad 4$ istum aerem] om. $P \quad 19$ non amplius se tangant] unum non potest attingere aliud $B a K l L U \quad 23$ sic fiat videlicet quod] om. Ba KlLU 26 fugare] nec movere add. BaKlLU 27 extremales] circumferentiales $B a K l L U \quad$ 29-30 per contrarium circumstans] om. $\mathrm{BaKl} \quad 3^{2}$ aque] aliquando $a d d . P$ 
tit. Et ita, quamvis in principio actionis unum contrarium intendat aliud, tamen postea ipsum destruit et corrumpit, postquam fugavit ipsum tantum et similiter condensavit quod ulterius fugere non potest, nec sub maiori densitate forma eius esse potest.

$\langle 19\rangle$ Quantum ad tertium, videlicet utrum ex condensatione alicuius subiecti caliditas vel frigiditas illius subiecti intendatur, breviter respondeo quod sic: istud enim patet ad experientiam, quia aqua congelata est frigidior quam aqua non congelata, quod videtur esse signum quod ex istius aque condensatione frigiditas eius intenditur. Similiter hoc patet ex alio, nam ignis in materia densa, sicut in ferro, fortius agit quam in materia rara, sicut in stuppa. Et potest confirmari hoc idem ratione, quia in condensatione partes propinquius iacent et magis sunt unite; virtus autem unita fortior est ipsa dispersa ${ }^{98}$. Sed diceres: tunc sequitur quod idem esset causa contrariorum, quia condensatio esset causa frigiditatis et caliditatis; hec autem sunt contraria. Breviter respondeo quod non est impossibile quod idem in alia $K l 8^{\mathrm{rb}}$ et alia materia sit causa alterius et alterius, quamvis non in eadem; unde | condensatio, quamvis in materia calida non sit causa intensionis caliditatis et frigiditatis, tamen in materia calida est causa intensionis caliditatis, in materia autem frigida est causa intensionis frigiditatis. Sed contra: posito quod in eodem subiecto sit simul caliditas et frigiditas et illud subiectum condensetur, tunc videtur quod condensatio in eodem subiecto sit causa intensionis caliditatis et frigiditatis. Respondetur quod casus est impossibilis. Ipso tamen concesso diceretur quod si caliditas et frigiditas essent $P 241^{\mathrm{v}} \quad$ equalium | graduum, tunc ex tali condensatione nec intenderetur caliditas nec frigiditas, quia continue per eorum actionem ad invicem manerent sub

$L 194^{\text {ra }}$ equalibus gradibus, | quamvis illud subiectum condensaretur. Vel posset dici $U 14^{\text {rb }}$ quod utrumque intenderetur, sed non posset intendi usque ad summum. $\mid \mathrm{Si}$ autem unum illorum esset intensius et aliud remissius, diceretur quod intensius remitteretur et non remissius.

$\langle 20\rangle$ Dubitabit aliquis a quo generabitur huiusmodi gradus qualitatis, cum ex condensatione qualitas subiecti condensati intenditur. Respondetur quod occasionaliter generatur a contrario circumstante, principaliter autem a forma intrinseca illius subiecti una cum virtute celesti.

10 fortius] potius $P \quad 15$ idem] condensatio $P \quad 28$ esset] om. $P \quad 28-29$ intensius remitteretur et non remissius] intensius remitteret remissius $P \quad$ 30 qualitatis] caliditatis $P \quad 32$ contrario] frigido $K l L \quad 33$ celesti] illius elementi $P$

98 Cf. Anonymum, Liber de causis, ed. Pattin, 138 $8^{15-16} ;$ Auct. Arist., 232, n. 13. 
$\langle 21\rangle$ Ad rationes. Ad primam: 'unum contrarium agit in aliud', etc., admittatur; cum hoc tamen stat quod in principio illius actionis istud contrarium intenditur, sicut dicebatur in questione ${ }^{99}$.

$\langle 22\rangle$ Ad secundam dico quod non est impossibile quod unum contrarium

5 generet aliud | occasionaliter et per accidens, quamvis hoc sit impossibile | pure naturaliter et per se-de quo etiam tangebatur in questione ${ }^{100}$.

$\langle 23\rangle$ Ad tertiam dico quod illa gutta aque in principio bene intenditur in eius frigiditate; postquam tamen penetrata est calore ignis, e contrario dilatatur et eius frigiditas remittitur et corrumpitur. Et sic similiter de pane in 10 furno.

$\langle 24\rangle$ Ad quartam dico quod ignis posset tantum augeri quod quamvis in principio alia elementa fortificaret, tamen postea, postquam calore ignis ipsa elementa penetrarentur, maior eorum pars ab igne corrumperetur.

$\langle 25\rangle$ Ad quintam: 'sequitur quod accidentia migrarent de subiecto', etc., 15 dico negando consequentiam, quia non solum caliditas que est in partibus extremalibus movetur versus partes centrales, verum etiam partes extreme in quibus est ipsa caliditas.

Et sic est finis questionis.

\section{I.11 Utrum semper media regio aeris sit frigida}

Queritur consequenter utrum semper media regio aeris sit frigida.

$20\langle 1\rangle$ Et arguitur primo quod non: semper media regio aeris est calida; igitur non frigida. Consequentia tenet; antecedens patet ex eo quod aer per se et naturaliter est calidus et humidus.

$\langle 2\rangle$ Secundo: si semper media regio aeris esset frigida, vel ergo illa frigiditas inesset sibi naturaliter, vel violente. Non potest dici quod naturaliter, 25 cum contrarium frigiditatis insit sibi naturaliter, puta caliditas; nec potest dici quod violente, | quia tunc non semper media regio esset frigida, cum nullum violentum semper duret ${ }^{101}$.

$\langle 3\rangle$ Tertio: si sic, sequeretur quod media regio aeris sit semper densa; sed hoc est falsum. Consequentia tenet ex quo frigiditas est causa condensatio-

13 maior eorum pars ab igne corrumperetur] maior eorum virtus corrumperetur et etiam pars $L$

99 I.10, 11.

$100 \quad \mathrm{I} .10,13$.

101 Cf. Aristotelem, De celo, I, 2, 269 b 9. 
nis. Falsitas consequentis patet, nam tunc impediret ne videremus celum et astra, nam propter eius densitatem species visibiles celi et etiam astrorum non possent multiplicari usque ad visum nostrum.

$\langle 4\rangle$ Quarto sequeretur quod aer qui est in media regione aeris esset gra-

$L 194^{\mathrm{rb}}$

$K l 18^{\mathrm{vb}}$ vior quam aer qui est hic inferius; hoc est falsum. Consequentia tenet ex eo quod | magis frigida | minus frigidis sunt graviora; aer autem hic inferius esset minus frigidus aere existente in media regione, si semper media regio aeris esset frigida. Falsitas consequentis patet, quia tunc aer qui est in media regione descenderet et aer qui est hic inferius ascenderet, cum ordo gravium et levium sit graviora esse sub levioribus et leviora esse super graviora.

$\langle 5\rangle$ Quinto: si sic, sequeretur quod in media regione non generarentur impressiones ignee; sed hoc est falsum. Consequentia tenet propter nimiam

$U 14^{\text {va }}$ frigiditatem medie regionis ipsius aeris. | Falsitas consequentis patet, nam ibi generantur corruscationes et fulgura; ista autem sunt impressiones ignee.

$\langle 6\rangle$ Sexto ad idem: ille aer qui est in media regione est magis remotus ab elementis frigidis — scilicet a terra et aqua_quam sit iste aer hic inferius, et similiter est magis propinquus igni et motui celi, quorum est calefacere, quam sit aer inferior; igitur est magis calidus quam sit aer inferius, et per consequens non semper media regio aeris est frigida.

$\langle 7\rangle$ In oppositum est Aristoteles in primo huius, ubi solvit illam questionem quare nubes non fiant in suprema regione aeris, sed in media: dicit huius

$K l 19^{\text {ra }}$ causam esse quia | suprema regio aeris semper est calida; et ergo, quamvis sufficiat elevare, tamen non potest convertere vaporem elevatum in nubem $P 242^{r}$ et in aquam, ipsam convexando, sed ipsam dissolvit et consumit | ut non generentur nubes ex eo. Sed quia in media regione aeris est frigiditas, cum vapores calore Solis elevantur usque ibi per frigiditatem aeris existentis in media regione, illi vapores condensantur-frigidi enim est condensare-et ex tali condensatione vaporis generantur nubes ${ }^{102}$. Ecce qualiter Aristoteles in solvendo predictam dubitationem supponit mediam regionem aeris esse frigidam. Et per 'mediam regionem aeris' debet intelligi non ille aer qui est immediate prope terram, nec ille qui est immediate prope ignem, sed ille qui est in medio per aliquam distantiam a terra et similiter per aliquam distantiam ab igne. Et vocatur a philosophis 'medium interstitium aeris' ab

6 magis] om. $P \quad 12$ ignee] in aere $P \quad$ 2o huius] tractatu primo capitulo secundo add. $K l$ tractatu primo capitulo sexto $a d d$. $B a L$ capitulo sexto tractatus primi $a d d . U \|$ ubi solvit illam questionem] ubi dicit tres causas $B a \mathrm{Kl}$ ubi reddit tres causas $L U \quad 24$ ipsam convexando] om. Ba KlL $\quad 25^{-26}$ cum vapores] iter. $P$ 30 non] iter. $P$

102 Aristoteles, Meteorologica, I, 3, 340 b 29-32. 
'inter' et 'sto, stas', quasi stans inter partes extremas aeris. Et ille aer qui est infra medium interstitium potest vocari 'inferior regio aeris'; ille autem qui est super vocatur 'suprema regio aeris', ita quod orbis ipsius aeris in eius spissitudine ymaginetur dividi in tres partes, scilicet in inferiorem, | mediam et supremam.

$\langle 8\rangle$ In ista questione videndum est primo de qualitate medie regionis aeris; secundo de causa qualitatis illius medie regionis; tertio incidentaliter videndum est de quantitate medie regionis aeris; quarto de figura eius; quinto de variatione eius secundum diversa tempora.

〈9) Quantum ad primum, sit prima conclusio quod semper media regio aeris est frigida. Patet, quia vapores calore Solis elevati usque ibi convertuntur in aquam, que est frigida, quod est signum quod media regio aeris est frigida. Similiter ibi generantur impressiones frigide, sicut nix, grando et similia, quod non esset nisi media regio aeris esset frigida.

$\langle 10\rangle$ Secunda conclusio est quod media regio aeris non est frigida in summo. Patet, quia | tunc esset aqua. Ista consequentia tenet per Aristotelem in primo et in secundo De generatione, ubi vult quod frigiditas inest primo aque $^{103}$; nichil ergo potest esse frigidum in summo nisi sit aqua. Sed contra: immo probatur quod media regio aeris sit ita frigida sicut est aqua, quia condensando et infrigidando vaporem elevatum generat aquam et generat tantam frigiditatem quanta est frigiditas aque; sed nichil agit nec generat intensiorem gradum alicuius qualitatis quam ipsummet habeat; ergo, si media regio aeris generat tantam frigiditatem quanta est frigiditas aque, videtur etiam quod tantam habeat. Quod autem nichil agat intensiorem gradum ali-

25 cuius qualitatis quam ipsummet habeat probatur, nam alias simile ageret in simile sibi, quod est contra Aristotelem in primo De generatione ${ }^{104}$, et contra naturalem appetitum ipsius agentis, quia solum agens appetit passum sibi assimilare. Respondetur negando | consequentiam, quod aliquid scilicet ageret intensiorem gradum alicuius qualitatis quam ipsummet haberet.

30 Et cum dicebatur: 'media regio aeris non est frigida in summo', sicut dicit secunda conclusio, concedo. Et cum ulterius dicebatur: 'tamen generat frigiditatem in summo in ipso vapore', nego; sed bene generat in ipso tantum gradum frigiditatis quantum ipsamet habet, et isto habito et generato, ille

17 primo] celi $a d d . K l L \quad 27$ appetit] intendit $B a K l L U$

103 Aristoteles, De generatione et corruptione, I, 329 a 25-35; II, 3, 331 a 4-5.

104 Ibid., I, 7, 323 b 19-25. 
vapor, cum sit de natura aque, ulterius per formam eius intrinsecam ducitur ad frigiditatem aque, recte sicut aqua calefacta se ipsam reducit ad frigiditatem pristinam.

$\langle 11\rangle$ Quantum ad secundum, videlicet que sit causa quod media regio aeris est frigida, breviter una potest esse causa distantia eius a Terra una cum quibusdam aliis concurrentibus. Unde ymaginandum est quod aer hic inferius prope Terram calefit ex reflexione luminis Solis a Terra. Et cum radius incidens et reflexus prope Terram sint magis propinqui, aer prope Terram est magis calidus. Et cum illi radii recedendo a Terra magis et magis elongen$L 194^{\mathrm{vb}} \quad$ tur ab invicem, continue ex tali elongatione | istorum radiorum ab invicem

$B a 17^{\text {ra }}$ aer qui est magis et magis distans a Terra $\mid$ minus et minus calefit, ex eo $U 15^{\text {ra }}$ quod $\mid$ propinquitas radii incidentis et reflexi est causa calefactionis. Et cum isti radii in media regione aeris sint valde distantes ab invicem, modicam vel nullam generant ibi caliditatem. Et cum alia sint que generant ibi fri-

$P 242^{\mathrm{v}}$ giditatem, de quibus statim | dicetur, que etiam generarent frigiditatem in inferiori regione ipsius aeris, si non esset propinquitas radii incidentis et reflexi, sequitur ipsam mediam regionem aeris esse frigidam. Sed suprema regio aeris, quamvis non calefaciat ex reflexione luminis Solis a Terra, tamen $K l 19^{\mathrm{vb}}$ calefit aliunde, videlicet ab igne existente in spera sua, | quia illi igni suprema regio aeris est immediata. Et tunc, ubi ignis calefaciendo supremam regionem aeris terminat suam actionem, ibi incipit media regio aeris et terminatur ibi ubi radius incidens et reflexus tantum distant quod non sufficiunt calefacere.

$\langle 12\rangle$ Alia causa frigiditatis potest esse remissio luminis, quia, cum lumen sit productivum caloris, sicut prius dicebatur ${ }^{105}$, sequitur quod ubi est remissius lumen, ibi minus de calore producitur; sed in media regione aeris est minus de lumine, quia lumen causatur per reflexionem speciei lucis; igitur, ubi est minor reflexio, ibi est minus de lumine. Sed cum in media regione aeris sit minor reflexio quam hic prope terram, cum aer sit minus densus et minus reflectens quam terra, sequitur quod est minus de lumine et per consequens minus de calore. Et cum sint ibi alia valde istum aerem infrigidantia, sequitur quod ille aer est frigidus. Sed diceres: videtur quod istud non valeat, quia in nocte, cum non est lumen Solis apud nos, aer inferior adhuc est magis calidus quam aer qui est in media regione. Respondetur quod ille

\footnotetext{
7 a terra] ad terram $P \quad 21-23$ et terminatur ibi ... non sufficiunt calefacere] om. Ba Kl LU 25 est] iter. $P$

$105 \quad$ I.9, 18.
} 
calor aeris inferioris, quamvis non generatur in nocte ex reflexione luminis Solis a Terra, tamen generabatur in die. Et huius signum est quod, quando noctes sunt longe, propter absentiam luminis Solis quasi totus calor aeris inferioris remittitur. Unde semper de mane aer hic inferius est magis frigidus quam de sero, ceteris paribus.

$\langle 13\rangle$ Tertia causa frigiditatis medie regionis potest | esse quia vapores frigidi elevantur calore Solis, in tantum quod veniunt iuxta supremam regionem aeris, qui est valde calida ab igne; et cum unum contrarium fugat aliud, sicut predictum est ${ }^{106}$, illi vapores | fugantur a suprema aeris regione et condensantur et infrigidantur, tendendo ad eorum | dispositionem naturalem. Et huiusmodi vapores | fugantur versus mediam regionem aeris et aerem ibi existentem infrigidant, et ex isto aer ibi existens est frigidus.

$\langle 14\rangle$ Quarta causa frigiditatis medie regionis ipsius aeris potest assignari talis, quod aer qui est in suprema regione aeris movetur circulariter cum 15 igne, et ex tali motu calefit et rarefit. Et cum aer in suprema regione rarefit, oportet aerem sub eo condensari ne dimensiones se penetrent; et ex tali condensatione una cum aliis causis causatur frigiditas in media regione aeris.

$\langle 15\rangle$ Quinta causa potest assignari quod aer prope terram calefactus quosdam vapores fugat a terra, cum unum contrarium fugat aliud, et quosdam 20 vapores fugat sursum versus mediam regionem. Et cum vapor de natura sit frigidus, quia tendit ad naturam aque, isti vapores, fugati ad mediam regionem, aerem ibi existentem infrigidant; et tunc, cum illum aerem circumstet aer supreme regionis, qui est calidus, et etiam aer inferioris regionis, qui etiam est calidus, frigiditas medie regionis intenditur; nam ex predictis con25 trarium circumstans suum contrarium fortificat ipsum ${ }^{107}$.

〈16〉 Sexta causa potest assignari quod influentia celestis causat frigiditatem in media regione aeris ad istum finem, ut fiat ibi generatio et corruptio mixtorum imperfectorum; impressiones enim generate in media regione, sicut est pluvia et consimiles, multum faciunt ad generationem et augmen30 tationem / mixtorum perfectorum. Dicit enim Aristoteles secundo Physicorum: pluvia cadit ut crescant frumenta ${ }^{108}$.

3 absentiam] et umbrationem $a d d$. KlL $\quad 9$ sicut predictum est] om. Ba Kl L U 9-10 condensantur] inspissantur $B a \quad 19$ a terra] ad terram $P U \quad 21-22$ fugati ad mediam ... ibi existentem infrigidant] expellunt et fugant istum aerem $B a$ fugant istum aerem $K l L U \quad 24$ calidus] propter quam causam $a d d . P \quad 30$ secundo] tertio $P \quad 31$ frumenta] gramina $L$

$106 \quad$ I.10, 9 .

107 I.10, 11; cf. Auct. Arist., 172, n. 10.

108 Aristoteles, Physica, II, 8, 198 b 16-23; cf. Nicolaum Oresme, Questiones in Physicam, II, 16, ed. Caroti [et al.], 291 ${ }^{204-205}$. 
$\langle 17\rangle$ Quantum ad tertium restat videre de quantitate et situ medie regionis aeris. Unde sciendum est quod media regio aeris est bene spissa et pro-

$B a 1^{\text {va }}$ funda; | unde Alhazen dicit in tractatu suo De crepusculis quod vapores ex quibus fiunt nubes bene possunt elevari a terra per quinquaginta duo miliaria $^{109}$. Et certum est quod illi vapores, si ex illis fiunt nubes, non elevantur

$P 243^{\mathrm{r}} \quad$ ultra mediam regionem aeris; | igitur tante spissitudinis, scilicet quinquaginta duorum miliarum, est media regio aeris, excepto illo spatio quod est inter terram et illum locum aeris ubi primo possunt generari nubes, quod spatium est bene parvum. Ex hoc patet quod media regio aeris est valde spissa et profunda. Quod autem illud spatium quod est inter terram et locum

$U 15^{\mathrm{va}}$ aeris in quo | possunt generari nubes sit parvum, patet, nam visum est quod aliquis stans super montes vidit nubes inferius, et hoc est signum quod tale spatium non est multum magnum. Ex hoc ulterius patet quod media regio $L 195^{\mathrm{rb}} \quad$ aeris non est aer purus, sed multis grossis vaporibus permixtus; | nec est ita rarus sicut est aer supreme regionis. Et ergo, quia videmus Solem per

$K l 20^{\text {va }}$ mediam regionem, radii | refranguntur supra illo aere ibi existente et non veniunt non fracti ad visum nostrum. Et propter hoc dicit Alhazen in tractatu allegato quod videmus lumen Solis antequam Sol sit super nostrum horizontem ${ }^{110}$. Unde, cum videmus aliquod visibile per media diversarum rationum in raritate et densitate, tunc videmus istud visibile per radios refractos supra superficie illa duo media coniungente. Et per talem refractionem apparet visibile maius quam si videretur per radios non fractos, aliquando etiam minus, et similiter apparet in alio loco quam sit. Hoc patet, nam denarius in fundo aque apparet maior quam extra aquam. Et aliquando, si poneretur in aliquod vas, non videretur in aliqua distantia visus ab eodem, et si superfunderetur aqua, videretur in illa distantia ${ }^{111}$. Sic etiam propter interpositionem medie regionis inter Solem et visum nostrum — que quidem media regio multis vaporibus grossis est permixta-aliquando apparet nobis Sol $B a 17^{\mathrm{vb}}$ citius super horizontem quam in veritate | sit in eius ortu, et in eius occasus diutius apparet nobis esse super horizontem quam sit. Et propter hoc etiam de mane, cum oritur, propter pluralitatem vaporum inter Solem et visum nostrum, super quibus vaporibus refranguntur radii Solis, apparet Sol

3 crepusculis] crepusculo $P \quad 14$ multis grossis vaporibus permixtus] grossus quasi vapore permixtus $B a K l L$ grossus quasi vaporibus permixtus $U \quad 28$ aliquando] enim add. $P$

109 Ibn Mu'had, De crepusculis et nubium ascensionibus, ed. M. Smith, in "The Latin Version of Ibn Mu'ādh's Treatise on Twilight and the Rising of Clouds", Arabic Sciences and Philosophy 2 (1992), 83-132, at $100^{91}-116^{418}$.

110 Ibid., $97^{20}-99^{67}$.

111 Cf. I.9, 12. 
maior quam in meridie. Item patet spissitudo medie regionis ex eo quod aliquando videmus nubem bene alte super nubem, et tam nubes inferior quam superior sunt in media regione, ex quo potest argui spissitudo et profunditas medie regionis.

$\langle 18\rangle$ De situ autem medie regionis sciendum est quod media regio non dicitur 'media' propter equalem distantiam a terra | et a concavo orbis ignis; unde punctus medius qui est inter terram | et inter concavum orbis ignis non est signandus in medio medie regionis aeris-immo forte nec in aliquo puncto medie regionis-, sed in puncto supreme regionis, ita quod ymaginandum est quod suprema regio aeris est spissior quam sit totus aer inter ipsam et terram. Et ideo, sicut dixi, non est media quia equaliter distet ab igne et terra, sed dicitur 'media' per interpositionem eius inter supremam regionem aeris et illam regionem aeris in qua non possunt generari nubes propter nimiam eius propinquitatem ad terram. Quod autem aer qui est ultra mediam regionem sit spissior quam totus ille qui est inter supremam regionem aeris et terram patet ex eo quod dicitur quod quidam montes sunt ita alti quod plus et maior portio | illorum montium est in suprema regione aeris quam sit totus aer qui est inter terram et supremam regionem aeris, et illi montes adhuc non attingunt speram ignis; modo hoc non esset verum

20 nisi suprema regio aeris esset multo spissior quam totus aer infra eam. Et si sic, tunc media regio aeris non est in medio per equalem distantiam a terra et a suprema regione aeris. Hoc etiam patet ex alio, quia comete qui generantur in suprema regione aeris plus ascendunt super convexum medie regionis quam sit distantia a terra usque ad convexum medie regionis; hoc

25 iterum non esset verum nisi suprema regio aeris esset multo spissior quam totus aer inferior.

$\langle 19\rangle$ Quantum ad quartum | restat videre de figura medie regionis aeris. Et $B a 18^{\text {ra }}$ dico primo quod versus polos est multo spissior quam versus equinotialem. Patet, quia versus polos est minor caliditas quam versus equinotialem. | Primo, quia ibi radii Solis magis oblique reflectuntur, et ergo statim tantum elongantur ab invicem | radius incidens et reflexus quod non possunt generare caliditatem in aere, et sic ibi bassius incipit media regio aeris quam si radius incidens et reflexus non tantum statim ab invicem elongarentur. Similiter circa polos partes celi moventur tardius quam circa equinotialem, et cum ex motu causetur calor, sequitur quod si motus est minus velox, quod

20 infra eam] a terra usque ad illam regionem $B a$ inter terram et ipsam $K l L U \quad 23$ ascendunt] elevantur $B a K l L U \quad 24$ convexum medie regionis] supremam regionem aeris $\mathrm{Ba} \mathrm{Kl}$ $L U$ 
$U_{1} 6^{\text {ra }}$ est causativus minoris caloris; et ergo suprema | regio aeris non est ibi ita spissa sicut circa equinotialem, sed est ibi magis tenuis, et per consequens media regio magis spissa. Hoc etiam patet signo, quia in illis partibus nubes fiunt magis basse quam in partibus versus equinotialem. Ex hoc potest ymaginari qualis figure sit media regio aeris et in convexo et in concavo.

$\langle 20\rangle$ Quantum ad quintum, restat videre de variatione medie regionis. Pro quo dico quod in hieme media regio aeris super nos est magis spissa. Patet, quia radii solares incidunt magis oblique super terram quam in estate; et ergo radius incidens et reflexus statim tantum elongantur quod non sufficiunt calefacere aerem; et ergo bassius incipit media regio aeris, et propter hoc in hieme nubes sunt bassiores quam in estate.

$\langle 21\rangle$ Secundo dico quod in estate media regio aeris est magis tenuis, et una illius causa est quia in estate radii solares minus oblique incidunt super

$K l 21^{\mathrm{rb}}$

$L 195^{\mathrm{vb}}$

$\mathrm{Ba} 18^{\mathrm{rb}}$ terram, et propter hoc radius incidens et reflexus recedendo a terra minus elongantur | ab invicem quam si radii | solares inciderent oblique, et igitur altius calefaciunt aerem, et per consequens concavum medie regionis plus distabit a terra; per consequens media regio aeris non erit ita spissa. Alia causa est quia in superiori parte aeris in estate propter accessum Solis causatur maior calor, et per consequens suprema regio aeris augetur. Sed ad augmentationem supreme regionis aeris sequitur diminutio medie regionis; igitur in estate media regio aeris diminuitur. Tertia causa potest esse | quia in estate suprema regio aeris est magis calida et similiter inferior; ergo media regio aeris, que est frigida, circumdatur contrariis fortioribus; et per consequens, cum unum fugat aliud, partes extreme medie regionis moventur versus partes interiores medie regionis, et per consequens fit condensatio medie regionis, et per consequens fit minus profunda, sed tamen magis frigida quam in hieme, per antiparistasim, quia circumdatur fortioribus contrariis. Et huius signum est quod in estate aliquando generantur grandines tante quantitatis quod tante non possunt generari in hieme.

$\langle 22\rangle$ Ad rationes. Ad primam respondetur quod quamvis aer de natura sua sit calidus, tamen potest infrigidari violente per aliquid extrinsecum; et sic fit de aere in media regione, sicut prius dicebatur.

4 basse] spisse et spissiores $B a K l$ spisse vel spissiores sive bassiores $L \quad 5$ figure] dispositionis $\mathrm{BaKl}$ figure sive dispositionis $L \quad 10$ bassius incipit media regio aeris] ibi spissius est tunc interstitium medium $B a$ ibi spissius incipit media regio aeris $K l \quad 11$ bassiores] spissiores $B a$ KlL $\quad 26$ fit] om. $P \quad 28$ est] om. $P$ 
$\langle 23\rangle$ Ad secundam dico quod illa frigiditas est sibi violenta. Et cum dicebatur: 'violentum non diu durat', concedo; et ergo bene concedo quod ibi continue non manet idem aer, sed bene alius et alius; et quamvis nullum | violentum sit perpetuum, tamen semper est aliquod violentum. Et ideo, quamvis nullus aer in media regione sit semper frigidus, tamen semper aliquis aer in media regione est frigidus.

$\langle 24\rangle$ Ad tertiam: 'sequeretur quod media regio aeris esset valde densa', conceditur. Et cum dicitur: 'ergo impediret ne videmus celum et stellas', dico quod densitas non impedit visionem, sed bene opacitas. Unde per unum vitrum quod est densius quam sit unum lignum, | bene videmus, et tamen per lignum non possumus videre. Sed verum est quod ista densitas medie regionis bene facit quod non quamlibet partem celi videmus per radium rectum, sed plures partes celi videmus per radium refractum.

$\langle 25\rangle$ Ad quartam: 'sequitur quod ille aer fiet magis gravis quam aer infe15 rior', concedo. Et ergo, postquam est magis gravis, descendet, et inferior ascendet et infrigidatur, et sic continue unus post alium.

$\langle 26\rangle$ Ad quintam dico quod ibi non fiunt impressiones ignite propter caliditatem medie regionis, sed fiunt ibi per antiparistasim propter frigiditatem medie regionis, de quo postea videbitur ${ }^{12}$.

$\langle 27\rangle$ Ad sextam: 'ille aer est propinquior causis calefacientibus', etc., nego consequentiam quod ergo debeat esse calidior, quia cause infrigidantes illum | aerem sunt fortiores, de quibus dicebatur in secundo articulo huius questionis.

Et sic finitur questio.

\section{I.12 Utrum omnium impressionum metheorologicarum vapor et exalatio fuerit principium materiale}

25 Queritur consequenter utrum omnium impressionum metheorologicarum vapor et exalatio sint principium materiale.

$\langle 1\rangle$ Arguitur primo quod non: impressionum | ignitarum nullum istorum est principium materiale; ergo questio falsa. Consequentia tenet. Antecedens probatur, nam non potest dici quod talium impressionum vapor sit materia, nam Aristoteles in primo huius vult oppositum: vult enim quod talium

21 infrigidantes] agentes frigiditatem $B a K l L U$

112 I.12, 15; I.13, 12-14. 
impressionum que generantur per inflammationem non vapor, sed exalatio sit principium ${ }^{113}$. Nec etiam potest dici quod talium impressionum exalatio sit materia; cum sit de natura terre per Aristotelem ${ }^{114}$, videtur esse tante gravitatis quod non potest attingere locum illum sursum ubi generantur huiusmodi impressiones. Et confirmatur hoc: materia impressionum ignitarum debet esse bene inflammabilis; sed exalatio non est huiusmodi, quia exalatio est sicca, per Aristotelem ${ }^{115}$. Siccum autem non est bene inflammabile, sicut patet de cimiteribus; inflammabile enim faciliter debet esse pingue. Et confirmatur adhuc quod exalatio non sit materia talium impressionum; $U 16^{\text {va }}$ nam materia impressionum aquearum segregatur ab aqua, | sicut est vapor, et etiam materia impressionum ignearum debet segregari ab igne; sed exalatio non segregatur nec extrahitur ab igne, immo magis a terra; igitur.

$\langle 2\rangle$ Secundo ad principale: vapor non est materia impressionum generatarum sursum, sicut pluvie, rores, grandines et pruine, etc.; igitur questio falsa. Consequentia tenet, quia non potest dici quod huiusmodi impressionum exalatio sit materia, cum sit calida et sicca, huiusmodi autem impressiones sunt frigide et humide. Antecedens patet, nam vapor, cum sit de natura aque, est tante gravitatis quod non potest moveri sursum usque ad illum locum ubi generantur huiusmodi impressiones.

$\langle 3\rangle$ Tertio probatur quod impressionum aquearum vapor non sit materia nec impressionum que generantur per inflammationem exalatio sit mate$B a 18^{\mathrm{vb}}$ ria, quia, cum vapor segre|gatur ab aqua et exalatio a terra, sequitur quod supra in aere non fierent nisi impressiones humide et aquee, et huiusmodi $K l_{22} 2^{\text {ra }}$
$L 6^{\text {rb }}$ impressiones $\mid$ non fierent super terram, cuius oppositum ex|perimur. Consequentia tenet eo quod vapor solum segregatur ab aqua, exalatio solum a terra.

〈4〉 Oppositum vult Aristoteles in primo huius, tractatu secundo, capitulo primo ${ }^{116}$.

$\langle 5\rangle$ Breviter in ista questione videndum est quid sit exalatio et quid vapor; secundo videndum est de comparatione istorum ad invicem; tertio respondendum est ad quesitum.

3 per aristotelem] om. Ba Kl U 15 tenet] quia non potest dici ergo questio falsa consequentia tenet $a d d . P \quad 24$ fierent] fiunt $P$

113 Aristoteles, Meteorologica, I, 4, 341 b 10-25.

114 Ibid.

115 Ibid., I, 4, 341 b 10.

116 Ibid., I, 4, 341 b 10-25. 
$\langle 6\rangle$ Quantum ad primum, sciendum est quod 'exalatio' dicitur quoddam corpus subtile, seu fumus calore Solis a terra vel ab aqua terra permixta elevatus. 'Vapor' autem dicitur quoddam corpus subtile, seu fumus calore Solis ab aqua vel a terra aqua permixta elevatus. Ex isto patet quod exalatio est sicca siccitate terrestri et calida accidentaliter a Sole, et vapor est humidus humiditate aquea et accidentaliter calidus a Sole.

$\langle 7\rangle$ Hic dubitatur utrum vapor sit eiusdem speciei cum aqua et exalatio eiusdem speciei cum terra. Ad istum dubium diversi diversimode respondent; unde dicit unus expositor quod exalatio que generatur ex corpore 10 simplici, sicut a terra, est eiusdem speciei cum eo corpore, differens ab eo solum secundum dispositiones accidentales ${ }^{117}$. Et assignat rationem illius quod omne corpus naturale quod derelictum nature sue proprie ex se reddit ad dispositionem naturalem alicuius corporis et sequitur motum naturalem eius, est eiusdem speciei et eiusdem nature specifice cum illo corpore; sed

15 sic est quod exalatio dimissa nature sue proprie reddit ad naturam terre ex qua extrahebatur; igitur etc. Maior est nota. Minor patet, | nam, cum exalatio a terra segregata derelinquitur nature sue proprie, per absentiam caloris | Solis descendit ad terram unde venit. Similiter sic est de vapore extracto ab aqua, qui, cum est elevatus et derelinquitur nature sue, descendit; ergo etc.

$\langle 8\rangle$ Alii dicunt quod in tali segregatione exalationis a terra est vera generatio, et similiter in segregatione vaporis ab aqua, ita quod isti volunt quod exalatio est alterius speciei ab illo a quo segregatur, scilicet a terra; et similiter vapor est alterius speciei ab aqua. Unde volunt quod quodlibet istorum 25 sit unum mixtum imperfectum habens formam substantialem distinctam a forma elementi, puta aque vel terre ${ }^{118}$. Et quando dicitur eis quod Aristoteles dicit exalationem esse de natura terre et vaporem | esse de natura aque $^{119}$, dicunt quod Aristoteles hoc dicit propter hoc quod materia exalationis immediate ante eius generationem stetit sub forma terre et habet siccitatem terream; similiter sic dicunt de vapore in ordine | ad ipsam aquam.

9 expositor] om. $B a K l \quad 11$ dispositiones] proprietates $B a K l L U \quad 12$ quod] om. $P$

117 Cf. Iohannem Buridanum, Questiones in Meteorologica, I.11, ed. Bages, 2: 9-10; 21.

118 Cf. Iohannem Buridanum, Questiones in Meteorologica, I.11, ed. Bages, 2: 8; Albertum de Saxonia, Questiones in Meteorologica, I.12, in A. Panzica, "Albert of Saxony's Questions on Meteorology: Introduction, Study of the Manuscript Tradition and Edition of Book I-II.2", AHDLMA 86 (2019), 12; Themonem Iudeum, Questiones in Meteorologica, I.12, ed. Octavianus Scotus, Venice 1522, f. $95^{\text {ra }}$.

119 Aristoteles, Meteorologica, I, 4, 341 b 9-10. 
$\langle 9\rangle$ Breviter concedo quod prima opinio sit verior propter ipsam rationem quam adducit, nec illi de secunda opinione solvunt illam, nec video aliquam rationem pro eis quin faciliter possit solvi tenendo primam opinionem.

$\langle 10\rangle$ Quantum ad secundum, videlicet de comparatione istorum ad invicem,

$L 196^{\mathrm{va}}$ dico $\mid$ quod utrumque istorum, tam vapor quam exalatio, est calidus accidentaliter, videlicet a calore ipsum elevante; tamen exalatio est calidior vapore, quia exalatio est de natura terre, et ergo intensius et fortius incorporatur sibi

$K l 22^{\text {va }}$ calor quam vapori, qui est de natura aque, cum aqua sit minus densa quam terra.

$\langle 11\rangle$ Secundo dico quod utrumque istorum est leve, non a se, sed a calore 10 elevante, sed tamen magis exalatio quam vapor. Patet, quia exalatio est magis calida et habet calorem magis potentem elevare.

$\langle 12\rangle$ Tertio dico quod utrumque eorum elevatur sursum per calorem in eo generatum, sed magis sursum elevatur exalatio. Patet etiam quia est magis calida.

$\langle 13\rangle$ Sed diceres: sicut se habet terra ad aquam, ita se habet exalatio ad vaporem; sed terra est gravior aqua, et ergo exalatio est gravior vapore. Respondetur: concedo quod quantum ad naturam specificam et propriam, exalatio est gravior vapore sicut terra est gravior aqua; sed tamen accidentaliter exalatio per calorem elevantem fortius sibi incorporatum quam vapori, potest dici levior, et propter hoc magis sursum potest moveri, recte sicut fer-

$U 17^{\text {ra }}$ rum intensius recipit calorem $\mid$ ab igne quam stuppa, propter tenacitatem materie.

$\langle 14\rangle$ Verum est tamen quod duplex potest distingui exalatio: una que est elevata a terra pingui et unctuosa; et talis elevatur ut plurimum in uno globo, propter tenacitatem partium ad invicem, et illi calor accidentalis tantum incorporatur quod potest valde alte ascendere, et habet tantum de calore quod sine repulsu potest ambulare per mediam regionem aeris usque ad supremam; et ex tali per inflammationem eius generantur impressiones

$\mathrm{Kl} \mathbf{2 2}^{\mathrm{vb}}$ ignee. | Alia autem est exalatio que elevatur a terra non pingui nec unctuosa; et illa non sic elevatur in uno globo, nec partes eius propter siccitatem tenent se ad invicem, nec sibi fortiter incorporatur calor, nec ita etiam alte ascen$B a 19^{\mathrm{rb}}$ dit, | sed ipsa cito dissolvitur et ex tali generantur venti.

2-3 aliquam rationem pro eis] aliquam positionem illius opinionis $\mathrm{Ba}$ aliquam rationem probabiliorem $K l$ aliquam rationem probatam $L \quad 15$ calida] et habet calorem magis potentem elevare $a d d$. $B a K l L \quad 20$ incorporatum] incorporatur $P \quad 21$ hoc] om. $P \|$ potest] posset $P$ 22 tenacitatem] densitatem $B a$ paucitatem $P \quad 3^{2-33}$ ascendit] elevatur $B a$ movetur $K l L U$ 
$\langle 15\rangle$ Quantum ad tertium, sit prima conclusio: omnium impressionum siccarum vel ignitarum exalatio est materia. Patet, nam exalatio que elevatur, vel elevatur ultra mediam regionem aeris, vel manet in media regione, vel manet infra mediam regionem, vel manet in concavitatibus ipsius terre. Si elevatur usque ad supremam regionem aeris, vel ergo quasi usque ad speram ignis, vel infra. Si primum et ibi inflammatur, fiunt comete vel fit cometa. Si autem citra et ibi inflammatur, fiunt capre saltantes vel trabes ignite et consimilia. Si autem exalatio elevatur usque ad mediam regionem aeris et includitur in nube et inflammatur, fiunt corruscationes et fulmina. Si autem non includitur $\mid$ in nube nec inflammatur et est multitudo talis exalationis et movetur a frigido medie regionis, fiunt ex ea venti. Si autem talis exalatio est conglobata et non inclusa in nube et repellitur versus terram a frigiditate medie regionis, fiunt ex ea sydera cadentia, cum ex tali motu et pulsu incenditur. Si autem talis exalatio non movetur notabiliter directe versus terram vel ad latus nec

15 inflammatur, sed coloratur lumine celesti, fiunt hyatus et voragines et colores sanguinei secundum aliam et aliam dispositionem illius exalationis. Si autem illa exalatio manet infra mediam regionem et dissolvitur et cadit ad mare, fit salsedo maris. Si autem talis exalatio non pertingit | ad aerem, sed manet in mari vel in | concavitatibus terre, tunc, cum manet in mari, fit ex hoc salsedo maris, et cum manet in concavitatibus terre, fit motus terre.

$\langle 16\rangle$ Secunda conclusio: omnium impressionum humidarum vel frigidarum vapor est materia. Patet, nam vapor, | si elevatur usque ad mediam regionem et ibi condensatur in nubem et in aquam, fit pluvia. Si autem congelatur et conglutinatur multum, fit grando. Si autem congelatur et conglutinatur,

25 sed non tantum, fit nix. Si autem vapor elevatus manet infra mediam $\mid$ regio$B a 19^{\mathrm{va}}$ nem et de nocte infrigidatur et non congelatur, fit ros. Si autem congelatur, fit pruina. Si autem vapor manet in concavitatibus terre et propter frigus condensatur, fit aqua et fiunt rivuli. Si autem vapor elevetur supra in mediam regionem et fiunt nubes quiescentes vel etiam ante generationem nubium 30 vapores ibi elevati quiescunt, tunc, per reflexionem vel refractionem luminis Solis vel Lune supra illis fit halo. Et quandoque in elevatione talium vaporum per reflexum luminis fit iris. De hiis plenius apparebit postea.

$\langle 17\rangle$ Tertia conclusio: quod questio est vera. Patet inducendo in singulis impressionibus: omnes enim vel generantur ex exalatione vel ex vapore.

6 comete] om. $P \quad 13$ cadentia] volantia $B a K l L U \|$ incenditur] calor eius intendatur $B a$ intendatur $K l L U \quad 15$ celesti] solis $B a K l L \quad 24$ conglutinatur] conguletur $P \quad 28$ fiunt rivuli] fiunt fontes et rivi $B a K l L U$ 
$\langle 18\rangle$ Ad rationes. Ad primam 'exalatio non est materia', etc., negatur. Et quando probabatur: 'exalationes non possunt ita alte ascendere, cum sint $K l_{23}{ }^{\text {rb }}$ de natura terre', concedo ex se; | nichilominus hoc potest fieri per calorem elevantem ipsas exalationes. Et ad confirmationem: 'materia impressionum ignitarum debet esse inflammabilis', concedo; et ulterius dico quod alique

$L 197^{\text {ra }}$ exalationes sunt inflammabiles, sicut exalationes segregate | a terra pingui et unctuosa, nichilominus iste exalationes adhuc tenent terrestrem siccitatem. Ad aliam confirmationem nego quod si materia impressionum aquearum segregatur ab aqua, quod ergo materia impressionum ignitarum debet segregari ab igne, quia ignis non est ad hoc dispositus quod ab eo segregatur materia impressionum ignitarum, sed aqua bene est ad hoc disposita ut ab ea segregatur materia impressionum aquearum.

〈19〉 Ad secundam dico quod immo vapor est materia impressionum aquearum. Et cum dicitur: 'non potest ita alte elevari sicut generantur huiusmodi impressiones', concedo quantum est de se, sed tamen potest per calorem ipsum elevantem.

$\langle 20\rangle$ Ad tertiam dico quod immo a mari potest segregari et elevari exalatio, propter terrestrem mari admixtum. Similiter ex terra potest segregari et extrahitur vapor propter aqueum sibi permixtum. Et sic patet ad argumentum.

Et sic finitur questio.

\section{I.13 Utrum impressiones ignite, seu ille que fiunt per inflammationem, fiant naturaliter in aere}

$U 17^{\mathrm{va}}$ Queritur consequenter utrum impressiones ignite, seu ille que fiunt per inflammationem, fiant naturaliter in aere.

$K l 23^{\text {va }}\langle 1\rangle$ Et arguitur quod non, nam impressiones ignite videntur esse de natura ignis; igitur non fiunt naturaliter in aere. Consequentia tenet ex eo quod

$B a 19^{\mathrm{vb}}$ aer vel locus aeris non est locus naturalis | illius vel illorum que sunt de natura ignis; nam impressiones ignite habent pro materia exalationem, que est calida et sicca, quod est proprium igni.

$\langle 2\rangle$ Secundo: si huiusmodi impressiones naturaliter fierent in aere, tunc generarentur ab aere; sed hoc non, quia aer non est ita calidus sicut sunt

1 ad primam] om. $P \quad 14$ elevari] levari $P L \quad 26-27$ illius vel illorum que sunt de natura] om. Ba KlL U 
huiusmodi impressiones; et quia nichil agit gradum intensiorem quam ipsummet habeat, sequitur quod huiusmodi impressiones non generantur ab aere.

$\langle 3\rangle$ Tertio ad idem: illa que fiunt violente in aere non fiunt naturaliter; 5 sed impressiones ignite sunt huiusmodi; ergo etc. Maior patet. Minor probatur, quia huiusmodi impressiones fiunt ex exalatione elevata ad aerem; sed elevatio exalationis est violenta, cum exalatio sit de natura terre, per Aristotelem in primo huius ${ }^{120}$; ergo etc.

〈4) In oppositum arguitur: primo, quod huiusmodi impressiones fiunt in 10 aere, patet sensibiliter; sed quod fiant ibi naturaliter probatur, quia fiunt ibi a causis naturalibus et a causa naturaliter agente, quod quidem agens est ipse calor.

$\langle 5\rangle$ In ista questione videndum est quomodo diversificantur huiusmodi impressiones; secundo videndum est de causis harum impressionum et in 15 generali et in speciali, quibus visis patet faciliter responsio ad quesitum.

〈6) Quantum ad primum, | sciendum est quod huiusmodi impressiones $K l 23^{\mathrm{vb}}$ diversificantur in magnitudine et in parvitate: alique enim sunt magne, alique parve, secundum magnitudinem et parvitatem exalationis.

$\langle 7\rangle$ Secundo etiam diversificantur | in figura: alique enim apparent figure

20 oblonge; alique etiam apparent figure late; alique etiam apparent sicut globi. Et ista diversitas provenit ex diversitate figure ipsius exalationis elevate.

$\langle 8\rangle$ Tertio etiam diversificantur qualitate, sicut raritate et $\mid$ densitate et colore. Alique enim fiunt ex exalatione magis densa, alique vero ex exalatione magis rara. Et secundum hoc etiam alique apparent coloris rubei, 25 alique coloris albi. Alique etiam earum sunt venenose et infective, alique vero non, immo aliquando alique inficiunt homines vel alia animalia.

$\langle 9\rangle$ Quarto diversificantur etiam in motu. Alique enim apparent velociter moveri, alique vero tarde. Similiter alique apparent moveri sursum, alique ad latus. Similiter alique aliquando motu suo faciunt sonum | in aere, recte $B a 2^{\mathrm{ra}}$ sicut esset sonus aliquorum armatorum.

$\langle 10\rangle$ Quinto etiam diversificantur tempore, quia alique diu durant, alique cito evanescunt; | et alique aliquando durant per unum mensem, alique per

6 ad aerem] ab aqua $B a K l L U \quad 11$ a causa] ab agente $P \quad 24$ hoc $]$ om. $P \quad 30$ armatorum] almatorum $P$ armorum $B a$

120 Aristoteles, Meteorologica, I, 4, 341 b 10. 
annum, alique per noctem, et alique ut plurimum fiunt tempore venenoso et tempore epidimie.

$\langle 11\rangle$ Sexto diversificantur loco, nam alique fiunt prope terram, ita quod apparent stare super terram vel ire; alique etiam fiunt modicum altius; ali$\mathrm{Kl}_{2} 4^{\text {ra }}$ que etiam fiunt prope mediam | regionem aeris; alique etiam fiunt in media regione aeris—et de istis postea dicetur, et non modo ${ }^{121}$. Alique etiam fiunt super mediam regionem aeris. Similiter alique ut plurimum fiunt in locis ubi sunt cadavera mortuorum, sicut iuxta patibula et in cimiteriis.

$\langle 12\rangle$ Quantum ad secundum, sciendum est quod exalatio calida et viscosa et inflammabilis est materia harum impressionum. Causa efficiens earum est ipsum calidum, et aliquando frigidum circumstans comprimens materiam, scilicet exalationem unde debet fieri impressio. Causa autem formalis est quia habent formam mixti imperfecti, que potest dici quedam flamma, ex quo patet quod omnes sunt eiusdem speciei, licet differant accidentaliter propter causas extrinsecas. Causa finalis est propter generationem mixtorum perfectorum, etiam ad pronosticandum quedam futura. Et ideo dicitur quod quando est descensus stellarum in aliqua parte celi, tunc ex ista parte veniunt postea magni venti et fiunt procelle in mare.

$\langle 13\rangle$ Eundo autem magis ad causas particulares, sciendum est quod quando exalatio est in continua segregatione a terra et illa exalatio est pinguis et unctuosa et sic quod adhuc unum eius extremum est prope terram et aliud extremum in aere, aliquando de nocte ista exalatio frigiditate noctis comprimitur et condensatur, et calor interius tunc intenditur et incendit et inflam$B a{ }_{2}{ }^{\mathrm{rb}} \quad$ mat illam exalationem. Et quando sic fit, tunc apparet sicut candela $\mid$ stans ardens, et huiusmodi impressiones accidunt et contingunt super sepulcra

$L 197^{\text {va }}$ mortuorum. Aliquando autem exalatio | pinguis et inflammabilis elevatur modicum altius, sic quod eius extremum inferius non immediate est prope terram. Et tunc, quando de nocte talis exalatio inflammatur et aere moto movetur, apparet sicut lucerna vel candela ambulans vel currens super terram, et homines talibus impressionibus non possunt bene appropinquare;

1-2 et alique ut plurimum fiunt tempore venenoso et tempore epidimie] et hoc secundum naturam ipsius exalationis $B a$ secundum preiacentiam ipsius exalationis $K l U$ et hoc secundum potentiam ipsius exalationis $L \quad 7-8$ ubi sunt cadavera mortuorum] in locis pinguibus et unctuosis $B a K l L U$ 10 earum] istarum impressionum que fiunt in suprema regione aeris prope ignem $B a L U \quad$ 12-18 causa autem formalis ... procelle in mare $]$ om. $P \mathrm{Kl} \quad 20-21$ pinguis et unctuosa et sic quod] calida et inflammabilis bene et quando sic est disposita $B a$ calida et inflammatur sic quod $K l$ calida et inflammabilis sic quod $L U \quad 26$ exalatio] inflammatio $P$

121 I.13, 14. 
nam, cum homines volunt eis appropinquare, | movent aerem, et aere moto iste impressiones moventur et deportantur in aere continue antecedendo homines volentes eis appropinquare. Aliquando etiam accidit quod huiusmodi impressiones fiunt supra auribus equorum ambulantium, nam, | cum de auribus ipsius equi continue extrahitur huiusmodi exalatio unctuosa, ipsa potest incendi et inflammari et apparebunt huiusmodi impressiones. Unde bene visum est huiusmodi impressiones de nocte supra auribus equorum apparere.

$\langle 14\rangle$ Quando autem exalatio elevatur usque ad mediam regionem, aliquando frigiditate medie regionis repellitur et tunc, secundum quod illa exalatio est aliter et aliter disposita et aliter et aliter in repulsu movetur, secundum hoc fiunt alie et alie impressiones. Si enim exalatio est longa et non multum lata et, cum repellitur a frigiditate medie regionis, uritur, fit una impressio ad modum trabis ardentis. Si autem illa exalatio est ad modum globi et, cum pertingit ad mediam regionem, | in repulsu eius descendit totaliter versus terram, quamvis oblique, et ignitur in eius descensu, apparet tamquam stella cadens. Si autem huiusmodi exalatio est ad modum globi et, cum pertingit ad mediam regionem, repellitur et, cum modicum distat a media regione iterum ascendit et tunc iterum repellitur, per inflammatio-

20 nem talis exalationis $\mid$ apparet ignis ludens. Si autem ista exalatio in medio $B a 2^{\text {va }}$ est grossa et in extremis constricta et, cum pertingit ad mediam aeris regionem, repellitur et incenditur, apparet draco volans.

$\langle 15\rangle$ Si autem exalatio non impedita forte per nubes medie regionis et aliquid huiusmodi transit per mediam regionem usque ad supremam et 25 ibi | incenditur, et si ista res est magna et lata, apparet tamquam magna $P 246^{r}$ res accensa. Si autem ista exalatio est dispersa per globos, qui tamen globi adherent per exalationes subtiles et raras intermedias, tunc, cum uno globo incenso et consumpto reliquus incenditur, apparet ignis saltare sicut capra. Cum autem ista exalatio habet longitudinem sine magna latitudine et in 30 extremo superiori est magis subtilis et magis inflammabilis quam in extremo inferiori, tunc ista exalatio in extremo superiori primo incenditur, et parte | extrema incensa et consumpta, pars prope incenditur, et tunc iterum apparet sicut stella cadens. Si autem illa exalatio tota simul incenditur, apparet sicut lancea ardens. Si autem illa exalatio habet longitudinem et etiam aliqualem latitudinem et tota simul incenditur, apparet sicut columna

13 uritur] om. $B a K l U \quad 14$ trabis] turbis $P \quad 15^{-18}$ in repulsu eius ... ad mediam regionem] om. hom. $B a L U \quad 18$ ad] om. $P \quad 20$ ludens] saltans $B a$ saltare $K l \quad 22$ incenditur] inflammatur $B a K l L U \quad 25$ lata] et add. $P \quad 28$ sicut capra] om. BaKlLU 29 magna] om. BaKl $L$ 
ardens, et inferior pars illius exalationis, que est grossior, apparet tamquam basis illius columne.

$U 18^{\mathrm{rb}} \quad\langle 16\rangle$ Dubitaret aliquis utrum huiusmodi impressiones $\mid$ ignite, si tangerentur manu, comburerent manum. Respondetur quod ille que sunt in materia multum rara non comburerent, sed possent esse ex materia ita densa quod utique comburerent manum. Istis visis, patet quod questio est vera.

$\langle 17\rangle$ Ad rationes. Ad primam, cum dicitur: 'exalationes sunt de natura ignis', nego, immo exalatio que est materia harum impressionum est de natura $K l 24^{\mathrm{vb}} \quad$ terre, quamvis sit | calida calore accidentali ipsam elevante.

$\langle 18\rangle$ Ad secundam dico quod huiusmodi materia, que in se iam habet calo10 rem bene fortem, bene potest incendi cum movetur in aere, quia est materia valde inflammabilis.

$\langle 19\rangle$ Ad tertiam dico quod illa exalatio elevatur sursum a calore sibi incorporato. Et quamvis iste motus sit violentus quantum est ex parte passi, $\mathrm{Ba} 2 \mathrm{O}^{\mathrm{vb}}$ tamen est naturalis | quantum est ex parte agentis; unde ista elevatio est 15 motus naturalis, quamvis eam precessit motus violentus.

Et sic patet ad questionem.

I.14 Utrum de nocte, serenitate existente, debeant apparere hyatus et voragines et sanguinei colores in celo

Queritur consequenter utrum de nocte, serenitate existente, debeant apparere hyatus et voragines et sanguinei colores in celo.

$\langle 1\rangle$ Et arguitur quod huiusmodi impressiones non debeant apparere in celo, 20 quia celum non est receptivum huiusmodi impressionum; ergo huiusmodi impressiones non sunt in celo, sed in aere; igitur non deberent apparere in celo, sed magis in aere, cum res magis debet apparere ubi est quam ubi non est.

$\langle 2\rangle$ Secundo: huiusmodi impressiones non apparent in celo nec etiam 25 in aere de die; ergo minus debent apparere de nocte. Antecedens patet ad sensum; sed consequentia probatur, quia illa que per Aristotelem possunt movere visum, magis videntur in maiori lumine ${ }^{122}$; sed cum huiusmodi impressiones sunt huiusmodi, ergo, cum maius sit lumen de die quam de

9 calida] sicca et calida $\mathrm{Ba} \mathrm{Kl} L \mathrm{U}$

122 Aristoteles, De anima, II, 7, 419 a 7-9; cf. Auct. Arist., 18o, n. 72. 
nocte, sequitur huiusmodi impressiones magis debere apparere in die quam in nocte.

$\langle 3\rangle$ Tertio videtur quod non debeant apparere serenitate existente, quia, cum huiusmodi impressiones fiant per lumen diruptum ex obscuro | et nigro, sicut dicit Aristoteles ${ }^{123}$, sed cum in tempore nebuloso maior fiat diruptio luminis ex obscuro, videtur quod magis debeant apparere in tempore $\mid$ nebuloso quam sereno.

〈4〉 Quarto ad idem: si sic, hoc esset isto modo, sicut dicit Aristoteles, quod nigrum dirumpens lumen apparet remotius ${ }^{124}$. Sed propter hoc non debet esse, quia, cum istud nigrum sit ita propinquum visui sicut residuum, debet apparere ita propinquum visui sicut residuum; aliter enim sensus visus sic iudicando deciperetur. Et cum sic iudicando iudicet de colore-puta de nigredine, de albedine vel rubedine-, et cum color sit proprium obiectum visus, | tunc sensus circa suum proprium obiectum deciperetur, quod est contra Aristotelem in secundo De anima ${ }^{125}$.

$\langle 5\rangle$ Quinto videtur quod non debeant apparere colores sanguinei, quia non videtur quod magis debeant apparere illi quam alii; sed ita est quod alii colores non apparent, sicut est color viridis vel color croceus vel aliquis talis.

〈6) In oppositum est Aristoteles ${ }^{126}$, et etiam patet ad sensum, quia aliquando de nocte, serenitate existente, apparent huiusmodi impressiones.

$\langle 7\rangle$ In ista questione primo exponendi sunt quidam termini in questione positi; secundo ponende sunt quedam | suppositiones; tertio ponende sunt quedam conclusiones; quarto videndum est de causa unius effectus qui etiam aliquando contingit de nocte, serenitate existente.

$25\langle 8\rangle$ Quantum ad primum, sciendum est quod 'hyatus' et 'voragines' dicun$B a 21^{\mathrm{ra}}$ tur quedam aperture quibus celum apparet apertum, et differunt secundum magis et minus. Unde quidam dicunt quod cum illa apertura apparet magna et profunda, tunc dicitur 'vorago'. Cum autem illa apertura apparet minus |

10 visui] om. $B a K l L U \quad 11$ visui] om. $B a K l L U \quad 14$ sensus] visus $B a K l L$ lect. dub. $U \quad 19$ aristoteles] primo huius tractatu secundo capitulo secundo conclusione prima $a d d$. Ba KlLU 20 huiusmodi impressiones] hyatus voragines et sanguinei colores $B a K l L U \quad 26$ quibus celum apparet apertum] celi $B a K l L U$

123 Aristoteles, Meteorologica, I, 5, 342 a 34-b 21.

124 Ibid., I, 5, 342 a 14-16.

125 Aristoteles, De anima, II, 6, 418 a 14-15; cf. Auct. Arist., 179, n. 66.

126 Aristoteles, Meteorologica, I, 5 . 
profunda, tunc dicitur 'hyatus'. Alii autem dicunt quod cum illa apertura apparet cum rubedine, ac si esset ibi ardor, dicitur 'vorago'; cum autem apparet sub quadam obscuritate, tunc dicitur 'hyatus' ${ }^{127}$.

$\langle 9\rangle$ Quantum ad secundum, sit prima suppositio: quando aliqua duo equaliter distant a visu, quorum unum est coloratum vel saltem apparens sub colore magis claro, reliquum vero sub colore minus claro, tunc istud quod apparet sub colore clariori apparet esse propinquius quam istud quod est coloratum colore minus claro. Et istud sciunt pictores: partem enim que debet apparere supereminere colorant colore magis claro et illam que debet apparere densa colore minus claro, sicut colore nigro vel alio tendente ad nigredinem. Et propter istam causam potest contingere quod aliqua superficies plana potest apparere concava vel convexa. Si enim continue versus medium coloretur colore claro et versus extremum colore obscuro, iudicaretur convexa, quia partes medie apparerent propinquiores, quia essent colorate colore clariori. Si autem partes versus medium alicuius superficiei plane essent colorate colore obscuro et versus extremum colore claro, tunc illa superficies apparet concava, quamvis esset plana, quia partes extreme apparent propinquiores quam partes medie; nam essent colorate colore clariori. Sic similiter superficies convexa posset apparere plana, sicut si partes magis versus nos essent colorate colore obuscuro et remotiores a nobis colore claro, tunc posset fieri recompensatio claritatis et distantie.

$\langle 10\rangle$ Secunda suppositio: cum lux vel album videtur per nigrum, apparet rubeum. Ista suppositio patet cum videmus Solem per fumum ${ }^{128}$, et prop$L 198^{\text {rb }}$ ter hoc ignis etiam in carbone apparet coloris rubei; | carbo enim est nigri coloris, ignis autem est lucidus.

$\langle 11\rangle$ Quantum ad tertium, sit prima conclusio quod possibile est quod aliquando appareat vorago in celo. Probatur, nam possibile est quod aliquando $U 18^{\mathrm{vb}}$ elevetur exalatio in medio densior et profundior, in extremo autem eius |

1 apertura] et profunditas $a d d$. Ba $L$ est profunda et $a d d$. $U$ 8-10 partem enim que ... colore minus claro] quando enim volunt aliquam partem magis facere apparere colorant ipsam colore magis claro quam illam quam volunt minus apparere $B a K l L U$ 10-11 sicut colore nigro vel alio tendente ad nigredinem] om. BaKlLU 12 vel convexa] et profunda $B a K l L U$ 12-21 si enim continue ... claritatis et distantie] om. Ba KlLU 23 cum videmus solem per fumum] quia cum solem videmus per fumum tunc apparet nobis rubeus $B a K l L U \quad 26-27$ aliquando] de nocte serenitate existente $a d d . B a K l L U \quad 28$ extremo] extrema $P$

127 Ibid., I, 5, 342 b 15-18, translatio Guillelmi de Morbeka (translatio noua), $A L$ X 2.2, $18^{258-}$ 261.

128 Cf. ibid., III, 374 a 3-8; 347 b 8-11. 
minus densa et minus profunda. Et cum | exalatio sit de natura terre, etiam participat colorem terre, videlicet nigredinem. Cum autem huiusmodi exalatio est inter nos et celum, lux celestis minus clare videtur per medium illius exalationis et magis clare videtur per extremum illius exalationis. Igitur, per secundam suppositionem, celum visum per medium illius exalationis apparet coloris minus clari, videlicet rubedinis minus clare, et per extremum apparet rubedinis magis clare. Ergo, per primam suppositionem, partes extreme illius exalationis apparent magis propinque, partes autem intermedie apparent magis remote, ergo iudicamus ibi profunditatem in medio, | et concavitatem, et tamen propter nimiam distantiam celi et exalationis et propter luciditatem celi in comparatione ad illam exalationem iudicamus illam exalationem non magis propinqua quam celum. Cum ergo talis fantasia et apparitio fiat in exalatione, nos iudicamus hoc esse in celo, et sic celum iudicamus apertum et concavatum.

$\langle 12\rangle$ Secunda conclusio est: possibile est quod appareat nobis hyatus in celo. Patet, quia exalatio potest esse in medio ita densa quod per eius medium non videmus lumen et per eius extremum videmus, quia partes in extremo sunt rariores et minus dense; et tunc in medio iudicatur obscuritas et in extremo claritas, et illa apparitio est hyatus.

$\langle 13\rangle$ Tertia conclusio: quod possunt apparere sanguinei colores. Patet, nam possibile est quod exalatio | sit uniformis in raritate et densitate in partibus eius extremis et mediis. Et quando sic est, equaliter lumen vel lux videtur per huiusmodi exalationem, et tunc partes extreme iudicantur equaliter prope sicut medie. Et cum lux visa per nigrum faciat apparere rubeum, sequitur 25 illam exalationem apparere rubeam, et illam rubedinem iudicamus in celo, propter causam prius dictam. Ex isto est quod Sol, cum de mane videtur et fiunt vapores et exalationes inter Solem et visum, quod Sol apparet rubei coloris, quia lux Solis visa per nigrum, sicut per vapores et exalationes, facit apparere rubeum.

$30 \quad\langle 14\rangle$ Quarta conclusio: huiusmodi impressiones, videlicet hyatus, vorago, etc., non apparent | de die. Patet, quia ex nimio | lumine Solis opacitas et obscuritas ipsius exalationis totaliter supervincitur, et sic apparet totum clarum.

$\langle 15\rangle$ Quinta conclusio: huiusmodi impressiones fiunt in tempore sereno 35 et non in tempore nebuloso. Patet, quia in tempore sereno possunt elevari exalationes usque ad supremam regionem aeris non impedite a nubibus;

11 propter] magnam add. $B a K l L U \quad 15$ conclusio] est add. $P \|$ quod] de nocte serenitate existente $a d d$. Ba Kl LU 16 in medio] om. $B a K l L U \quad$ 31 etc.] et sanguinei colores $B a K l L$ $U \quad 36$ exalationes] vapores $B a K l L$ 
in tempore autem nebuloso non possunt, quia tunc impediuntur a nubibus, que non possunt pertingere usque ad supremam regionem.

$B a 21^{\text {va }}\langle 16\rangle$ Quantum ad quartum, videlicet qualiter aliquando in nocte, | tempore existente sereno, audiuntur aliqui soni, ac si essent voces hominum vel brutorum: causa illius solet dari quod, cum in aliquo vapore elevato aliqua exalatio includitur, isto vapore compresso, illa exalatio petit exitum, et tunc causatur talis sonus, sicut ferrum calidum quando ponitur in aqua.

$K l 2^{\text {ra }} \quad\langle 17\rangle$ Sed diceres: quomodo est quod aliquando apparet sicut vox hominis vel vox alterius animalis? Solet dici quod hoc est ex virtute constellationis et dispositionis materie, recte sicut ex constellatione grandines descenden10 tes aliquando sunt figurate figura hominis, aliquando alterius animalis. Ita etiam in proposito dicatur de diversificatione et varietate illius soni sic causati.

$\langle 18\rangle$ Ad rationes. Ad primam concedo quod huiusmodi impressiones non sunt in celo, nec celum est receptivum huiusmodi impressionum; bene tamen apparent in celo propter causam prius dictam ${ }^{129}$.

$\langle 19\rangle$ Ad secundam dicatur quod non fiunt de die, sed de nocte, propter causam prius dictam ${ }^{130}$.

$\langle 20\rangle$ Ad tertiam dico quod non fiunt in tempore nebuloso propter nimiam spissitudinem vaporis elevati et etiam quia nubes est bene cumstricta, et propter hoc non facit talem fantasiam.

$\langle 21\rangle$ Ad quartam dico quod visus bene decipitur in iudicando de distantia vel situ; situs autem non est proprium obiectum visus, sed est sensibile commune. Circa autem sensibilia communia sensus plures decipitur, sicut habet videri circa secundum De anima ${ }^{131}$.

$\langle 22\rangle$ Ad quintam dico quod causa quare ibi non apparent colores crocei vel virides est quia lux visa per nigrum non est apta nata facere apparere huiusmodi colores.

Et sic finitur questio.

2 que] quia $P \quad 4-5$ brutorum] animalium $a d d . B a K l L U \quad 15$ receptivum huiusmodi impressionum] aptum natum huiusmodi impressiones recipere $B a K l L U \quad 24-25$ sicut habet videri circa secundum de anima] om. $B a K l L U$

129 I.14, 11.

130 I.14, 14 .

131 Cf. Aristotelem, De anima, II, 6, 418 a 14-15. 


\section{I.15 Utrum cometa sit de natura celi vel elementari}

Queritur consequenter utrum cometa sit de natura celi vel elementari.

$\langle 1\rangle$ Et arguitur quod sit de natura celi: illud est de natura celi | cui convenit $K l 26^{\mathrm{rb}}$ motus naturalis ipsius celi; sed sic est quod motus circularis ipsius celi convenit comete. Maior est nota, | ex eo quod motus arguit formam. Sed minor

5 patet, quia motus circularis est motus naturalis ipsius celi; ille autem convenit comete: cometa enim est aliquando visus moveri motu diurno circa Terram.

$\langle 2\rangle$ Secundo: si cometa non esset de natura celi, sed fieret ex exalatione vel vapore elevato, sicut fiunt alie impressiones, vel igitur fieret in aere, vel in 10 igne. Nullum istorum | potest dici. Et primum non potest dici quod in aere, $B a 21^{\mathrm{vb}}$ et supponitur quod quia cometa diu durat, oporteret quod fieret de materia grossa et compacta; isto sumpto, probo quod non potest fieri in aere: non enim in media regione, quia, que fiunt in media regione vel infra per inflammationem, oportet quod sint de materia minus grossa et de materia magis

15 rara, ut cito et faciliter possit inflammari; sed cum materia comete sit valde grossa et compacta, caliditas infra mediam regionem et etiam antiparistasis non sufficerent ad inflammationem talis materie ex qua dicitur fieri cometa. Nec etiam potest dici quod fiat | in summa regione aeris vel in igne, nam, quamvis materia ita grossa, si ipsa esset ibi, bene posset inflammari, tamen videtur quod propter eius nimiam grossitiem non potest ita alte elevari.

〈3〉 Tertio ad idem: si esset de natura elementari et non celi, tunc aliquando posset fieri sub alia figura quam solet fieri, videlicet sine cauda vel sine coma vel sine barba. Consequentia tenet, quia exalatio de qua tunc generaretur, si non esset de natura celesti, posset taliter fieri vel disponi quod

25 fieret sub figura rotunda.

$\langle 4\rangle$ Quarto ad idem rationibus Senece, nam, si esset de alia natura quam de natura celi, tunc fieret in aere, sicut alie impressiones; sed quecumque impressiones fiunt in aere sunt parve durationis, sicut videmus de nubibus et consimilibus ${ }^{132}$; sed comete non sunt parve durationis, immo magne; igitur etc.

1 elementari] elementorum $\mathrm{Ba} K \mathrm{~K}$ elementali $L \quad{ }_{15}^{-16}$ materia comete sit valde grossa et compacta] exalatio de qua fit cometa sit de materia grossa $B a$ exalatio sit de materia comete $K l L$ exalatio sit de materia grossa $U \quad 24$ fieri vel] $\mathrm{om}$. Ba Kl $L U$

132 Seneca, Questiones naturales, VII, 22, 1. 
〈5 Quinto: impressiones que fiunt in aere non durant nec manent sub eodem astro nec moventur ad motum illius astri, et hoc si fiunt per inflam$U 19^{\text {va }}$ mationem; | sed visum est quod cometa movebatur ad modum astri.

$\langle 6\rangle$ Sexto: comete sunt magne significationis et significant aliquos effectus futuros qui non statim eveniunt; sed impressiones alie, si significant aliquos effectus proprios, illi statim eveniunt, sicut patet de rubedine matutina, postquam statim videtur sequi pluvia. Ex hiis videtur quod comete sint de $L 199^{\text {ra }}$ natura celi et non elementari, | de qua sunt alie impressiones.

$\langle 7\rangle$ In oppositum est Aristoteles, qui ostendens modum generationis comete, dicit quod fit per inflammationem exalationis elevate usque ad summam 10

$B a 2^{\text {ra }}$ regionem | aeris bene alte ${ }^{133}$.

$\langle 8\rangle$ In ista questione primo enunciande sunt quedam experientie quibus apparet diversitas cometarum; secundo sunt recitande opiniones dicentium ipsum esse de natura celi; tertio post ista in alia questione videndum est de qua natura sit secundum veritatem ${ }^{134}$.

$K l_{2} 6^{\mathrm{vb}}\langle 9\rangle$ Quantum ad primum, sciendum est quod comete differunt | primo magnitudine: aliquando enim sunt visi valde magni; etiam aliquando visi sunt parvi, et aliquando ita parvi quod de difficili propter eorum parvitatem possunt videri ${ }^{135}$.

$\langle 10\rangle$ Secundo ipsi comete differunt multitudine: quia aliquando visus est unus, aliquando vero plures simul.

$\langle 11\rangle$ Tertio differunt in figura: nam aliquando apparet caudatus, aliquando barbatus et aliquando comatus, secundum quod coma apparet retro, vel ante, vel supra ${ }^{136}$. Unde visus est cometa habens caudam ita magnam quod extendebatur usque ad medium celi, ut dicit Aristoteles ${ }^{137}$.

$\langle 12\rangle$ Quarto differunt comete in colore: nam aliqui apparent coloris rubei, aliqui vero coloris candidi ${ }^{138}$.

2 astro] erratico $a d d$. $B a K l L U \quad 5$ si] qui $P \quad 6$ proprios] futuros $B a K l L U \quad 17$ magni] immo aliquando tanti vel maiores sicut sol $a d d$. $B a K l L U$

133 Aristoteles, Meteorologica, I, 7, 344 a 5-344 a 33.

134 I.16, 10-11.

135 Cf. Senecam, Questiones naturales, VII, 17, 3.

136 Cf. Senecam, Questiones naturales, VII, 11, 2.

137 Aristoteles, Meteorologica, I, 6, 343 b 1; 343 b 17-25.

138 Cf. Senecam, Questiones naturales, VII, 17, 3. 
$\langle 13\rangle$ Quinto differunt motu et quiete: aliquando enim cometa visus est quiescere, aliquando visus est etiam moveri, aliquando transversaliter, aliquando etiam motu diurno, aliquando etiam ad motum unius stelle, ita quod apparuit insequi stellam, et aliquando velocius et aliquando tardius.

〈14 Sexto differunt loco: quidam enim generantur altius, quidam vero bassius. Similiter generantur sub diversis partibus ipsius celi, sed ut plurimum generantur sub parte celi septentrionalis et solent apparere circa Viam lacteam.

$\langle 15\rangle$ Septimo differunt tempore: quia aliquando sunt multi anni quod non videtur cometa, aliquando autem in parvo tempore, sicut in duobus annis, visi sunt duo vel tres. Et etiam differunt tempore sicut quod aliqui diu durant, aliqui autem durant minus. Unde quidam dicunt quod ad minus durant per septem dies et ad plus per sex menses ${ }^{139}$.

$\langle 16\rangle$ Octavo differunt in variatione coloris: quidam enim visi sunt variare colorem, quidam autem visi sunt non variare colorem. Similiter quidam visi sunt deficere propter eorum approximationem ad Solem; quidam autem visi sunt | deficere sine huiusmodi approximatione.

$\langle 17\rangle$ Nono differunt in significatione: quidam enim significant hoc et qui$U 19^{\mathrm{vb}}$ dam aliud, sicut patet postea in una questione ${ }^{140}$.

$\langle 18\rangle$ Decimo differunt quia aliqui fiunt sub aliquo astro fixo vel erratico; aliqui autem fiunt per se, non sub aliquo astro.

$\langle 19\rangle$ Quantum ad secundum, sciendum est quod dicentes cometas esse de natura celi diversificabantur | in suis opinionibus; unde quidam dixerunt quod cometa esset unus de planetis ${ }^{141}$. Sed breviter hoc non valet, | quia aliquando visus est cometa aliis | planetis apparentibus, quod est signum quod non est aliquis planetarum ${ }^{142}$.

$\langle 20\rangle$ Alii autem dixerunt quod cometa esset una stella que ad tempus apparet habere comam propter vapores sub illa stella elevatos ${ }^{143}$. Sed illud

\footnotetext{
1 quinto] aliquando add. $P \quad 2$ transversaliter] motu retrogrado $B a K l U$ retrograde $L \quad 4$ stellam] motum unius stelle $B a K l L U \|$ et aliquando velocius et aliquando tardius] om. $B a$ $K l L U \quad 5^{-6}$ quidam vero bassius] om. $B a K l L U \quad 9$ sunt] transeunt $B a K l L U \quad 10$ annis] vel tribus $a d d . L \quad 11 \mathrm{diu}]$ om. $P \quad 13$ per sex menses] per octo dies et alii dicunt quod per sex menses $B a$ per octo menses $K l \quad 17$ deficere] om. $P \quad 20$ fiunt] moventur $B a K l L U \quad 21$ fiunt] moventur $B a K l L U \quad 25$ planetis] omnibus add. $B a L$
}

139 Plinius, Naturalis historia, II, 22, 90.

$140 \quad$ I.18.

141 Cf. Aristotelem, Meteorologica, I, 6, 342 b 30-35.

142 Cf. ibid., I, 6, 343 a 30-35.

143 Cf. ibid., I, 6, 342 b 35-343 a 20. 
dictum non valet, nam, quamvis aliquando sic fiat, tamen non semper, quia non semper cometa apparet moveri ad motum alicuius stelle. Sed tamen, si semper predicto modo fieret et non alio, semper deberet apparere moveri ad motum alicuius stelle.

$\langle 21\rangle$ Alii dixerunt quod ex coniunctione plurium stellarum apparet cometa $^{144}$. Istud iterum non valet, quia semper cometa deberet apparere moveri, ex quo semper stelle moventur-sive sint coniuncte, sive non; sed consequens est falsum, quia aliquando apparet quiescere. Secundo, si sic, sequeretur quod statim, postquam cometa deficeret, stelle deberent ad invicem apparere divise ex quarum coniunctione apparuit cometa; modo hoc non est verum: non enim semper, ubi cometa apparet deficere, apparent alique stelle divise ${ }^{145}$. Tertio, nam non est verisimile quod stelle ita diu essent coniuncte sicut apparet cometa et durat. Quarto, nam, cum stelle non sunt coniuncte, apparent quantitatis valde parve, et non est verisimile quod ex $\mathrm{Kl} 27^{\mathrm{rb}}$ coniunctione | duarum vel trium stellarum que per se apparent ita parve debeant apparere ita magne ${ }^{146}$ sicut cometa.

$\langle 22\rangle$ Alia erat opinio Senece quod cometa non est aliqua de stellis fixis nec est aliquis de planetis, sed est una alia stella que habet motum valde diversum et incognitum, et aliquando est hic et aliquando est alibi ${ }^{147}$.

$\langle 23\rangle$ Sed contra: non est verismile quod aliqua stella habeat talem figuram qualem habet cometa; ergo nec est verisimile quod cometa sit aliqua $U_{2} \mathrm{O}^{\mathrm{ra}}$ stella. Antecedens patet per Commentatorem in secundo Celi, | dicentem quod omnes stelle sunt figure sperice ${ }^{148}$. Sed diceretur quod talis stella non est talis figure, sed apparet talis ex lumine et radiis eius-propter hoc enim apparet coma. Hoc non valet, quia, cum talis stella sit sperica et equaliter cir-

$B a 22^{\text {va }}$ cum se diffundit | lumen et radios, sequitur quod non magis propter radios et lumen eius ex una parte apparet coma quam ex alia. Aliter diceretur quod forte illa stella apparet habere comam propter exalationes sub ipsa eleva-

5 coniunctione] vel ex commixtione $a d d$. $L \quad 9$ postquam] post postquam $P \quad 15$ apparent] apparet $P \quad 16$ magne] magna $P$ in coniunctione $a d d . B a K l L U \quad 19$ hic et aliquando est alibi] idem $P \quad 25$ equaliter] aliqualiter $P$

\footnotetext{
144 Cf. ibid., I, 6, 342 b 27-29.

145 Cf. ibid., I, 6, 343 b 25-27.

146 Aristoteles, Meteorologica, I, 6, 343 b 33-344 a 2.

147 Seneca Questiones naturales, VII, 22, 1; VII, 24, 2; VII, 27, 6.

148 Averroes, Commentarium magnum in De celo, II, comm. 26, eds. Carmody, Arnzen, 2: $313-314$.
} 
$\operatorname{tas}^{149}$. Hoc non valet, quia sic illa stella aliquando deberet apparere sine tali coma, cum aliquando deficiant ex|alationes sub ipsa ${ }^{150}$.

$\langle 24\rangle$ Secundo; quia cometa aliquando movetur ita diversimode quod non est verisimile quod ita diversimode movetur aliqua stella celi, sive sit fixa sive erratica. Similiter cometa aliquando quiescit, sed numquam aliqua stella celi quiescit.

$\langle 25\rangle$ Tertio, nam cometa ita prope aliquando accedit ad polos quod nulla stella erratica ita prope potest accedere.

$\langle 26\rangle$ Quarto, nam aliquando cometa est alterius et alterius coloris; nulla autem pars celi est modo unius coloris et postea alterius.

$\langle 27\rangle$ Quinto, nam aliquando apparent simul plures comete, et igitur non potest dici quod cometa sit una stella celi; isti enim qui dixerunt non posuerunt plures stellas una.

$\langle 28\rangle$ Sexto, nam aliquando cometa deficit absque hoc quod intret sub 15 radiis Solis; numquam autem aliqua stella apparet deficere nisi subintret radios ipsius Solis; ergo finaliter non est aliqua stella celi.

〈29〉 Ad rationes. Ad primam: 'cometa movetur circulariter', dico quod hoc est ad motum aeris continentis, qui movetur circulariter ad motum ignis, et ignis ad motum celi. Nec propter hoc oportet quod cometa sit de natura celi plus quam aer vel ignis: talis enim motus non inest istis naturaliter, sed inest eis preter naturam, sicut prius dicebatur ${ }^{151}$.

$\langle 30\rangle$ Ad secundam: 'vel fieret in aere, vel in igne', dico quod fit in aere. Et quando dicitur: 'materia de qua generatur est ita grossa quod non potest ita alte elevari', dico quod immo propter calorem inclusum et incorporatum in 25 ipsa materia.

$\langle 31\rangle$ Ad tertiam: 'tunc aliquando deberet', etc., respondetur quod forte pluries sic fit, sed tunc apparet quod sit una stella celi propter | eius rotunditatem. Sed quando apparet cum cauda vel barba, tunc iudicatur differentia inter ipsum cometam et alias stellas celi.

1 apparere] om. $P \quad 3$ quia cometa] iter. $P \quad 8$ erratica] celi KlLU om. Ba 16 celi] cometa

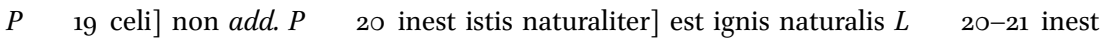
eis preter naturam] violenter $B a K l U$ violentus $L \quad 24$ propter] fortem add. $K l L B a U \|$ et incorporatum] om. Ba KlLU 27 propter] nimiam add. Ba KlLU $27-28$ rotunditatem ] profunditatem $B a K l L U \quad 29$ alias stellas celi] planetas $B a K l U$ planetas vel stellas $L$

149 Cf. Aristotelem, Meteorologica, I, 6, 342 b 35-343 a 20.

15 O Cf. ibid., I, 6, 343 a $27-3$ o.

151 I.8, 24. 
$\langle 32\rangle$ Ad quartam: 'quecumque impressiones', etc., verum est in media

$U 20^{\mathrm{rb}}$

$P_{24} 8^{\mathrm{v}}$

$B a 22^{\mathrm{vb}}$ durare.

regione vel infra. Si tamen fiant super mediam regionem, tunc tamen propter multitudinem materie et compacitatem et grossitiem | possunt diu |

$\langle 33\rangle$ Ad quintam | concedo quod alique impressiones que fiunt in aere non diu apparent sub aliquo astro. Cum hoc stat quod alique impressiones que fiunt magis alte, ubi aer movetur circulariter, possunt continue moveri sub aliquo astro et moveri motu diurno una cum aere in quo sunt.

$\langle 34\rangle$ Ad sextam de significatione comete videbitur seorsum in una questione $^{152}$.

\section{I.16 Utrum cometa sit exalatio calida et inflammata}

Queritur consequenter utrum cometa sit exalatio calida et inflammata.

$L 199^{\mathrm{vb}} \quad\langle 1\rangle$ Et arguitur quod non, nam talis exalatio vel esset $\mid$ multa vel pauca. Si dicatur quod talis exalatio sit pauca, tunc cito per ignitionem et inflammationem eius consumitur, et sic cometa non ita diu duraret sicut visus est durare. $\mathrm{Si}$ autem dicatur quod illa exalatio sit multa, tunc sequitur quod cometa debeat apparere continue crescere et augeri; nam, primo una parte ignita, alia igniretur; vel si simul omnes eius partes ignirentur, non ita diu duraret sicut visus est durare.

$\langle 2\rangle$ Secundo, nam, si esset exalatio calida ignita, non deberet apparere in suprema regione aeris, quod est contra experientiam. Consequentia pro-

$K l 28^{\text {ra }}$ batur, nam talis exalatio non potest transire per mediam | regionem aeris: cum ipsa sit frigida et illa exalatio sit calida, sequitur quod cum pertingit ad mediam regionem aeris, pellitur et fugatur per viam a qua venit; nam prius dicebatur quod unum contrarium movet suum contrarium localiter ${ }^{153}$.

$\langle 3\rangle$ Tertio ad idem: si esset aliqua talis exalatio ignita, aliquando deberet eclipsari, quia aliquando esset in umbra Terre, causata ex obiectione Terre ad Solem; sed consequens est falsum, quia numquam visus est cometa eclipsari.

7 ubi aer movetur circulariter] om. $B a K l L U \|$ continue moveri] diu durare $B a K l L U \quad 8$ sub aliquo astro] om. $B a K l L U \quad 13$ ignitionem] ignem $P \quad 16$ ignita] consumpta $B a K l L U$ 23 per viam a qua] ad locum a quo $B a U$ a via a qua $K l$ ad viam a qua $L \quad 26-27$ causata ex obiectione terre ad solem] om. $\mathrm{Ba} \mathrm{Kl}$

$152 \quad$ I.18.

153 I.10, 13. 
〈4〉 In oppositum est Aristoteles, qui opinionibus Antiquorum reprobatis dicentium cometam esse de natura celi, dicit quod cometa est de natura elementari; et ponens modum generationis eius, dicit ipsum esse exalationem calidam et ignitam et inflammatam ${ }^{154}$.

$5\langle 5\rangle$ In ista questione primo ponende sunt opiniones aliquorum dicentium cometam esse de natura elementari; secundo ponende sunt conclusiones secundum opinionem Aristotelis.

〈6〉 Quantum ad primum, sciendum est quod illi qui posuereunt cometam esse de natura elementari erant diversificati, sicut et illi qui posuerunt cometam de natura celi. Unde quidam posuerunt quod cometa esset ignis condensatus; unde ymaginabantur quod aliqua pars ignis supra aliquando condensetur in tantum quod sic lucet ad modum ad quem apparet nobis cometa. Et secundum quod iste ignis secundum suas partes alias et alias est condensatus, apparet nobis aliquando barbatus, aliquando caudatus.

$\langle 7\rangle$ Breviter ista opinio non videtur | vera, nam ignis non $\mid$ potest stare sub tanta densitate quod sic luceret, immo nec adhuc aer ad modum ad quem cometa apparet lucere.

<8 Alia erat opinio quod materia comete | bene est exalatio, sed non talis qualis est $\mid$ exalatio aliarum impressionum. Unde ista opinio ymagina$\mathrm{Ba} 23^{\mathrm{ra}}$ $U 2 \mathrm{O}^{\mathrm{va}}$ batur quod exalatio que est materia comete virtute stellarum purgatur et subtiliatur ab omni terrestri. Ulterius ymaginatur quod nec cometa fit per inflammationem huius exalationis ab igne, sed a natura alicuius planete, ita quod ista opinio ymaginabatur quod cometa est unum corpus valde simile nature stellarum, nec est ibi proprie inflammatio, sed illud corpus fit sic lucidum quia valde declinat ad naturam stellarum ${ }^{155}$.

$\langle 9\rangle$ Ista opinio non posset multum formaliter impugnari, tamen potest contra eam argui, nam, cum illud corpus non sit lucidum per inflammationem, oportet quod sit lucidum a Sole, sicut et alie stelle; et si sic, sequitur quod cum illud corpus esset in umbra Terre, quod tunc deficiat a lumine; et si sic, sequitur cometam aliquando eclipsari. Hoc tamen numquam visus erat;

7 aristotelis] ponentis cometam esse de natura elementari $a d d . K l L U^{a c} \quad 24$ inflammatio] exalatio $B a K l L U$

154 Ibid., I, 6, 343 a 22-344 a 4; I, 7, 344 a 5-344 a 33.

155 Robertus Grossatesta, De cometis, ed. C. Panti, in Moti, virtù e motori celestinella cosmologia di Roberta Grossatesta. Studio ed edizione dei trattati De sphera, De cometis, De motu supercelestium, Florence 2001 (Corpus Philosophorum Medii Aevi. Testi e Studi, 16), $324^{61}-326^{117}$. 
ergo videtur magis quod sit unum corpus lucidum per inflammationem, et non per lumen Solis, sicut alie stelle.

$\langle 10\rangle$ Quantum ad secundum, sit prima conclusio: cometa non est de natura celi. Patet, nam, si sic, numquam deficeret a lumine nisi per approximationem et accessum eius ad Solem, sicut et alie stelle; sed hoc est falsum. Patet falsitas, quia sepe cometa visus est deficere a lumine absque eius approximationem ad solem.

$\langle 11\rangle$ Secunda conclusio: cometa est de natura elementari, quia vel cometa est de natura celesti, vel elementari. Sed non est de natura celesti per pri$K l 28^{\text {va }}$ mam conclusionem; ergo de natura elementari. Maior patet ex eo $\mid$ quod 10 omne corpus est de natura celi vel elementari.

$\langle 12\rangle$ Tertia conclusio: cometa est exalatio calida elevata ex istis inferiori$P 249^{r} \quad$ bus, inflammata in superiori regione | aeris propter caliditatem ibi habundantem ex eius proximitate ad ignem. Probatur, quia non fit per refractionem luminis celestis supra illa exalatione, sicut Aristoteles probat in littera ${ }^{156}$; ergo sequitur quod cometa sit unum corpus realiter lucidum. Sed illud non est aer neque ignis, quia ista propter nimiam eorum raritatem non $B a_{2} 3^{\mathrm{rb}}$
$L 20 \mathrm{O}^{\mathrm{rb}}$ possent sic lucere. Nec etiam illud | corpus lucidum est terra vel aqua, quia | huiusmodi propter eorum gravitatem non possent ita alte elevari. Ergo oportet quod illud corpus lucidum sit condensatius quam sit ignis et aer et sit subtilius quam terra et quam sit aqua. Tale autem corpus medio modo se

$U 2^{\mathrm{vb}}$ habens erit vapor vel exalatio. Sed non potest dici quod sit vapor, | quia ille non potest ita alte elevari sicut ubi est cometa. Ergo oportet dici quod illud corpus sic lucidum et inflammatum sit exalatio; exalatio enim altius potest elevari quam vapor, quia calor potest sibi fortius incorporari, quia talis exalatio est de natura terrestri.

$\langle 13\rangle$ Ex isto potest reddi causa quare cometa aliquando est maior, aliquando minor, nam hoc est secundum multitudinem et paucitatem illius exalationis. Et propter illud cometa aliquando durat diutius, aliquando minus diu. Per hoc etiam potest reddi causa quare cometa aliquando apparet coloris rubei, aliquando coloris magis tendentis ad albedinem, nam hoc est secundum quod illa exalatio est minus vel magis densa vel rara, vel magis $\mathrm{Kl} 28^{\mathrm{vb}}$ vel minus terrestris. Potest etiam reddi causa quare aliquando $\mid$ apparet cau-

5 est] om. $P \quad 6-7$ absque eius approximationem ad solem] quando recessit a sole $B a$ propter hoc quod approximabat ad solem $K l L U \quad 19$ gravitatem] grossitiem et gravitatem $K l L U$ 33-205.1 caudatus et non barbatus et aliquando e contrario] caudatus barbatus $P$

$15^{6}$ Aristoteles, Meteorologica, I, 6, 343 a 26-343 b 7 . 
datus et non barbatus, et aliquando e contrario, nam, si exalatio inferius inflammata est ante, apparet barbatus; si retro, apparet caudatus.

$\langle 14\rangle$ Ad rationes. Ad primam dico quod ista exalatio ignita, quamvis non sit in tanta quantitate quod ipsa non augmentata aliunde posset tam diu lucere

5 sicut apparet cometa, tamen continue nove et nove exalationes elevantur ad istum locum ubi est cometa. Inde est quod cometa potest tam diu apparere sicut apparet; et quando non amplius ille exalationes nove elevantur, cometa incipit deficere.

$\langle 15\rangle$ Ad secundam dico quod illa exalatio propter magnum calorem sibi 10 incorporatum potest transire per mediam regionem usque ad supremam, absque hoc quod repellatur a frigiditate medie regionis.

$\langle 16\rangle$ Ad tertiam dico quod numquam debet apparere eclipsari, quia ex inflammatione eius habet lumen, et non | a Sole; et ergo, non obstante quod sit in umbra Terre, adhuc apparet lucere.

\section{I.17 Utrum motus comete sit naturalis vel violentus}

15 Queritur consequenter utrum motus comete sit naturalis vel violentus.

$\langle 1\rangle$ Et arguitur primo quod non sit naturalis. Corpora elementaria non moventur naturaliter motu circulari; | sed cometa est corpus elementare-est enim de natura elementari, sicut prius dicebatur ${ }^{157}$; ergo etc. Maior est nota, quia corpora elementaria | moventur naturaliter motu recto, scilicet sursum vel deorsum, et non motu circulari; nam solum illo modo movetur celum $L 200^{\text {va }}$ $K l 29^{\text {ra }}$ naturaliter. Et cum idem motus in specie non conveniat naturaliter corporibus distinctis specie, sequitur motum circularem aliis corporibus quam celo non esse naturalem; | et per consequens non naturaliter inest comete.

$B a 23^{\text {va }}$

$\langle 2\rangle$ Secundo: motus naturalis alicuius est solum secundum unam diffe-

25 rentiam positionis; sed sic non est de motu comete, nam aliquando movetur circulariter ab oriente versus occidentem, aliquando dimittit illum motum et movetur ab occidente versus orientem, et aliquando descendit, aliquando ascendit.

17-18 est enim de natura elementari] quia non est de natura celi $B a K l L U \quad 20$ vel] om. $P$ 22 quam] cum $P \quad 26$ circulariter] om. Ba Kl LU

157 I.16, 10-11. 
$\langle 3\rangle$ Tertio ad idem: nullum corpus grave vel leve naturaliter circumfertur; sed cometa est corpus grave vel leve; igitur etc.

〈4〉 Quarto: omnis motus qui inest alicui ab extrinseco non est naturalis; sed sic est de motu comete: ille enim sibi inest a celo vel ab aere ipsum continente.

〈5〉 Quinto: nichil movetur naturaliter motibus contrariis; sed cometa movetur motibus contrariis; ergo cometa non movetur naturaliter, nam cometa aliquando movetur ascendendo, aliquando movetur descendendo.

<6) Sexto ad idem: ille locus in quo est cometa vel est sibi naturalis vel violentus. Si est sibi naturalis, ergo debet in eo quiescere et per consequens, si movetur extra ipsum, hoc non est motu naturali. Si autem dicatur quod ille locus sit sibi violentus, et cum omne corpus habeat locum sibi naturalem, sequitur quod cometa habet alium locum sibi naturalem. Vel igitur ille $P 249^{v}$ locus est supra cometam vel infra: si dicitur quod supra, ergo debet moveri | ascendendo; si dicitur quod infra, tunc debet moveri descendendo.

$\langle 7\rangle$ In oppositum arguitur quia tali motu visi sunt omnes comete moveri; igitur videtur quod talis motus ad minus comete non sit violentus.

$K l_{2} g^{\mathrm{rb}} \quad\langle 8\rangle$ In ista questione primo videndum est quibus motibus | comete visi sunt moveri et que sint cause talium motuum. Secundo videndum an tales motus comete sint naturales vel violenti vel preter naturam insint sibi.

$B a 3^{\text {vb }}\langle 9\rangle$ Quantum ad primum, sciendum est $\mid$ quod erat una opinio que dixit cometam non moveri, quamvis appareat nobis quod movetur. Unde ista opinio ymaginabatur quod exalatio que est materia comete esset ad modum

$L 200^{\mathrm{vb}}$ corporis girativi, vertens unum extremum versus orientem, | aliud vero versus occidentem. Et quando ista exalatio in extremo versus orientem inflammaretur, tunc ista parte consumpta, reliqua incenderetur, et sic continue apparet moveri versus occidentem tam diu quod illa exalatio est consumpta.

$U \mathbf{2 1}^{\mathrm{rb}} \quad$ Et secundum | istum modum etiam potest salvari quare aliquando apparet ascendere et aliquando descendere. Si sic diceretur, non potest convinci aerem superius moveri circulariter ad motum celi, quia non videtur ex alio posse probari quod aer superius movetur circulariter nisi per motum comete; si autem negetur motus comete talis, non habebimus modum probandi aerem superius moveri circulariter. Sed breviter ista opinio non valet,

7-8 movetur motibus contrariis ... aliquando movetur descendendo] est huiusmodi igitur scilicet ascendendo vel descendendo quare etc. $P \quad 17$ ad minus] om. $B a K l L U \quad 23$ materia] de natura $B a K l U$ natura $L$ 
quia secundum talem modum non possemus probare quod cometa aliquando occidit, aliquando oritur, aliquando movetur versus septentrionem, aliquando versus meridiem, aliquando versus occidentem, et dimittit illum motum et incipit moveri versus orientem.

$\langle 10\rangle$ Dicendum est ergo quod cometa vere movetur, et aliquando movetur motu diurno, et aliquando velocitat $\mid$ motum suum, et aliquando retardat motum suum, scilicet diurnum, et aliquando movetur versus occidentem, et dimittens illum motum movetur versus orientem, quasi motu reflexionis, et aliquando ascendit et aliquando descendit. Causa primi, quod movetur motu diurno, est propter motum ipsius aeris continentis cometam. Sicut enim vinum movetur ad motum dolii continentis ipsum, ita cometa movetur ad motum aeris continentis ipsum; sed quia aer movetur motu diurno ad motum celi, sequitur, etc. Sed | aliquando velocitat illum motum, ita quod velocius circuit quam aer totus. Causa est quia, quod aer movetur circulariter, est a virtute celi sibi impressa; et quia exalatio que est materia comete recipit fortius illam virtutem, inde est quod cometa velo|cius circuit quam aer. Et aliquando visum est quod cometa tantum velocitavit motum suum quod uno vespere erat retro Solem et post lapsum parvi temporis, ut tertium vel quartum dierum, erat ante Solem. Dicitur enim quod tempore quo

20 Karolus intravit Ceciliam, uno vespere videbatur cometa post occasum Solis et postea per aliquos dies videbatur ante ortum Solis ille idem cometa. Et causa huius potest esse quia exalatio que fuit materia illius comete virtute alicuius astri precedentis Solem erat elevata et in ascensu illius exalationis forte per ventum vel aliquid huiusmodi impedita, quod non poterat elevari 25 directe sub illo astro, et propterea prepulsa ad aliquem locum post Solem et ibi inflata tunc apparuit post Solem. Et cum continue virtute astri | precedentis Solem insequitur illud astrum et trahitur ab illo astro ad modum | ad quem ferrum trahitur a magnete, tandem movetur quod venit ad locum | aeris infra illud astrum. Et quia illud astrum est ante Solem, ille cometa ali30 quando precedit Solem quem primo sequebatur.

$\langle 11\rangle$ Aliquando etiam cometa movetur versus orientem vel versus unam partem et postea, dimittens illum motum, movetur versus aliam. Et huius causa potest dari quod exalatio virtute coniunctionis aliquarum stellarum elevatur, et postquam elevata est et inflammata, movetur ad motum stelle

12 motu diurno] circulariter $B a K l L U \quad 15$ que est materia comete] om. $B a K l L U \quad 16$ virtutem ] a celo $a d d$. $K l L U \quad 18-19$ ut tertium vel quartum dierum] om. $B a K l L \quad 22$ que fuit] om. $P \quad 25^{-26}$ et propterea prepulsa ... tunc apparuit post solem] om. Ba Kl L 26 inflata] et $a d d . P \quad 27$ solem] ista exalatio $a d d . K l L U$ ipse cometa $a d d . B a \quad 28$ ferrum] om. $P$ 
que tunc habet dominium. Et postea, quando virtus illius stelle et influentia debilitatur et una alia incipit habere dominium, tunc dimmitens primam insequitur secundam.

$\langle 12\rangle$ Aliquando etiam cometa movetur ascendendo et descendendo, et huius causa est quia taliter movetur planeta in suo epiciclo, cuius planete motum cometa insequitur. Vel aliter posset dici quod in principio inflammationis, cum est ibi multum de materia subtili et inflammabili, cometa ascendit et postea, materia subtiliori consumpta et grossiori remanente, $\mathrm{e}$ converso descendit.

$B a 24^{\mathrm{rb}} \quad\langle 13\rangle$ Quantum $\mid$ ad secundum, breviter dicendum quod motus comete non 10 est sibi violentus nec est sibi naturalis nisi ad modum ad quem motus ferri ad magnetem dicitur ferro naturalis, sed inest comete preter naturam. Patet, quia motus diurnus et motus quo insequitur stellam vel planetam est sibi impertinens; similiter motus quo movetur ascendendo vel descendendo ad

$L 201^{\mathrm{rb}}$ motum planete in epiciclo. Sed si dicitur quod sic ascendit | vel descendit 15

$\mathrm{Kl} 3^{\mathrm{O}^{\mathrm{ra}}}$ propter levitatem vel gravitatem materie, tunc | debet dici quod illi motus sunt sibi pure naturales ad modum ad quem descendere est gravi naturale et ascendere levi.

$\langle 14\rangle$ Ad rationes hinc inde facte: non probant nisi quod motus comete non est sibi naturalis nec violentus; non tamen probant quin insit sibi preter 20 naturam.

Hoc de questione.

\section{I.18 Utrum comete significent mortem principum, siccitatem et ventos et motus terre}

Queritur consequenter utrum comete significent mortem principum, siccitatem et ventos et motus terre.

$U \mathbf{2 1}^{\mathrm{vb}} \quad\langle 1\rangle$ Et arguitur $\mid$ primo quod non significent mortem principum, quia indiffe25 renter respiciunt homines populares sicut principes, propter quod non plus debent significare mortem principum quam mortem popularium ${ }^{158}$.

17 gravi] gravis $P \quad 21$ naturam] id est propter aliquam virtutem sibi impressam add. $L U$

$15^{8}$ Cf. Albertum Magnum, Meteora, lib. 1, tract. 3, cap. 11, ed. Colon. vi/1, 32 $2^{55-57}$. 
$\langle 2\rangle$ Secundo: galaxia non significat ista; ergo nec cometa. Consequentia tenet ex eo quod galaxia est de natura comete. Patet per Aristotelem in littera $^{159}$. Antecedens est notum de se.

$\langle 3\rangle$ Tertio: cometa aliquando insequitur planetas benivolos sicut mali5 volos; ergo non semper debet significare ista mala. Confirmatur, nam aliquando visus est cometa qui ista mala non significavit; unde Seneca dicit quod sub Nerone, id est Nerone regnante, apparuit quidam cometa qui detraxit aliorum cometarum infamiam ${ }^{160}$. Unde post apparitionem unius comete non secutum fuit aliquid malum cuius quidem mali ille cometa fuisset signum.

$\langle 4\rangle$ Quarto: probatur quod cometa non significet siccitates. Nam, per Aristotelem in littera, cometa significat inundationes aquarum ${ }^{161}$; et si sic, non videtur significare siccitates: aliter enim significaret opposita.

$\langle 5\rangle$ Quinto: patet quod non significat ventos et motus terre; | nam, si 15 significat ventos, non significabit motum terre, quia motus terre fit tranquillitate | existente, sicut postea videbitur ${ }^{162}$. Cum autem est ventus, aer non est tranquillus; ergo non potest simul significare motum terre et ventos.

$\langle 6\rangle$ Oppositum dixerunt plures philosophi ${ }^{163}$ et oppositum est expertum. Illud autem quod omnes vel plures dixerunt, prestat fidem tamquam ab experientia dictum, sicut dicitur in De somno et vigilia, supra quo Commentator dicit: 'impossibile est ut aliquod dictum famosum sit falsum secundum totum'164. Fama enim quam omnes clamant non omnino deprehenditur ${ }^{165}$.

5 ista] om. $P \quad 6-7$ dicit quod] om. $P \quad 8$ detraxit] destruxit $P$ destraxit $B a$ traxit $K l L \quad 16$ sicut postea videbitur] om. $B a K l L U \quad 22$ fama enim quam ... non omnino deperditur] om. $\mathrm{BaKlL} U$

159 Aristoteles, Meteorologica, I, 8, 345 b 33-36.

16o Seneca, Questiones naturales, viI, 17, 2, ed. P. Oltramare, Paris 1961, 2, 319: "Nec est quod putemus eundem uisum esse sub Claudio quem sub Augusto uidimus, nec hunc qui sub Nerone Caesare apparuit et cometis detraxit infamiam illi similem fuisse qui post excessum diui Iulii ludis Veneris Genetricis circa undecimam horam diei emersit".

161 Aristoteles, Meteorologica, I, 6, 343 b 1-4.

162 III.5, Utrum tranquillitas sit signum terre motus. Cf. Aristotelem, Meteorologica, II, 8, 366 a $5^{-6 .}$.

163 Cf. Aristotelem, Meteorologica, I, 7, 344 b 28-345 a 10; Senecam, Questiones naturales, VII, 28; Albertum Magnum, Meteora, ed. Colon. IV/1, lib. 1, tract. 3, cap. 11.

164 Aristoteles, De insomniis et de divinatione per somnum, 3, 1462 b 14-16, ed. Drossaart Lulofs, $33^{5-7}$ : 'nam quod omnes quidam vel plures existimant habere aliquam significationem sompnia prestat fidem tamquam ab experientia dictum'; Averroes, In De somno et vigilia, ed. Shields, $95^{32-33}$ : “impossibile enim est ut famosum sit falsum secundum totum"; cf. Auct. Arist., 204, n. 101.

165 Cf. Aristotelem, Ethica, vII, 14, 1153 b 27-28; Auct. Arist., 241, n. 126. 
$\langle 7\rangle$ In ista questione primo ponenda est una distinctio significationis cometarum; secundo, prosequendo de una, ponende sunt conclusiones.

$\langle 8\rangle$ Quantum ad primum, sciendum est quod duplex est significatio comete: quedam generalis, que convenit quasi omnibus cometis indifferenter; et ista

$L 201^{\text {va }} \quad$ significatio est verior, et etiam de ista significatione considerare pertinet $\mid$ ad presentem scientiam. Alia est significatio comete specialis, de qua considerare pertinet ad astrologos. Unde astrologi ponunt diversas species cometarum, quibus imposita sunt ab eis nomina distincta, et quilibet illorum cometarum habet unam significationem specialem a significatione aliorum, de quibus significationibus specialibus non in proposito.

$\langle 9\rangle$ Sed quantum ad significationes generales cometarum sit prima conclusio: omnis cometa est signativus alicuius mali. Patet, nam omnes philosophi hoc dixerunt. Et quando dicitur de cometa viso sub Nerone quod ille non significavit aliquid malum ${ }^{166}$, respondetur quod immo, quia tunc fuit

$U_{22}{ }^{\text {ra }}$ ille pessimus homo Nero. Similiter | confirmatur auctoritate Plinii, dicen$K l_{3}{ }^{\text {va }}$ tis quod cometa est sydus $\mid$ terribile $^{167}$, et non capit illum sydus pro celesti sydere, sed vocat cometam 'sydus' quia apparet quod sit sydus. Similiter Ptolemeus in secundo sui Quadripartiti, capitulo secundo et tredecimo, declarat quod cometa est signus multorum malorum ${ }^{168}$.

$\langle 10\rangle$ Secunda conclusio: cometa est signativus magnorum ventorum. Patet 20 quia cometa, sicut prius dictum est, fit ex elevatione exalationis calide et sicce, et hoc siccitate terrestri ${ }^{169}$; sed talis exalatio est materia ventorum, sicut postea videbitur ${ }^{170}$; ergo, cum tunc sit sufficiens materia, fit multitudo ventorum et fiunt venti magni. Similiter, cum subtile et pingue illius exala-

\footnotetext{
7 astrologos] astronomos $B a \|$ astrologi] astronomi $B a \quad 9$ unam] om. $P \quad 13$ viso sub nerone] neronis $B a K l$ nerone regnante $L U \quad 15$ plinii] cuiusdam dicti $B a \quad 17$ sit] om. $P$ 18 tredecimo] tertio $B a K l L U \|$ declarat] declaret $P \quad 23$ materia] tunc add. $P$

166 Cf. Senecam, Questiones naturales, VII, 17, 2.

167 Plinius, Naturalis historia, II, 22, 92, ed. J. Beaujeu, Paris 1950, 40: “Terrificum magna ex parte sidus".

168 Ptolemeus, Tetrabiblos, translatio Guillelmi de Morbeka, eds. G. Vuillemin-Diem and C. Steel, Ptolemy's Tetrabiblos in the Translation of William of Moerbeke. Claudii Ptolemaei 'Liber Iudicialium', Leuven 2015 (Ancient and Medieval Philosophy. Series 1, 19), 222-223: 3; II.14, 230: 10.

169 I.16, 12. Cf. Aristotelem, Meteorologica, I, 7, 344 b 18-26.

170 III.1, Utrum ventus sit exalatio calida et sicca. Cf. Aristotelem, Meteorologica, II, 4, 36o a $10-14$.
} 
tionis per inflammationem est consumptum, grossiori terrestri remanente et cometa deficiente de illo grosso, fiunt venti magni.

〈11 Tertia conclusio: cometa est signativus motus terre. Nam, cum talis exalatio a terra elevata calore Solis calefacta continue ascendit, aliquando propter frigus adveniens pori terre clauduntur, et exalatio et caliditas repellitur, que sunt causa motus terre, sicut postea videbitur ${ }^{171}$.

$\langle 12\rangle$ Quarta conclusio: cometa est signativus inundationum aquarum. Patet, quia est signativus magnorum ventorum. Cum autem fiunt magni venti, aqua maris et fluviorum repellitur super terram et fiunt inundationes | 10 aquarum. Similiter cometa est signativus magni motus terre. Cum autem fit magnus motus terre, fiunt casus et eversiones terrarum et montium; et aliquando illi montes cadentes in fluvios faciunt effluere fluvios ad terram siccam, et sic fiunt inundationes aquarum. Et sic patet qualiter cometa per accidens est signum inundationis aquarum.

$\langle 13\rangle$ Quinta conclusio: cometa est signativus sterilitatis terre. Patet, quia ad generationem comete | requiritur multa | exalatio, et in elevatione talis exalationis humiditates extrahuntur a terra unde deberent generari fructus $P 251^{\mathrm{r}}$ $K l_{3} \mathrm{O}^{\mathrm{vb}}$ $L 201^{\mathrm{vb}}$ terre; illa autem deficiente, terra redditur sterilis.

〈14 Sexta conclusio: cometa significat mortalitates et epidimias. Patet, quia alique partes illius exalationis sunt venenose et ipse extracte a terra ad aerem reddunt aerem venenosum, a quo aere inficiuntur animalia, et sic fiunt aliquando mortes subitanee.

$\langle 15\rangle$ Septima conclusio: cometa significat guerras et homicidia et huiusmodi. Patet, quia per talem exalationem siccam et calidam existentem in 25 aere homines excitantur et fiunt quasi colerici. | Colerici autem pervi sunt ad guerras et homicidia et huiusmodi. Etiam per talem infectionem hominum ab exalatione illa existente in aere homines quasi perdunt sensus et semper sunt pervi ad guerras et iracundias, quas consequuntur homicidia.

$\langle 16\rangle$ Octava conclusio: comete precipue significant mortem principum. 30 Patet, quia significant guerras et bella. In bellis autem principes sunt primi, vel saltem deberent esse. Confirmatur, quia principes magis delicate sunt

\footnotetext{
1 grossiori] siccitate $\mathrm{Ba} K \mathrm{KL} U \quad 2$ cometa deficiente de illo grosso] tunc de illa siccitate terrestri grossa $B a$ tunc siccitate terrestri manente $K l$ cometa de siccitate terrestri grossiori manente $L U \quad 4$ elevata] om. $B a K l L U \quad 11$ eversiones] scissiones $L \quad 17$ humiditates extrahuntur] pinguedo extrahitur $B a K l L U$ 30-31 sunt primi, vel saltem deberent esse] perduntur $B a K l L U \quad 31-212.2$ principes magis delicate ... et confirmatur quia] om. hom. $\mathrm{Ba} \mathrm{Kl}$ magis delicati aliis sunt interfici ideo citius interficiuntur et moriuntur propter aerem existentem venenosum $L$
}

171 III.4, Utrum motus terre sit possibilis. Cf. Aristotelem, Meteorologica, II, 8, 366 a 3-5. 
nutriti, et igitur citius inficiuntur per aerem existentem venenosum. Et confirmatur, quia, sicut dicunt astrologi, ad principes est specialis influentia ab illa que est ad populares et cometa apparente illa influentia est vigorosior, et est illa que est causa mortalitatum principum.

$\langle 17\rangle$ Nona conclusio: cometa est signum mutationum regnorum. Probatur, quia est signum guerrarum et bellorum regni contra regnum. In talibus autem bellis aliquando unum regnum obtinet contra aliud; et sic gentes de uno regno incipiunt habitare aliud regnum, sicut accidit cum Saxones expulerunt Anglicos.

$\langle 18\rangle$ Notandum quod cometa non significat ista sic quod sit causa istorum

$\mathrm{Kl}_{31^{\mathrm{ra}}}$ effectuum, | sed quia ista quodam ordine fiunt ex consimili causa ex qua fit cometa.

$\langle 19\rangle$ Ad rationes. Ad primam patet ex dictis in questione.

$\langle 20\rangle$ Ad secundam negatur quod galaxia sit de natura comete. Et cum dicitur quod hoc dicit Aristoteles, potest dici quod non; licet hoc ponitur in nova translatione ${ }^{172}$, forte est ex vitio scriptoris, quia stabat in margine exemplari $B a 25^{\text {ra }}$ et posuerunt hoc ad textum. | Unde in antiqua translatione Aristoteles non videtur hoc dicere ${ }^{173}$. Et adhuc, supposito quod galaxia esset de consimili $L \mathbf{2 O}^{\mathrm{ra}}$ exalatione, tamen, quia illa ex|alatio non est tanta nec ita venenosa nec ita a profundo terre extrahitur sicut exalatio ex qua fit cometa, igitur galaxia non significat talia.

$\langle 21\rangle$ Ad tertiam: quamvis aliquando sequatur planetam benivolum, nichilominus est ex exalatione tali de qua dictum est ${ }^{174}$, unde fiunt multa mala, sicut dictum est in questione. Et forte quod talis cometa qui insequitur planetam benivolum non est signum tantorum malorum sicut cometa qui insequitur planetam malignum, sicut Martem vel aliquid talem.

$\langle 22\rangle$ Ad quartam patet ex questione qualiter significat aquarum inundationes.

3 ad] om. $P \quad 6-9$ in talibus autem ... saxones expulerunt anglicos] om. Ba Kl LU 10 ista sic] ita $P \quad 14$ negatur quod] om. $P \quad 15$ nova] antiqua $B a K l$ om. $P \quad 17$ et posuerunt hoc ad textum] om. $P \quad 20$ igitur] et $a d d . P K l \quad 23$ de qua] quali $P$

172 Aristoteles, Meteorologica, I, 8, 345 b 36-346 a 6, translatio Guillelmi de Morbeka (translatio noua), $A L \times 2.2,26^{465-470}$.

173 Aristoteles, Meteorologica, translatio Gerardi Cremonensis, I, 8, in P.L. Schoonheim (ed.), Aristotle's Meteorology in the Arabico-Latin Tradition: A Critical Edition of the Texts, with Introduction and Indices, Leiden/Boston/Cologne 2000 (Aristoteles Semitico-latinus, 12), 20-21.

174 I.16, 12. 
$\langle 23\rangle$ Ad quintam respondetur quod significat motum terre et magnitudinem ventorum disiunctive, ita quod si exalatio tota extrahitur non manente aliqua, saltem magna et multa in concavitatibus terre, tunc fiunt multi et magni venti propter exalationem extractam a terra ad aerem, et tunc non fit motus terre. Quando autem non tota extrahitur, sed multa manet in terra, non tunc fiunt venti, sed motus terre.

\section{I.19 Utrum galaxia sit de natura celi vel de natura elementari}

Queritur consequenter utrum galaxia sit de natura celi vel de natura elementari.

$\langle 1\rangle$ Et arguitur primo quod sit de natura elementari auctoritate Aristote10 lis dicentis eandem esse materiam galaxie et comete ${ }^{175}$; sed quia materia | comete est elementaris, sicut prius dicebatur ${ }^{176}$, sequitur etiam quod natura galaxie sit elementari, et per consequens galaxia non erit de natura celi, sed elementari. Quod autem eadem sit natura comete et galaxie Aristoteles probat a signo, nam pauci fiunt comete propter hoc quod exalatio ex qua 15 deberent fieri comete convertitur in galaxiam ${ }^{177}$.

$\langle 2\rangle$ Secundo: si una stella erratica potest tantam exalationem elevare quod fiat cometa, tunc etiam multe stelle possunt tantam exalationem elevare quod per eius inflammationem fiat galaxia. Sed ita est quod una stella erratica potest tantam exalationem elevare quod fit cometa; ergo etiam plures stelle propinque possunt tantam exalationem elevare quod fit galaxia per inflammationem talis exalationis. Et ideo, ut videtur, est quod semper galaxia apparet sub illa parte celi ubi sunt multe stelle propinque seminate, ac si huiusmodi stelle talem exalationem elevent per cuius inflammationem fit galaxia.

$\langle 3\rangle$ Tertio: si galaxia esset de natura celi et non elementari, hoc esset $\mid$ per illum modum, sicut postea plenius declarabitur, quod una pars celi esset densior et alia pars minus densa ${ }^{178}$. Sed hoc est inconveniens, nam celum

2 extrahitur] a terra $a d d . B a K l L U \quad 16$ tantam] latam $P \quad 26$ postea plenius declarabitur] prius declarabatur $B a K l L$

175 Aristoteles, Meteorologica, I, 8, 345 b $36-346$ b 10.

$176 \quad$ I.16, 11-12.

177 Aristoteles, Meteorologica, I, 8, 346 b 7-10.

178 I.19, 17 . 
$L 22^{\mathrm{rb}}$ videtur esse uniforme $\mid$ in raritate et densitate, cum in celo non debeat esse aliqua difformitas propter eius nobilitatem.

$\langle 4\rangle$ Quarto ad idem: si galaxia esset de natura celi, tunc de ea non esset determinandum hic in isto libro, cuius oppositum facit Aristoteles ${ }^{179}$. Consequentia tenet, quia in isto libro solum determinandum est de impressio- 5 nibus aeris et impressionibus que sunt de natura elementari.

$K l_{3} 1^{\text {va }}\langle 5\rangle$ Oppositum arguitur: nulla impressio elementaris semper durat; | sed galaxia semper durat; ergo galaxia non est impressio elementaris. Minor nota est ad sensum. Antecedens patet, vel maior, quia propter habere materiam, quod est causa corruptionis, nulla impressio elementaris semper 10 durat.

<6) Secundo: galaxia movetur ad motum celi; ergo galaxia videtur esse de natura celi. Consequentia tenet, quia motus arguit naturam sicut formam, ut dicitur secundo Physicorum ${ }^{180}$. Antecedens patet de se, quia circumducitur cum celo.

$\langle 7\rangle$ Tertio: si galaxia esset nature elementaris, tunc esset consimilis nature cum cometa, sicut dicit Aristoteles ${ }^{181}$; sed hoc est falsum, cum galaxia sit semper, cometa autem raro.

$U_{22^{\mathrm{vb}}} \quad\langle 8\rangle$ Et ex alio, quia cometa significat mortem principum et consimilia mala sicut predictum est ${ }^{182}$, galaxia autem non.

$\langle 9\rangle$ In ista questione primo ponende sunt opiniones de galaxia quid sit et improbationes earum; secundo ponende sunt conclusiones; tertio videndum est secundum veritatem de galaxia quid sit et quomodo causetur.

$\langle 10\rangle$ Quantum ad primum, sciendum est quod erat una opinio Antiquorum qui dixerunt quod quondam Sol errando in motu eius exivit viam suam consuetam, et sic errando in suo motu transivit per illam partem celi et combussit eam, propter quod adhuc illa pars celi apparet alba ${ }^{183}$. Breviter ista opinio non valet, quia celum non est receptivum impressionum corruptivarum sicut est combustio; igitur, posito adhuc quod Sol per illam viam

13-14 ut dicitur] cum dicitur natura $P \quad 20$ sicut predictum est] om. $B a K l L U$

179 Aristoteles, Meteorologica, I, 8.

180 Aristoteles, Physica, 192 b 20-23; cf. Auct. Arist., 144, n. 5 o.

181 Aristoteles, Meteorologica, I, 8, 345 b $36-346$ b 10.

182 I.18, 9-17.

183 Cf. Aristotelem, Meteorologica, I, 8, 345 a 11-18. 
transisset quam dicimus esse Viam lacteam, non tamen propter hoc illam partem celi combussisset, cum celum non possit comburi nec calefieri, et etiam cum Sol non sit formaliter calidus. Et ex alio, quia tunc magis illa pars celi per quam continue transit Sol, sicut zodiacus seu circulus animalium, deberet apparere magis alba vel quasi iam tota combusta, quod est falsum ${ }^{184}$.

$\langle 11\rangle$ Secunda opinio de galaxia erat quod aliquando de nocte, serenitate existente, Terra interponitur | Soli et illis | astris in multitudine seminatis; igitur ibi apparet Via lactea, | ita quod tunc Sol non radiat super illas stellas et tunc ille stelle sic lucent, et sic illa pars celi apparet sic albescere. Sed alie partes celi que respiciuntur a Sole $\mid$ et non sunt in umbra Terre non sic lucent nec sic apparent nobis albescere propter hoc quod lumen Solis, quod est maius, lumen eorum offuscat. Sed quia lumen illius partis celi ubi apparet Via lactea non est offuscatum per lumen Solis, cum Sol illas partes non respiciat propter interpositionem Terre, ille partes celi apparent nobis albescere ${ }^{185}$. Sed

15 breviter ista opinio non valet, quia ille partes celi et ille stelle ubi apparet galaxia sunt ita remote quod ad ipsas non attingit umbra Terre, et per consequens semper respiciuntur a Sole. Nec obstat interpositio Terre; ergo non magis deberet ibi apparere galaxia quam alibi, nisi aliter dicatur quam dicit ista opinio. Secundo, dato quod aliquando Sol non respiceret illam partem 20 celi propter interpositionem Terre, tamen propter motum Solis aliquando illam partem celi respiceret; et tunc secundum predictam opinionem non debet apparere albescere ${ }^{186}$.

$\langle 12\rangle$ Tertia opinio erat ista, quod galaxia causaretur ex reflexione luminis a Sole ab humiditate vel exalatione elevata. Unde ymaginabantur $\mid$ quod sub illa parte celi ubi apparent tam multe stelle elevantur multe exalationes, et quod de nocte Sol existens sub nobis proicit lumen super illas exalationes, quod quidem lumen ibi reflectitur versus visum nostrum. Et quia sic illa exalatio | propter reflexionem luminis super ipsam apparet albescere, et quia talis exalatio est sub illis stellis, nos dicimus ibi esse galaxiam et Viam lacteam ${ }^{187}$. Breviter ista opinio non valet, nam ad eam sequitur quod non

2 nec calefieri] om. BaKlLU 6 de nocte] om. $P \quad 8$ ibi] ubi $P \quad 16$ remote] alte $B a K l L U$ 18 ibi] om. $P \quad 20$ propter interpositionem terre] om. $B a K l L U \quad 22$ albescere] sed hoc est falsum quia continue apparet ibi galaxia ubi stelle sunt seminate in multitudine $a d d$. $B a K l L$ $U \quad 24$ humiditate] humore $B a K l L U$

184 Cf. ibid., I, 8, 345 a 19-25.

185 Cf. ibid., I, 8, 345 a $26-31$.

186 Cf. ibid., I, 8, 345 a $32-$ b 9.

187 Ibid., I, 8, 345 b 10-12. 
semper galaxia apparet nobis sub eadem parte celi. Sed consequens est fal$B a 25^{\mathrm{vb}}$ sum, nam continue apparet nobis | in illa parte celi ubi sunt tam multe stelle. Consequentia probatur, nam, speculo et oculo quiescente, re visa mutante locum, non semper iudicamus rem visam in eadem parte speculi; nec iudi-

$L 202^{\mathrm{vb}}$ cium manet uniforme, sed mutatur. Cum ergo | Sol continue moveatur, sequitur quod nobis quiescentibus et similiter illa exalatione quiescente que ab illis dicitur tamquam speculum reflectens lumen solis ad nos, illa Via lactea, seu illud lumen reflexum, non debeat nobis apparere continue in eodem loco nec sub eadem parte celi, cuius oppositum experimur ${ }^{188}$.

$\langle 13\rangle$ Quarta opinio erat quorundam dicentium, sicut recitat Albertus, galaxiam esse concursum duorum luminum, scilicet luminis ignis in spera sua et luminis stellarum sic sparsarum in multitudine. Unde ymaginabantur quod cum ille stelle luceant versus speram ignis et ignis versus celum, quod ibi appareat galaxia et talis albedo ubi concurrunt illa duo lumina ${ }^{189}$. Contra istam opinionem argumentat Albertus quia, si ignis in spera sua concederetur lucere, tamen valde modicum luceret; aliter enim prohiberet visionem stellarum. Et ergo, quia valde modicum luceret, obfuscaretur lumen suum a lumine illarum stellarum, et per consequens una cum lumine talium stellarum non causaret talem albedinem qualis apparet ibi ubi apparet Via lactea. Secundo, nam, secundum Avicennam, secundum Algazelem, secundum Alexandrum et plures alios ${ }^{190}$, ignis in spera sua non lucet; et quia ista opinio hoc supponit, ipsa est falsa ${ }^{191}$. Quod autem ignis in spera sua non luceat, $\mathrm{Kl} 3^{2}$ huius ratio est sua | nimia raritas; unde Avicenna: 'nichil lucet nisi sit aliqualiter densum'. Unde aer propter sui raritatem non lucet; sed ignis est multum rarior aere; igitur nec ignis | propter sui raritatem lucet. Ad idem: | ille partes celi que non sunt stelle habent plus de lumine quam ignis, et tamen

4 speculi] celi $K l$ om. $B a \quad 7$ lumen solis] istam exalationem $K l L U$ om. $B a \quad 10$ sicut recitat albertus] om. $B a K l L U \quad 13$ speram ignis] ignem $B a K l L U \quad 14$ galaxia] via lactea $B a K l L U$ 16 prohiberet] prohibet $P \quad 20$ algazelem] galienum $B a K l L U \quad 21$ alios] philosophos $B a$ $K l L U \quad 25$ igitur nec ignis] iter. $P \quad 25^{-26}$ ille partes celi que non sunt stelle] alique partes celi sunt que $\mathrm{Ba} \mathrm{Kl}$

188 Cf. ibid., I, 8, 345 b 28 .

189 Albertus Magnus, Meteora, lib. 1, tract. 2, cap. 6, ed. Colon. vi/1, 22 $2^{54-63}$.

190 Alexander Aphrodisiensis, Expositio libri Meteorologicorum Aristotelis, I, 4, ed. A.J. Smet, Leuven 1968 (Corpus Latinum Commentariorum in Aristotelem Græcorum, 4), $34^{9}$ sqq.; Algazel, Metaphysica, pars 2, trac. 3, ed. J.T. Muckle, Toronto 1933 (St. Michael's Mediaeval studies), $156^{69-81}$. Cf. Albertum Magnum, De causis proprietatum elementorum, lib. 1, tract. 2, cap. 11, ed. Colon. v/2, 817-22.

191 Albertus Magnus, Meteora, lib. 1, tract. 2, cap. 6, ed. Colon. vi $/ 1,22^{63}-23^{6}$. 
propter earum raritatem non lucent; igitur videtur quod ignis in sua spera non luceat ${ }^{192}$.

〈14〉 Quinta opinio, quam pretendit nova translatio, est ista: quod galaxia sit inflammata exalatio. Unde ymaginatur quod sub illa parte celi in qua ille stelle sunt in multitudine seminate que nobis apparent ubi apparet nobis Via lactea, continue virtute illarum stellarum elevatur exalatio, que in suprema | aeris regione inflammatur; et ipsa | inflammata, apparet nobis Via lactea in celo $^{193}$. Et si dicatur contra istam opinionem: sequeretur quod galaxia potius deberet apparere sub circulo animalium, hoc est sub zodiaco, propter hoc quod ibi sunt plures stelle potentes elevare et extrahere exalationem que posset inflammari in suprema regione aeris et facere huiusmodi fantasiam et apparitionem, tenentes istam opinionem respondent quod quamvis sub circulo animalium fiant multe elevationes exalationum, tamen nimio calore Solis ibi vigente huiusmodi exalationes dissolvuntur, sic quod non faciunt ibi

15 huiusmodi apparitionem, quia statim consumuntur, et propter hoc etiam ibi comete raro apparent ${ }^{194}$.

$\langle 15\rangle$ Quantum ad secundum, sit primo ista suppositio: quod eadem impressio aeris a diversis hominibus in diversis regionibus existentibus non apparet sub eadem parte celi, sed sub diversis. Et ratio huius est, nam, sit unus eorum Sortes et alius Plato, | et videant eandem impressionem aeris; tunc radii visuales istorum duorum intersecantur se in illo visibili et proceduntur ad diversas partes celi. Et tunc Sortes iudicat illam impressionem esse sub illa parte celi ad quam terminatur suus radius visualis, et Plato iudicabit illud idem visibile esse sub illa parte celi ad quam terminatur suus radius visualis.

25 Et quia huiusmodi radii visuales ad diversas partes celi terminantur, idem visibile ab illis duobus iudicatur esse sub diversis celi partibus, sicut faciliter patet in figura. Propter hoc etiam existentes in diversis Terre partibus iudicant Lunam esse sub diversis partibus ultimi celi et iudicant Lunam non esse sub illa parte ultimi celi sub qua in rei veritate est preterquam illi quibus Luna est in Zenith capitis.

6 stellarum] continue $a d d . P \quad 10-11$ que posset inflammari] a terra et inflammare $B a K l L U$ 15 hoc $]$ om. $P \quad 26-27$ sicut faciliter patet in figura] om. Ba Kl L $\quad$ 30 capitis] om. Ba Kl L $U$

192 Cf. Albertum Magnum, Meteora, lib. 1, tract. 2, cap. 6, ed. Colon. vi $/ 1,23^{6-34}$.

193 Aristoteles, Meteorologica, I, 8, 345 b 33-346 b 10.

194 Cf. ibid., I, 8, 345 b 11-16. 


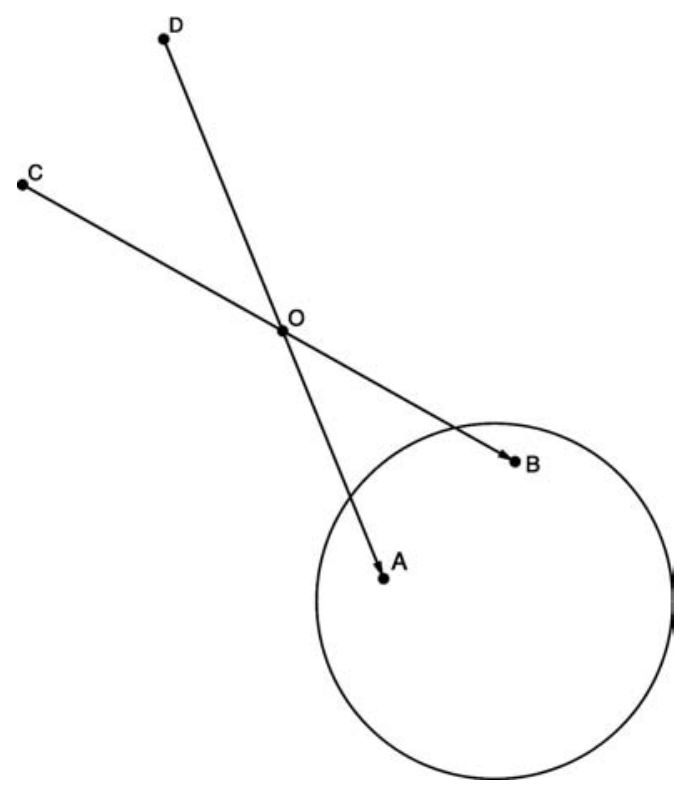

$\langle 16\rangle$ Tunc sit prima conclusio: galaxia non est in aere. Probatur, quia tunc a diversis hominibus in diversis regionibus existentibus non appareret sub eadem parte celi stellati, sed sub diversis partibus eius. Sed hoc est falsum. Consequentia tenet per suppositionem; sed falsitas consequentis patet, quia in quacumque regione homo est, semper apparet sibi galaxia sub eadem parte celi stellati. | Semper enim apparet ibi ubi sunt | tam multe stelle propinque sine ordine seminate.

$\langle 17\rangle$ Secunda conclusio: galaxia non est impressio elementaris, nam, si sic, tunc esset in aere, quamvis appareat in celo. Sed hoc est contra primam conclusionem. Et confirmatur, nam, si esset impressio causata ex inflam-

$B a 6^{\text {rb }}$ matione exalationis sub | illis stellis in tam magna multitudine seminatis, sequitur quod non semper appareret ita uniformis sicut apparet in sua claritate, sed aliquando eius claritas intenderetur et aliquando remitteretur, cuius oppositum videmus. Consequentia tenet ex eo quod non semper illa exalatio est equaliter subtilis vel equaliter grossa vel rara, et quia etiam virtus elevativa talis exalationis non semper est uniformis, immo aliquando $K l 32^{\mathrm{vb}}$ maior, aliquando minor secundum adiutorium | aliarum stellarum. Verum est quod aliqui, volentes sustinere quod galaxia fieret ex elevatione exalationis sub illis stellis, possent dicere quod illa exalatio sic elevata non apparet

15 grossa] vel equaliter spissa $a d d . B a K l L U \quad 18$ fieret] non esset in celo sed in aere $B a K l L$ $U$ 
esse Via lactea propter hoc quod ipsa sit inflammata, sed propter hoc quod reflectit lumen illarum stellarum e contrario versus celum, et propter hoc celi partes interposite apparent albescere. Et sic potest impediri argumentum factum pro prima conclusione, non tamen argumentum factum pro secunda.

$\langle 18\rangle$ Tertia conclusio: quod galaxia est de natura celi. Probatur, quia vel est de natura celi vel elementari: non elementari, per secundam conclusionem; igitur relinquitur quod de natura celi. Secundo: vel exalatio seu fantasia seu Via lactea est in aere, quamvis appareat in celo, vel est in celo, sicut apparet in celo. Non potest dici quod sit in aere, quia tunc a diversis hominibus in diversis regionibus existentibus appareret sub diversis partibus celi, quod est falsum, quia continue et ubicumque homo sit, apparet sibi Via lactea ibi ubi apparent sibi ille stelle in tam magna multitudine seminate. Si autem dicatur quod est in celo, vel igitur est in celo propter reflexionem luminis illa-

15 rum stellarum supra exalationem elevatam, vel non propter hoc. Non potest dici primum, quia secundum quod illa exalatio aliquando plus vel minus illud lumen reflecteret secundum quod esset plus vel minus densa vel rara, secundum hoc Via lactea appareret magis vel minus clara et alba, | cuius oppositum apparet, quia semper apparet uniformis claritatis et albedinis. $\mathrm{Si}$ enim dicatur quod non propter hoc est in celo quod lumen illarum stellarum | supra illa exalatione reflectitur versus celum, sequitur quod vere est de natura celi, et hec est conclusio.

$\langle 19\rangle$ Dicendum est ergo quod galaxia est una pars celi; unde ymaginandum est quod alique partes celi sunt densiores et alique rariores, alique 25 medio modo se habentes. | Que sunt densiores, lucent et sunt stelle ${ }^{195}$; que $K l 33^{\text {ra }}$ vero rariores, non lucent, et sunt ille partes que sunt prope stellas et inter illas. Alique sunt medio modo se habentes, ita quod non sunt ita dense sicut stelle nec sunt ita rare sicut alie partes celi que non lucent. Et sic se habent ille partes celi que sunt interposite stellis ibi existentibus ubi apparet Via lac$3^{\circ}$ tea. Et propter hoc quia medio modo se habent in densitate et raritate, non omnino lucent sicut stelle nec omnino carent luce sicut alie partes celi, sed medio modo se habent, et propter hoc apparent albe. Et ergo illam partem

1 via lactea] galaxia $a d d . B a K l L U \quad 2$ reflectit lumen] reflectitur lumen $B a K l$ reflectitur a lumine $L U \quad 8$ vel] om. $P$ \| exalatio seu] om. Ba Kl $\quad 14$ celo] sicut apparet add. Ba $\quad 15$ elevatam] versus celum $a d d . B a \quad 31$ luce] lumine $B a K l L U$

195 Cf. Averroem, Commentarium magnum in De celo, II, comm. 42, eds. Carmody, Arnzen,

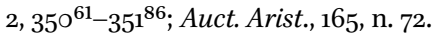


celi ubi sunt ille stelle in magna multitudine dicimus esse Via lacteam seu Viam albam seu galaxiam.

$\langle 20\rangle$ Ad rationes. Ad auctoritatem Aristotelis respondetur quod illa non fuit opinio Aristotelis, sed erat interposita eius textui ex vitio scriptoris vel translatoris, quia hodierno tempore, facientes scribere aliquos textus, videntes glosam quod eis placet in margine, dicunt suis scriptoribus quod illam glosam apponant textui, et ita potuit accidere textui aristotelis.

$\langle 21\rangle$ Ad secundam: 'nam, si una stella', etc., concedo quod ille multe stelle bene possent elevare talem exalationem. Sed quod continue talis exalatio haberet se uniformiter in magnitudine et parvitate, in densitate et raritate, 10 non concedo esse verum. Hoc tamen apparet propter hoc quod Via lactea semper apparet consimilis claritatis.

$\langle 22\rangle$ Ad tertiam concedo quod una pars celi est densior et alia rarior, quod etiam celum non est uniforme in raritate et densitate, sed difforme, et illa $K l_{33^{\mathrm{rb}}}$ difformitas eius in raritate et densitate facit ipsum magis $\mid$ pulchrum.

$\langle 23\rangle$ Ad quartam: 'si esset de natura celi, de ea non esset determinandum', concedo, sed tamen Aristoteles determinavit de ea hic propter hoc quod plures Antiquorum crediderunt galaxiam esse de natura elementari ${ }^{196}$.

Et sic patet ad questionem.

1 multitudine] seminate $a d d$. $B a K l L U \quad 3$ aristotelis] dicentis eandem esse materiam galaxie et comete $a d d$. Ba KlL $U \quad 5^{-7}$ quia hodierno tempore ... accidere textui aristotelis] om. Ba KlLU 6 quod] om. $P \quad 10$ in magnitudine et parvitate] om. Ba KlLU 12 claritatis $]$ et per consequens non est dicendum quod ista exalatio in superiori regione aeris inflammata sit via lactea $a d d$. $B a K l L U \quad 14$ in raritate et densitate] in suis partibus $B a K l L U \quad 15$ in raritate et densitate] om. $B a K l L U \quad 16$ si] sed $P$

196 Aristoteles, Meteorologica, I, 8, 345 a 14-3o. 